Portland State University

PDXScholar

Fall 11-12-2013

\title{
A Unique Support for Sexual-Minority Identity Development: An Interpretative Phenomenological Analysis of a Long-Term Formal Mentoring Relationship Between an Adult and a Youth From the Gay Community
}

Christian L. Rummell

Portland State University

Follow this and additional works at: https://pdxscholar.library.pdx.edu/open_access_etds

Part of the Counseling Commons, and the Gender and Sexuality Commons Let us know how access to this document benefits you.

\section{Recommended Citation}

Rummell, Christian L., "A Unique Support for Sexual-Minority Identity Development: An Interpretative Phenomenological Analysis of a Long-Term Formal Mentoring Relationship Between an Adult and a Youth From the Gay Community" (2013). Dissertations and Theses. Paper 1487.

https://doi.org/10.15760/etd.1486

This Dissertation is brought to you for free and open access. It has been accepted for inclusion in Dissertations and Theses by an authorized administrator of PDXScholar. Please contact us if we can make this document more accessible: pdxscholar@pdx.edu. 
A Unique Support for Sexual-Minority Identity Development: An Interpretative Phenomenological Analysis of a Long-Term Formal Mentoring Relationship Between an Adult and a Youth From the Gay Community

by

Christian L. Rummell

A dissertation submitted in partial fulfillment of the requirements for the degree of

Doctor of Education

in

Educational Leadership: Curriculum and Instruction

Dissertation Committee:

Karen J. Noordhoff, Chair

Emily C. de la Cruz

Samuel D. Henry

Thomas Keller

Portland State University

2013 
(C) 2013 Christian L. Rummell 


\begin{abstract}
An important need exists to build a baseline understanding of the phenomenon of formal mentoring relationships involving adults and youth from the gay community. During the formative years when gay adolescents navigate through the process of understanding, defining, accepting, and sharing their identity as a sexual minority, they are often faced with high levels of environmental risks, including victimization, stress, and negative social sanctions by others. Formal mentoring has been recommended as a potential strategy to offer unique one-to-one support to gay youth that can help to foster resilience and a range of positive outcomes, including strengthening processes involved in identity development; yet, no previous studies have captured insights about these relationships. Using Interpretative Phenomenological Analysis (IPA), this study investigated the following research questions: (a) What are the most important characteristics of long-term formal mentoring relationships between gay adults and gay youth from the perspectives of the participants? (b) How, if at all, do mentors and mentees perceive potential benefits and limitations for gay youth participating in longterm formal mentoring relationships with gay adults? (c) How, if at all, do mentors and mentees perceive their mentoring relationship uniquely contributing to sexual-minority identity development in gay youth? After a 2-year search for participants, a purposeful sample of one mentoring dyad was chosen. Semi-structured in-person interviews were conducted with the match at the 17-month and 22-month mark of their relationship. This study contained four assertions based on this study's findings: (a) This long-term
\end{abstract}


mentoring relationship between an adult and a youth from the gay community shared numerous similarities with other high quality mentoring relationships; (b) This mentoring relationship offered insight into how to create individualized and long-term support for sexual-minority identity development in youth; (c) This mentoring relationship represented an important but unrealized type of support that can potentially be used to complement existing peers, internet, and community-based resources for gay youth; and (d) Complexity continues to exist in using language and self-labeling to define, inquire, and provide support to individuals from the gay community-especially youth. Recommendations for programming, policy, and future research are provided. 


\section{Acknowledgments}

I would like to thank a number of people that have played a significant role in helping me complete this study. First and foremost, I want to thank my advisor-Dr. Karen Noordhoff-for guiding me along this journey. From you, I have learned so much about courage, mentoring, and resilience. I have been honored to be able to work with you over these years and am so thankful for your dedication to making sure I saw this through to the end (we did it!). I also want to thank my dissertation committee-Dr. Emily de la Cruz, Dr. Samuel Henry, and Dr. Thomas Keller. Your support, guidance, encouragement, and perspectives helped to shape and strengthen this inquiry. I also want to thank Dr. Susan Halverson-Westerberg for your advice and feedback. I want to especially thank "Daniel" and "Tony"-I was honored to be able to spend time with you, learn from you, and to be able to share your story and voices through this study. I want to thank Kristin Coyne for the unwavering support over the last twenty-plus years and for the acceptance and love that have been such gifts to me. Lastly, I want to thank my life partner-Jonathan Kauffman — for your patience, support, inspiration, editing skills, love, and your belief in my ability to succeed. I couldn't have done this without you. 
Table of Contents

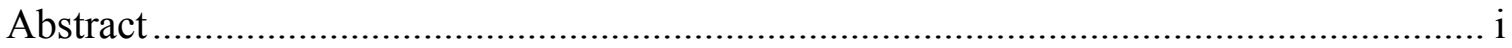

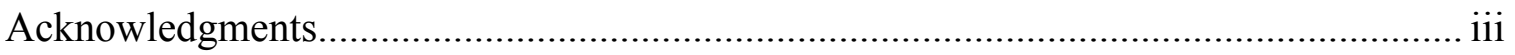

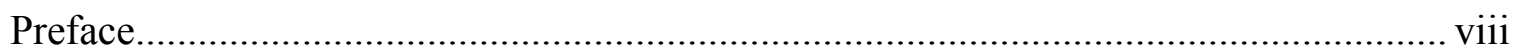

Chapter 1: Defining the Problem of Significance ..................................................... 1

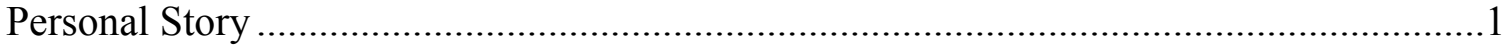

Understanding the Challenges Faced by Gay Youth ................................................

Causes of Stigma: Homophobia and Heterosexism .................................................

Examples of Homophobia and Heterosexism ..................................................

Victimization, Stress, and Social Interaction Anxiety in Gay Youth........................

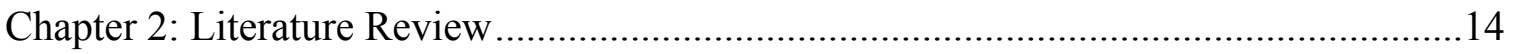

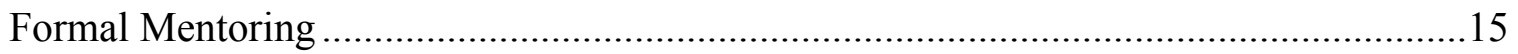

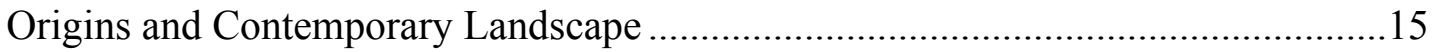

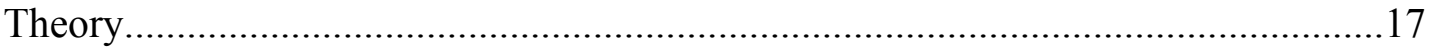

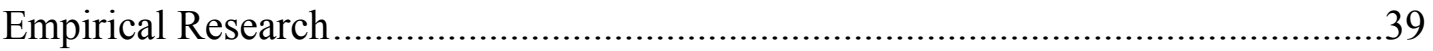

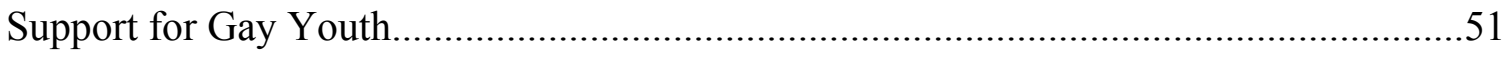

Definitions: Sexual Orientation and Sexual-Minority Identity Development............52

Cass Homosexual Identity Formation Model ...................................................54

Savin-Williams Differential Developmental Trajectories Framework .....................56

McCarn and Fassinger's Inclusive Model of Sexual Minority Identity Formation ...59

Supporting Sexual Identity Development in Gay Youth ......................................62

Strategies for Support: Educational Settings, Mental Health, and Community .........63

Queer Theory as Theoretical Framework/Grounding .............................................69 


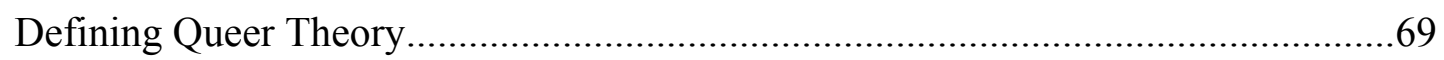

Implications for My Study …………………………….....................................

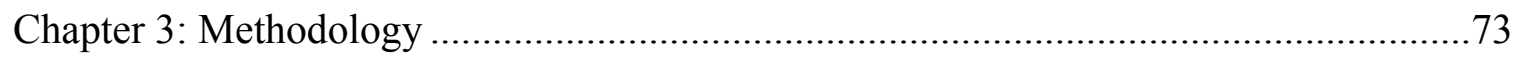

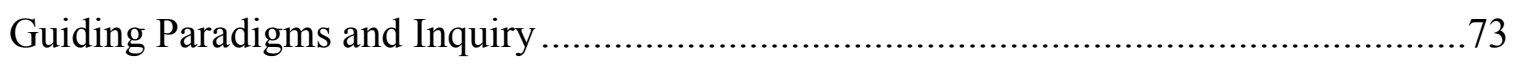

Connection Between Critical Theory and Queer Theory .............................................74

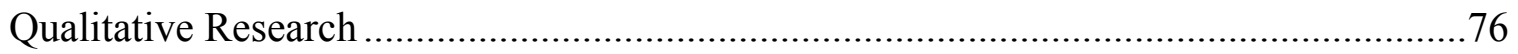

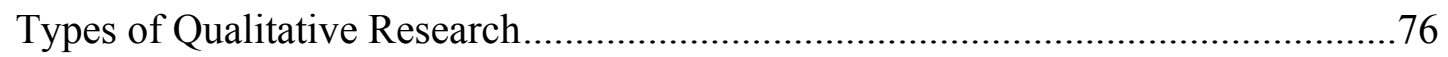

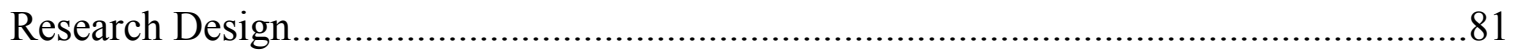

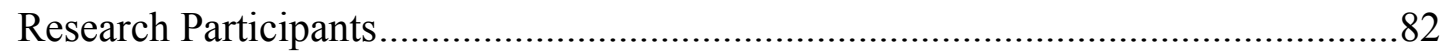

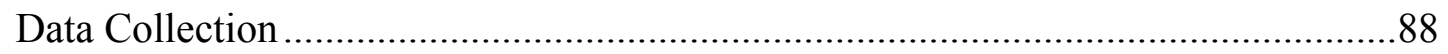

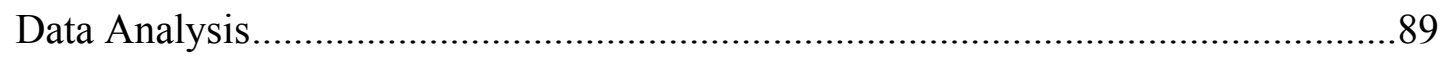

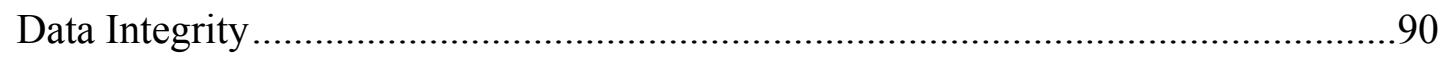

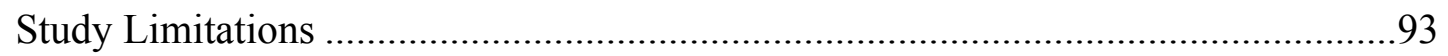

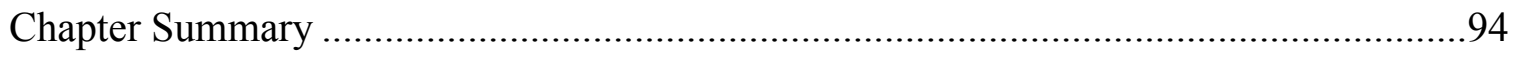

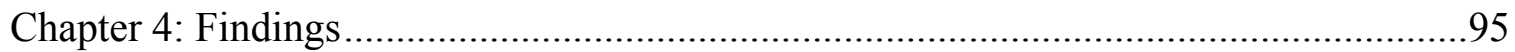

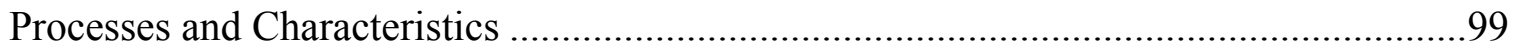

Before They Were Matched: Confusion and Coming Out .........................................99

Greater Involvement in Community: A Key Motivation .........................................104

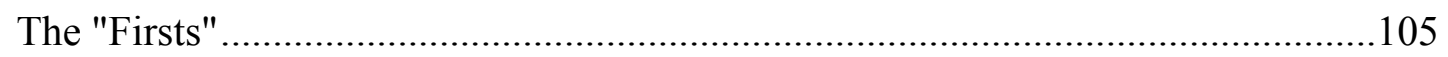

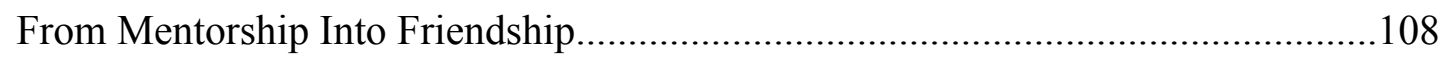

Similarities, Mutual Interests, and Differences ........................................................112

Changes in Frequency and Types of Contact ..........................................................114

Researcher Discussion for Characteristics and Processes ...............................................116

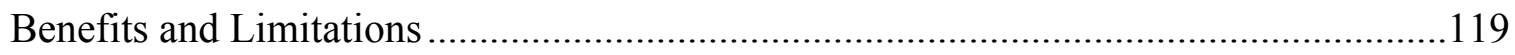


Support for Dating: A Relationship About Relationships ........................................119

Greater Comfort Meeting People From Gay Community ..........................................122

Support to Work Through Family Issues ..................................................................124

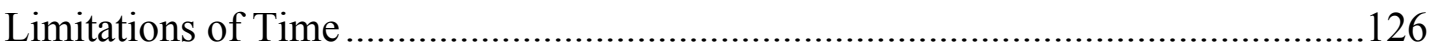

Concerns About How to Address Boundaries and Attraction....................................127

Researcher Discussion on Benefits and Limitations.....................................................130

Unique Support for Sexual-Minority Identity Development ...........................................133

A Unique and Individualized Space to Access Support...........................................134

Ongoing and Responsive Mentee-Centered Approach for Identity Exploration .....137

Leveraging the Relationship to Raise Awareness in Others.....................................141

Researcher Discussion on Support for Sexual-Minority Identity Development ..............144

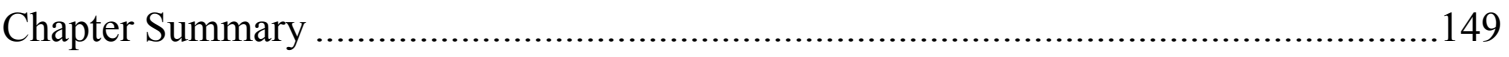

Chapter 5: Assertions, Discussion, and Recommendations.............................................150

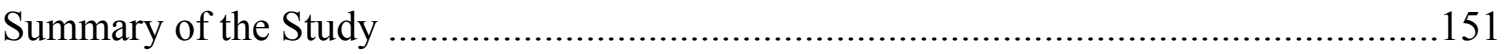

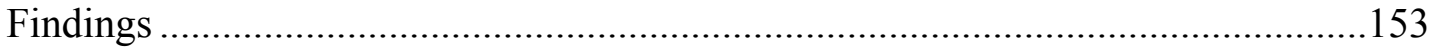

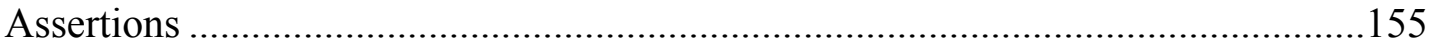

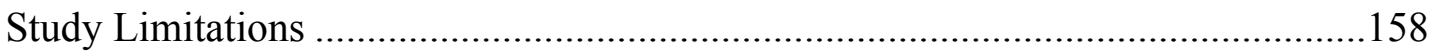

Contributions to Theoretical Frameworks and Empirical Research .................................159

Formal Mentoring

Sexual-Minority Identity Development.....................................................................161

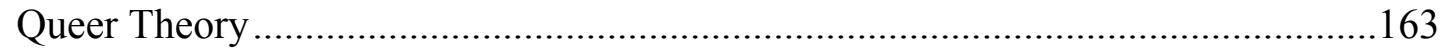

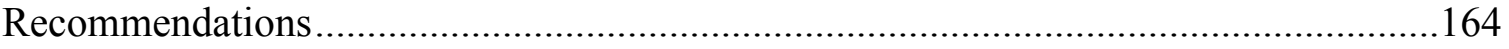

Programming and Practice....................................................................................164

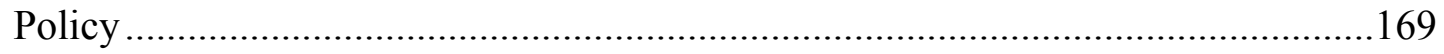




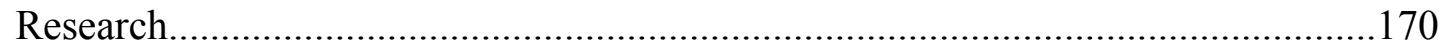

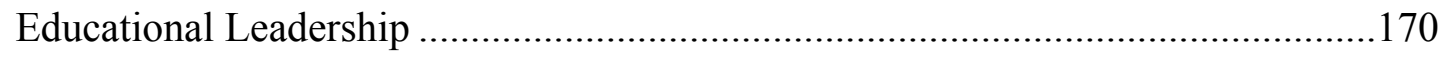

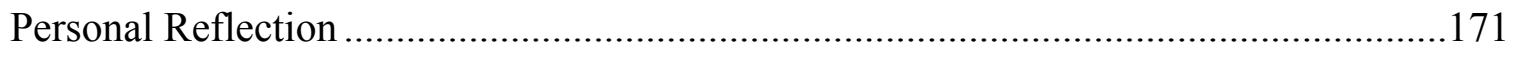

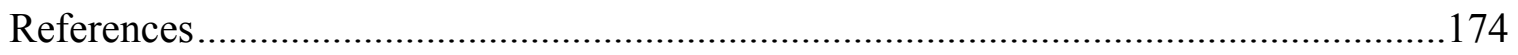

Appendices

A Pathways to Mentoring Influence Model .................................................... 186

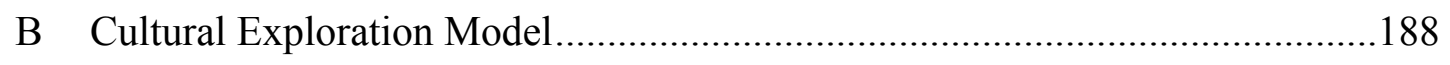

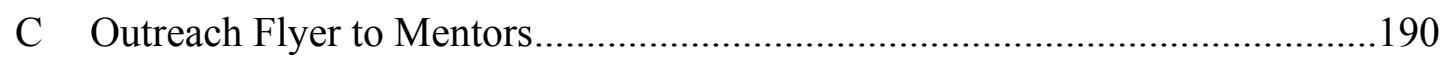

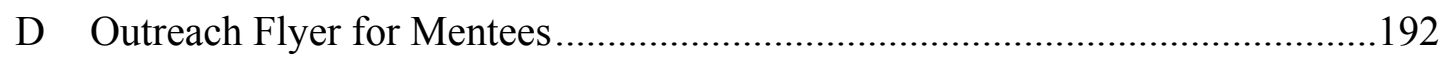

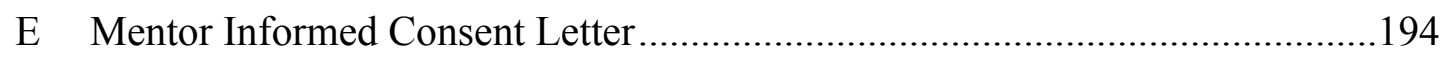

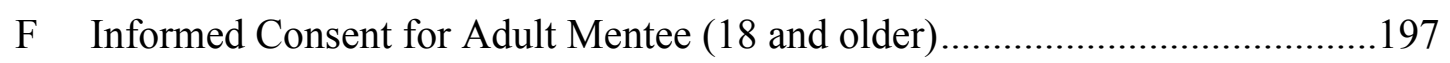

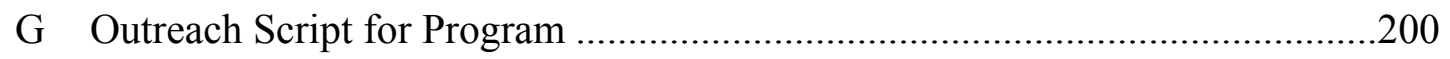

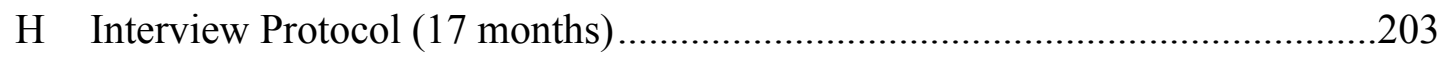

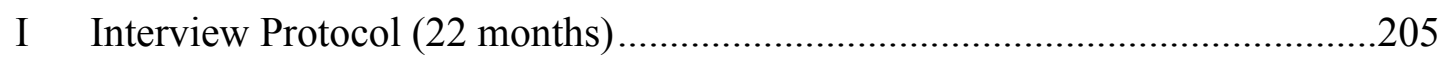




\section{Preface}

An important need exists to build a baseline understanding of the phenomenon of mentoring relationships involving adults and youth from the gay community. Gay youth often face stigma, negative social sanctions, and victimization during the period of searching for, sharing, and accepting their identity as a sexual minority (D’Augelli, 2006; Rotheram-Borus \& Langabeer, 2001). Further, gay youth often lack access to social support and positive role models that can provide protection against many of these environmental risks while also offering guidance during critical developmental phases of adolescence (Rotheram-Borus \& Langabeer, 2001; Safren \& Pantalone, 2006). Formal mentoring relationships have been recommended as a potential response to this need (Barajas, 2004; Jucovy, 2000). While a growing body of literature has captured the goals, influences, conditions, moderators, benefits and risks of formal mentoring relationships for many diverse populations of young people, very little is understood about the core ways in which these relationships work and offer support to gay youth.

There are several important reasons that little is understood about mentoring relationships involving gay youth and gay adults. First, no critical mass of empirical research has been conducted that accounts for the ways that gay youth participate in and benefit from formal mentoring relationships (DuBois \& Karcher, 2005). Second, while theory has been proposed around ways that mentors can generally benefit youth; neither research nor theory has attempted to describe the unique roles that mentors, especially gay mentors, play in ameliorating environmental risks related to stigma and victimization while also offering support during critical stages of sexual-minority identity 
development. Lastly, there are few formal mentoring programs that specifically target their services to gay youth; out of 4,000 identified mentoring programs in the country in 2012, less than four shared the mission of promoting and sponsoring one-to-one relationships between gay adults and gay youth (Barajas, 2004; MENTOR, 2012).

Because no previous study has captured the phenomenon and core essences of formal mentoring relationships involving gay adults and gay youth, the purpose of this study was threefold. First, this study sought to give heightened visibility to a population that has previously been ignored in research on youth mentoring - offering a voice to gay individuals to directly speak to the larger community about their experiences and perceptions. Second, this study sought to provide an important first glimpse into potential benefits and characteristics of these unique relationships - building a foundation of understanding that may later be used by mentoring programs and youth service practitioners to strengthen policies, procedures, and practices related to serving this population. Lastly, this study sought to explore a pathway for support that has often been met with concern by mentoring programs and agencies that target their efforts to gay youth. Fears of sexual abuse and program liability have traditionally limited programming that involves one-on-one relationships between gay adults and gay youth. By conducting this first inquiry into the potential and scope of one-to-one relationships involving adults and youth from the gay community, an avenue for further ameliorating risks and struggles faced by this population was initially understood. 
In order to accomplish these stated purposes and more closely examine the potential of mentoring relationships between gay adults and gay youth, the following research questions were developed:

1. What are the most important characteristics and processes of long-term formal mentoring relationships between gay adults and gay youth from the perspectives of the participants?

2. How, if at all, do mentors and mentees perceive potential benefits and limitations for gay youth participating in formal long-term mentoring relationships with gay adults?

3. How, if at all, do mentors and mentees perceive their mentoring relationship uniquely contributing to sexual-minority identity development in gay youth?

In order to frame this inquiry, this dissertation consists of five succinct chapters.

Chapter 1 describes the problem of significance-linking my personal struggle coming to terms with my identity as a sexual minority with literature that captures the complex stigma caused by homophobia and heterosexism, and negative social sanctions, stress, and victimization faced by many of today's gay youth. Chapter 2 examines the conceptual frameworks of youth mentoring and support strategies for gay youth, including an in-depth examination of the importance of offering specific support to sexual-minority identity development in this population. Chapter 2 also describes and details the inclusion and justification for using queer theory as a guiding theoretical framework/grounding for this study. Chapter 3 details this study's methodology, including participants, data collection, data integrity, data analysis strategies, and methodological limitations. Chapter 4 presents findings from the study, offering a baseline understanding of how participants in mentoring relationships describe the characteristics and processes, benefits and limitations, and unique support for sexual- 
minority identity development found in long-term mentoring relationships between gay adults and youth. Lastly, Chapter 5 describes conclusions, study limitations, recommendations, and a personal reflection of this dissertation experience and how I see this inquiry contributing to my role as an educational leader. Before I begin to explore the problem of significance in chapter 1 , I believe it is essential to address two key terms that are used throughout this dissertation—-formal mentoring and gay youth.

\section{Defining Formal Mentoring}

Broadly defined, mentoring consists of three important core elements and may take place in both informal and formal settings:

First, the mentor is someone with greater experience or wisdom than the mentee. Second the mentor offers guidance or instruction that is intended to facilitate the growth and development of the mentee. Third, there is an emotional bond between the mentor and mentee, the hallmark of which is a sense of trust. (Freedman as cited in DuBois \& Karcher, 2005, p. 3)

Mentoring relationships that contain these three core elements may occur in both formal and informal settings (Walker, 2005; Zimmerman, Bingenheimer, \& Behrendt, 2005). Informal mentoring occurs when non-parental adults provide guidance, support, and advocacy without support and ongoing oversight from a program (Zimmerman et al., 2005). Formal mentoring occurs when a program or agency explicitly facilitates a relationship between a caring adult and youth, using specific programmatic practices such as training of volunteer mentors and ongoing supervision of match between the mentor and mentee (Walker, 2005). For the purposes of establishing stronger parameters around this definition, formal mentoring within this dissertation refers to mentoring agencies that 
follow best practice guidelines such as The Elements of Effective Practice (MENTOR, 2003, 2009).

The Elements of Effective Practice (MENTOR, 2003, 2009) suggest that formal mentoring programs possess specific practices and features such as program planning and design, program management, program operations, and program evaluation. According to Weinberger (2005), these programmatic practices are essential ingredients necessary to promote safe and effective mentoring relationships. Additionally, research conducted on mentor program effectiveness has stressed the connection between following best practice guidelines and facilitating positive outcomes in participating youth (DuBois, Holloway, Valentine, \& Cooper, 2002; Dubois, Portillo, Rhodes, Silverthorn, \& Valentine, 2011).

\section{Defining Gay Youth}

In order to establish parameters around using gay youth in this dissertation, I feel it is important to offer insight into the complex process involved in selecting this terminology as well as offer a working definition for language that is contained within this inquiry. Many umbrella terms have been used to label and describe people that fall outside of the norm of heterosexuality. In the past, homosexual was commonly used to describe all gay and lesbian individuals (Bernal \& Coolhart, 2005). However, arguments have been made that the term homosexual focuses on same-sex behavior and is unable to account for the complexity of male and female sexuality, including sexual orientation, sexual attraction, and whether an individual actively identifies as gay or not. Instead, Bernal and Coolhart argued that the term queer be used to more fully create a collective 
and comprehensive term that better encompasses the unique experiences and sexual identities of all individuals that fall outside of the norm of heterosexuality due to their sexual and/or gender identification.

However, the use of queer may hold conflicting assumptions while also generalizing the experiences of all non-heterosexual individuals. Historically, queer has been used to refer to something strange, negative, or unfamiliar (Sullivan, 2003). Within this context, gays and lesbians, in their otherness, became known as queer-reflecting a negative and harmful way of labeling this group through their differences with those that are seen as normal in their sexuality. Recently, however, queer has been reclaimed by academic theorists as a way of disrupting assumptions around defining and naming sexualities, including how they see themselves and how others view them (Pinar, 1998). This attempt at reclaiming language has sparked great debate within the queer theorists movement about what queer actually is and what it represents (Morris, 1998; Shlasko, 2005). Further, queer, like homosexual and sexual minority, is indicative of an umbrella term - a term that may not account for important differences among individuals with nonheterosexual identities, behaviors, attractions, and orientations.

The term gay has been chosen for the purposes of this dissertation as a way of narrowing down and more specifically examining the experiences of one group of individuals that fall under these umbrella terms. However, it should be noted that great difficulty also exists in offering a comprehensive and inclusive definition for what constitutes gay (Savin-Williams, 2005). Savin-Williams argued that the presence of three distinct domains of sexuality are typically included in this definition-same-sex sexual 
orientation, same-sex sexual behavior, and sexual identity. However, he noted that adhering to a strict definition that requires the presence of all three of these domains is problematic because it does not account for the myriad of ways in which sexuality, especially adolescent sexuality, is understood, experienced, and described. For example, a young person with a same-sex orientation may not choose to actively engage in samesex sexual behavior. This same individual may also never self-identify as gay. To further illustrate this point, Savin-Williams noted:

Assuming that sexual orientation is determined prior to puberty, it is safe to conclude that at least 15 percent and maybe as high as 20 percent of all adolescents have some degree of a same-sex orientation. Less than half of these individuals are exclusively or near exclusively same-sex oriented. Teens with some degree of a same-sex orientation far outnumber the 3-4 percent who embrace a gay or bisexual identity or the 3 percent who report same-sex behavior. (p. 44)

Instead of strictly defining gay by the required presence of all three domains, a more suitable and flexible definition is offered by Ramafedi (1987). Ramafedi argued that gay should be broadly defined by patterns that include self-labeling, same-sex sexual orientation, same-sex attraction, and same-sex behavior. This broad definition holds important weight, especially when conducting research on adolescents that are undergoing enormous biological and psychosocial transformations that often contain fluidity regarding their sexuality (Graber \& Archibald, 2001).

In order to offer a more complete definition of gay youth, clarification related to parameters of age must be offered. For the purposes of this study, gay youth are comprised of adolescents between the ages of 14 to 18 at the time they were matched. These age parameters were selected due to the presence and/or emergence of several 
domains related to sexuality during this period of adolescent development. Research has indicated that gay youth, on average, report same-sex feelings at age 10, begin to selflabel at age 15, and first disclose their sexuality to others at age 17 (D’Augelli, 2006). Contained within this crucial time is the process of learning about, exploring, and sharing a gay sexual identity which is seen as a crucial milestone in a gay adolescent's development (D’Augelli, 2006). A more thorough description of the importance of sexual identity development and the potential ways in which support can be offered to gay youth at this time occurs in chapter 2 of this dissertation. 


\section{CHAPTER 1}

\section{DEFINING THE PROBLEM OF SIGNIFICANCE}

Many gay youth face great stigma related to their sexual orientation (D'Augelli, 2006). This stigma is often exemplified by negative social sanctions and victimization (D’Augelli, 2006; Rotheram-Borus \& Langabeer, 2001). In order to more closely examine these issues as the problem of significance, this chapter defines the root causes of stigma for gay people-homophobia and heterosexism. In addition, an overview of research that describes negative social sanctions and victimization of gay people in school and community settings is provided, highlighting an important need for support that has not been fully met. However, before these issues are explored, I believe it is important to describe my personal interest and reference point for wanting to conduct this research.

\section{Personal Story}

I remember the fear that overcame me each time the bell rang in my old high school some 20 years ago, knowing that I would have to walk from the safety of my classroom to my locker to get my books for the next class. Would I hear that word again? Would I be shoved this time? How could I explain to my parents that the other students harassed me because I am gay? Would my parents even accept me? Would I be able to hold my tears back until I made it through the school doors, into the open air where no one else would see me cry? I remember wishing that I was not alone - wishing that someone else understood or could guide me through this — but, there was no one, nothing, and that feeling of isolation was all I could understand. 
When I graduated high school, I vowed never to step foot in that building again. I left, knowing that I had endured something that would last with me for the rest of my life. I left, knowing that in the future when I was on a bus or walking down the street and heard the word faggot - that someone would be talking about me. I left the science hall that became synonymous with the black haired boy that would follow me, harass me, and tell me that I was going to hell. I left the pain, the isolation, the feeling of being utterly and completely different, alone. I left the feeling of being "other." It took many years for those wounds of high school to heal. Sometimes, I am not so sure they have completely disappeared.

Not too long after I graduated college, I had the opportunity to reclaim that place and confront many of my long-held fears. As an AmeriCorps Member, part of the national service movement started by President Clinton, I was responsible for starting a mentoring program that hoped to alter cycles of poverty and promote positive and lasting differences in youth that were most in need of caring adults and role models. Unfortunately, or fortunately, for me, that responsibility brought me back to the same high school that left me tattered, torn, insecure, and incomplete.

While creating and coordinating the mentoring program at my old high school, I saw many faces come through my door. I saw students that were poor, students that were struggling with insecurity, students that were struggling with abuse, drugs, or lack of a caring adult in their lives. I also saw a couple of students that reminded me of my high school self, who I could sense had the same look of fear each time they walked down that same science hallway that I dreaded. These students probably did not have the same black haired boy that followed them - but they still had to hear the hurt of that word, the 
sheer hatred associated with that word and I am sure they asked the same questions of themselves that I did, wondering if they would be able to stop their tears at least until they made it through the other side of the school's door.

\section{Understanding the Challenges Faced by Gay Youth}

While my story felt so unique and my experiences felt so personally painful, research on the challenges, risk factors, and experiences of gay youth shed light on important and documented examples of how little alone I really was in terms of the landscape of stigma, negative social sanctions, and victimization that appear to be experienced by many individuals that grow up gay. Here, I detail the problem of significance facing gay youth - offering definitions of homophobia and heterosexism and describing the implications that these important social and political constructs play in creating barriers and challenges for gay individuals and youth.

\section{Causes of Stigma: Homophobia and Heterosexism}

Brown and Colbourne (2005) stated that gay youth face significant stigma caused by the social and political (socio-political) constructs of homophobia and heterosexism. Coined by Weinberg (as cited in Brown \& Colbourne, 2005), homophobia is defined as "the irrational fear and hatred of gay, lesbian, and bisexual people, their behaviors, choices, and lives" (p. 264). Jucovy (2000) further defined this term:

Homophobia refers to the discomfort one feels with any behavior, belief, or attitude that does not conform to traditional sex-role stereotypes. Homophobia results in fear of knowing, befriending, or associating with gays, lesbians, bisexuals, and fear of being perceived as gay, lesbian, or bisexual. (p. 3) 
Expressions of homophobia may be internal, including attitudes or thoughts about gay individuals, or external, which involve actively targeting or physically assaulting those that are gay or perceived to be gay (Brown \& Colbourne, 2005).

Many similar definitions of heterosexism exist (e.g., Appleby \& Anasta, 1998; Herek, 1984; Pharr, 1988) with Brown and Colbourne (2005) most succinctly describing it as "institutionalized and cultural homophobia: the legitimization of prejudice on the basis of non-heterosexual orientation through overt social practices and systems and covert social mores and customs" (p. 264). Expressions of heterosexism may include only providing entitlement and social acceptance to those that meet social legitimacy requirements. For individuals that identify as a sexual minority, the culture of oppression found within heterosexist practices becomes dominant and overarching.

\section{Examples of Homophobia and Heterosexism}

Examples of homophobia and heterosexism can be found within historical depictions of gay people and also within contemporary media and politics. According to Pinar (1998) research and academic study on sexual minority populations before the 1970s were defined through either absence or deviance; very little had been written about the experiences, perceptions, and struggles of gay people. This absence reflected a "closeted" approach to hiding or keeping something from view. The term "in the closet" is a colloquial term that is still used to describe when a gay person is not open about who he is, whether internally or externally.

The other representation of gay people, deviance, offers perhaps an even harsher reflection and representation of homophobic and heterosexist attitudes. Pinar (1998) gave the example of a book for teachers written by 1932 by Walker which described 
homosexuality as being contagious in nature; it built a framework for denying gay men the opportunity to teach. This book was written around the same time that thousands of gay men perished within Nazi concentration camps, a chilling period that also reflects the perceptions of perversion and ostracism that this group faced in the early- and midtwentieth century. In fact, the pink triangle, a modern symbol of the equality movement for gays and lesbians, originated during this time. In concentration camps, the pink triangle was used to label the lowest grouping of prisoners - gay males (United States Holocaust Memorial, n.d.).

In 1973, a turning point for understanding and reflecting on gay people occurred when the American Psychological Association removed homosexuality from the Diagnostic and Statistical Manual of Mental Disorders (DSM), used to diagnose and treat mental illness. Through this action, and the similar action in 1975 of the American Medical Association, research and study of this population finally began to look at the humanness and minority status of gay, lesbian, bisexual, transgender, and questioning individuals as opposed to deviance.

While these changes reflected an important shift toward understanding and treating sexual minority populations with equality, the face of homophobia and heterosexism continues to create hardship for many gay people today. One of the highest profile cases of a hate crime against a gay man in recent years occurred near Laramie, Wyoming in October 1998. Matthew Shepard, a 21-year old college student at the University of Wyoming, was pistol whipped with a gun and tied to a fence post to die by two men he met at a bar, Russell Henderson and Arron Mckinney (Brooke, 1998). He suffered a fracture to the back of his head, brainstem damage, and had lacerations and 
cuts on his head, neck, and face. Five days after his attack, Matthew Shepard died in a hospital in Colorado. During the trial, the motivation for the attack was discussed, and testimony from Kristen Price, the girlfriend of Arron McKinney, indicated that the pair specifically wanted to rob and harm a gay man. Both of Matthew Shepard's assailants were convicted of murder and were given life sentences. Because Wyoming did not have any hate crimes legislation for such acts against sexual minorities, both men were never convicted of killing Matthew because of his sexuality.

To further illustrate the scope of homophobia that was present in this brutal murder, Matthew Shepard's funeral was picketed by members of the Westboro Baptist Church of Kansas. This church, with the leadership of Reverend Fred Phelps, held signs outside of the funeral, which included placards that read "God Hates Fags," and "Matthew Shepard Rots in Hell." These signs offered explicit examples of hate, homophobia, and discrimination targeted at further inflicting harm into the lives of people that cared about Matthew and into the lives of people that shared the same sexual orientation as he did.

Beyond the horrible tragedy of Matthew Shepard, other important examples of homophobia can be found in politics. In the state of Oregon, a public ballot measure in 1992 sought to change the state constitution to deny sexual minorities' access to governmental services, assistance, or equal educational opportunities. The text of 1992 Oregon Ballot Measure 9 read:

All governments in Oregon may not use their monies or properties to promote, encourage, or facilitate homosexuality, pedophilia, sadism, or masochism. All levels of government, including public education systems, must assist in setting a standard for Oregon's youth, which recognizes that these behaviors are abnormal, wrong, unnatural, and perverse and they are to be discouraged and avoided. 
While this ballot measure did not pass, it is important to note that a large percentage of Oregonians voted in favor of this constitutional amendment. In the November 3, 1992 , election, 638,527 people voted to support this measure, while 828,290 voted against it (Oregon Blue Book, n.d.).

By describing these examples, much can be understood about the attitudes, messages, and actions that currently and actively oppress gay people. The acts of violence found in Matthew Shepard's brutal killing and the political attempt at linking homosexuality with pedophilia and restricting access for sexual minorities to governmental and educational opportunities starkly reflect the reach and scope of how far homophobia and heterosexism has infiltrated today's society. These actions and messages also describe a larger climate that has important implications for the day-to-day community and educational settings in which many gay youth are present. In the next section, I describe these implications.

\section{Victimization, Stress, and Social Interaction Anxiety in Gay Youth}

Homophobia and heterosexism promote significant negative social sanctions and challenges within social and familial settings that often result in victimization of gay youth (D’Augelli, 2006). Victimization in this population is also closely related to increased stress, health, and mental health difficulties (Safren \& Pantalone, 2006). Further, experiences with victimization at a formative age may also increase levels of social interaction anxiety, which is seen to complicate gay youths' access to satisfactory social support from others that can help them receive assistance and guidance during this critical time (Safren \& Pantalone). Because of the close relationship between 
victimization, stress, and social interaction anxiety, a further examination of these issues within the problem of significance facing gay youth is merited.

Victimization. D’Augelli (2006) described research on six types of victimization that is often related to the sexual orientation of gay youth: verbal abuse, threats of physical attack, objects being thrown, assaults, threats with weapons, and sexual assaults. From a sample of 542 youths (62\% male and 38\% female), $74 \%$ self-identified as gay or lesbian. The participants were asked to complete a survey that assessed different factors related to their experience as a gay youth. Findings from the survey noted:

Most (81\%) had experienced verbal abuse related to being LGB; 38\% had been threatened with physical attacks, $22 \%$ had objects thrown at them; $15 \%$ had been physically assaulted; $6 \%$ had been assaulted with a weapon, and $16 \%$ had been sexually assaulted. More than half (54\%) had been subjected to three or more incidents of verbal abuse. Fourteen percent had been threatened with violence three or more times. (p. 46)

These findings are similar to a study conducted by the Gay, Lesbian and Straight Education Network (GLSEN, 2012) which regularly conducts a national school climate survey to better understand issues of victimization in educational settings.

The 2011 National Climate Survey (GLSEN, 2012) was conducted to better understand the perceptions and experiences of 8,584 gay, lesbian, bisexual, and transgender (GLBT) students between the ages of 13 and 20 in all fifty states and the District of Columbia. Outreach through national, regional, and local community and educational support organizations for gay and lesbian youth was conducted to obtain a national sample of youth for this study. Additionally, targeted advertising on Facebook was conducted. Both online and paper-based surveys were used. 
Findings from the 2011 National Climate Survey (GLSEN, 2012) indicted that GLBT youth are often placed in hostile learning climates where they frequently hear biased remarks and experience victimization. Findings for biased remarks: $84.9 \%$ of respondents reported hearing the word "gay" used negatively; $61.4 \%$ described hearing negative remarks about gender expression; $71.3 \%$ stated that they heard homophobic remarks like "dyke" and "faggot" on a regular basis; and over half of the youth described hearing such remarks from teachers or other school staff. In addition to hearing biased remarks, many students also report safety and victimization issues at school: $63.5 \%$ felt unsafe because of their sexual orientation; $81.9 \%$ were verbally harassed; nearly $40 \%$ were physically harassed; and almost $20 \%$ reported being physically assaulted; $55.2 \%$ of the student also reported experiencing online harassment. These findings indicate a learning environment filled with safety and bias issues that are fraught with difficulty for many students.

Lack of family support may also be another way in which gay youth are victimized due to their sexual orientation. In his study on victimization, D’Augelli (2006) found that many gay youth were verbally abused by their mothers $(13 \%)$ or were afraid of being verbally abused by their parents $(30 \%)$ due to their sexual orientation. Further, $13 \%$ of gay and lesbian youth lived in fear that a parent would physically abuse them. These numbers indicate a difficult home environment in which many gay youth must live on a daily basis.

In close relation to these findings, gay and lesbian youth may also represent high numbers of homeless youth. A recent report from the National Gay and Lesbian Task force (2007) estimated that as many as $40 \%$ of homeless youth in the United States are 
gay or lesbian. This report comprehensively reviewed literature on youth homelessness and described an epidemic of youth that were often displaced from their homes because of their family's disapproval of their sexual orientation or gender identity (National Gay and Lesbian Task Force, 2007). As these findings indicate, lack of familial support and negative social sanctions by others appear to be accompanied by detrimental effects.

Stress. In a climate of victimization, many gay youth are faced with heightened stress, mental health and health-related risks (Safren \& Pantalone, 2006). Issues related to stress may involve drug and alcohol abuse, increased risk for HIV, and suicide. Heightened drug and alcohol use by gay youth was reported in a study by Garofolo, Wolf, Kessel, Palfrey, and DuRant. (1998). In an anonymous survey of 4,159 high school students in Massachusetts, approximately $2.5 \%$ of the respondents in this study identified as gay or lesbian. Analysis of outcomes was done with multiple logistic regression, which indicated self-identified gay or lesbian youth were significantly more likely to have used cocaine, had early initiation of alcohol and marijuana use, and engaged in sexual behaviors than heterosexual youth in the study.

These risk-taking behaviors can be further demonstrated in research that has indicated that HIV levels and HIV risk taking behaviors are heightened for many gay youth. According to the U.S. Center for Disease Control and Prevention (CDC, 2012), young males that had sex with other males (MSM) represented high rates of HIV infection. CDC figures indicate that $26 \%$ of all new HIV infections are among youth ages 13 to 24, with nearly $80 \%$ of these infections occurring in MSM. African American and Latino youth accounted for Almost $60 \%$ of new infections. These figures offer an important picture of health risks associated with gay and bisexual youth. 
Research on suicidal ideation and suicide in gay youth offers important insight into mental health risks for this population. Using data from The Massachusetts Youth Risk Behavior Survey, Faulkner and Cranston (1998) found that youth that engaged in same-sex behavior were $50 \%$ more likely than heterosexual youth to seriously consider suicide in the previous year. Ramafedi, French, Story, Resnick, and Blum (1998) noted that $28.1 \%$ of bisexual and gay youth self-reported a suicide attempt compared to $4.2 \%$ of heterosexual high school and middle school males. Hershberger and D'Augelli (1995) noted that gay and lesbian youth that attempted suicide were often victimized and lost peer support upon disclosure of their sexuality. According to the U.S. Department of Health and Human Services, suicide is the leading cause of death among gay and lesbian adolescents (Gibson, 1989). This report noted that lesbian and gay youth are two to three times more likely to attempt to end their lives than their straight peers and it is estimated that nearly one third of all completed adolescent suicides is comprised of a gay or lesbian youth ending his or her life. These findings indicate an important link between gay youth and struggles with mental health that hold the potential to have devastating consequences.

Social interaction anxiety. In addition to stigma, victimization, and stress, gay youth may also face barriers to receiving support from others due to increased levels of social interaction anxiety (Safren \& Pantalone, 2006). Safren and Pantalone defined social anxiety as "fear and avoidance of situations that may involve evaluation by others" (p. 58). A central feature of social anxiety is social interaction anxiety, which is characterized by fear of initiating and maintaining social conversations and interactions with others and reflects an important barrier to acquire and maintain social supports (Safren \& Pantalone). While many gay youth experience negative social sanctions on a 
frequent basis, they also encounter barriers to receiving necessary support and positive social interactions - further complicating their already complex and risk-filled adolescence.

Safren and Pantalone (2006) examined the impact that social interaction anxiety held for gay youth. In their study, they sampled 104 young people (ages 16-21), comparing the experiences of gay, lesbian, and bisexual youth $(n=56)$ to heterosexual youth $(n=48)$. Participants responded to questionnaires that captured age, gender, educational attainment, ethnicity, sexual orientation and living situation. In addition, participants completed The Social Interaction Anxiety Scale, Social Support Questionnaire, Adolescent Perceived Events Scale, and the Marlow-Crown Social Desirability Scale. Results from this study indicated that gay and lesbian youth reported greater levels of social anxiety than heterosexual peers. Gay and lesbian youth also tended to feel less satisfaction with available social supports than heterosexual youth. Further, gay and lesbian youth also reported experiencing fewer positive events associated with social interaction. These findings indicate a growing need to learn more about strategies that can strengthen access and satisfaction with social supports that are available to gay youth.

As research has indicated, gay youth face many barriers and struggles during their adolescence. Stigma, negative social sanctions and victimization, and lack of satisfaction with social support indicate a growing need to learn more about strategies that can be used to ameliorate risks and provide access to satisfactory and protective relationships. Chapter 2 of this dissertation offers insight into the potential of formal mentoring relationships to meet these important needs. Chapter 2 also explores one pathway through 
which mentors may be uniquely able to offer personalized one-to-one support to gay youth—by offering assistance with sexual-minority identity development. 


\section{CHAPTER 2}

\section{LITERATURE REVIEW}

As gay youth face stigma, negative social sanctions, and victimization, many of these young people also lack social supports and positive role models that can act as protective influences and offer assistance during the critical period of developing and accepting a solid and healthy identity as a sexual minority (Safren \& Pantalone, 2006). Formal mentoring has been recommended as a strategy to ameliorate many environmental risks for youth in general, while also providing targeted support that can be tailored to the needs of gay adolescents (Barajas, 2004; Jucovy, 2000). Yet, while the call to provide mentoring relationships to gay youth has been recommended, very little is truly understood about the ways in which gay youth participate in and leverage support from the unique format of one-to-one mentoring relationships (DuBois \& Karcher, 2005).

In order to more fully examine the potential that formal relationships may hold for gay youth, this chapter reviews pertinent literature on formal mentoring, including origins and contemporary landscape, theory, and empirical research. This chapter also more closely examines the framework of sexual-minority identity development, including an overview of literature that describes how sexual minority identity is formed and shared and the potential roles that others, including mentors, can play in offering protection and support during this process. Further, this chapter also defines and describes the use of queer theory as the theoretical framework/grounding for my research inquiry. In the process of exploring these frameworks, important gaps in understanding how gay youth participate in and leverage formal mentoring relationships for support are examined- 
further justifying a need to establish a baseline of understanding that this dissertation seeks to build.

\section{Formal Mentoring}

Origins and contemporary landscape, theory, and empirical research provide important details about how to define and understand formal mentoring. This section describes literature that helps to provide context to understand this first conceptual framework.

\section{Origins and Contemporary Landscape}

The origins of mentoring within the United States can be closely linked with changes in how judicial systems treated juvenile offenders at the end of the nineteenth century and the formation of what is now known as Big Brothers Big Sisters of America (BBBS) at the start of the twentieth century. According to Baker and Maguire (2005), as the nation shifted toward an industrialized economy, high levels of poverty and criminal recidivism in major urban areas occurred, especially for children living in many of the growing cities on the east coast and in the mid-west. The creation of a juvenile court system in 1899 was a response to the judicial ineffectiveness of reducing recidivism rates in youth and the shift toward viewing youth as "a byproduct of a calamitous and toxic environment not of their making" (p. 17). Through the creation of this court system, a commitment was made to differentiate the needs of delinquent youth from those of adults and to recognize the potential for youth to rehabilitate, change, and become functioning members of society.

According to Baker and Maguire (2005), the formation of the BBBS program in the early 1900s reflected additional commitments to rehabilitate and nurture youth that 
had been involved with juvenile delinquent behaviors. Through pairing juvenile delinquents with high profile adults within communities, this program offered opportunities for rehabilitation, access to learn new skills, and the commitment of volunteers from the upper class to use their stature to make a difference in the lives of poverty stricken youth. Through the involvement of many secular and philanthropic groups, the initial incarnation of mentoring within the United States gained widespread acceptance and spread rapidly to at least 98 cities by 1917 .

Today, mentoring is undergoing a chapter of unprecedented growth, change, and possibility at the beginning of the twenty-first century, one which brings the potential of high rewards and high risks for millions of vulnerable youth. MENTOR (2005) estimated that over 3 million youth are currently participating in mentoring relationships, with nearly 15 million additional youth in need of caring adult role models. While these statistics appear impressive, even more extraordinary is the recent timeframe through which many of these mentoring programs have begun to provide these much needed services to vulnerable youth and the diversity of youth that mentoring programs are attempting to serve.

The expansion of mentoring programs has primarily occurred within the last 20 years. According to Rhodes (2002), nearly half of mentoring agencies have been in existence for less than five years. Even more notable is that only $18 \%$ of mentoring programs have provided mentoring services to youth for periods longer than 5 years (Sipe $\&$ Roder, 1999). Because the majority of programs have only recently begun to provide services to large populations of youth and because of the unique needs of each child within these mentoring programs, important questions have been asked about the 
potential cautions, possibilities, and concerns of these efforts, especially for special populations of youth.

Rhodes (2002) stated that mentoring relationships have extraordinary potential to create positive and affirming benefits in youth; however, because research has not captured the explicit ways that mentoring programs may best respond to and provide services to large numbers of diverse youth, she cautioned that "our challenge is, first, to not underestimate the complexities of mentoring relationships and second, to better understand and promote the conditions under which they are most likely to flourish" (p. 9). In order to heed Rhodes' advice, an in-depth examination of theories and empirical research on mentoring must be conducted.

\section{Theory}

DuBois and Karcher (2005) stated that: "there have been only limited efforts to articulate theoretical models of youth mentoring" (p. 8). However, they argue that important contributions from a wide range of interdisciplinary fields such as social work and psychology have helped to offer insight into how these relationships function, ameliorate risks, and offer benefits to youth. In order to more fully understand how these unique relationships work, this section examines various theories and models that explain key components of mentoring relationships, including potential goals and a description of the noteworthy Pathways to Mentoring Influence Model (Rhodes, 2002, 2005) that detailed such key features of mentoring relationships, including mentor influences, conditions, moderators, mediators, benefits and outcomes. (Rhodes, 2002, 2005).

Goals: Youth development and resilience. Much of the complexity of understanding the intricacies of mentoring relationships lies in the diverse scope of uses 
that have become synonymous with this practice. As previously noted, mentoring was initially used as a juvenile delinquency prevention strategy in the United States at the start of the twentieth century (Baker \& Maguire, 2005). Since that time, mentoring has expanded to become associated with assisting youth in a wide variety of contextsincluding school support (Herrera, Grossman et al., 2007; Herrera \& Karcher, 2013), work and service learning (M. A. Hamilton \& Hamilton, 2005, 2013), after-school programming (Hirsch \& Wong, 2005; Mekinda \& Hirsch, 2013), faith-based settings (Maton, St. Domingo, \& King, 2005), and electronic settings (Miller \& Griffiths, 2005). The wide net that is associated with mentoring can create great difficulty in assessing and understanding the intricate processes that are involved in mentoring relationships (DuBois \& Karcher, 2005, 2013). However, while the contexts of these relationships may widely vary, many of these relationships appear to hold the intention of assisting youth in their development (Lerner, 2007; Lerner, Napolitano, Boyd, Mueller, \& Callina, 2013) and acting as compensatory and protective influences that can foster resilience (Zimmerman, Bingenheimer, \& Behrendt, 2005). A more thorough description of these two important goals is offered.

Erikson (1963) defined development as a series of stages that an individual must go through in order to obtain the skills, values, and competencies required to become successful adults. In order, Erikson's stages of development are trust versus mistrust, autonomy versus shame and doubt, initiative versus guilt, industry versus inferiority, identity versus identity confusion, intimacy versus isolation, generativity versus stagnation, and integrity versus despair. As an individual completes each of these tasks, 
they gain vital tools that can assist in their transition into a healthy and nourished adulthood.

While Erikson (1963) offered an important framework to understand stages through which an individual navigates toward a healthy adulthood, Eccles and Gootman (2002) detailed important caveats about this model. First, while these tasks appear to follow a natural sequence, individuals may be faced with the need to resolve any one of these stages as their circumstances change throughout their lives. An individual may be required to work on resolutions of previous tasks that once appeared to be mastered. Second, the process through which individuals from different cultural groups or diverse backgrounds navigate through this model of development may not be accounted for in the sequencing of Erikson's stages (Eccles \& Gootman, 2002).

Mentoring has been closely linked with youth development because mentors have been seen to offer youth vital opportunities to practice developing assets that can assist them in navigating through their development (Lerner, 2007; Lerner et al., 2013). Lerner argued that mentors offer a positive milieu giving youth a safe relationship that can help to hone and enhance assets needed to advance into healthy adulthood. This milieu consists of three features that are often found within youth development programs: sustained, positive youth relations with caring adults; youth life-building activities, and youth participation in leadership and community activities.

Youth resilience has also been closely associated with mentoring (Rhodes, 2002). Resilience is defined as "the process of overcoming the negative effects of risk exposure, coping successfully with traumatic experiences, and avoiding the negative trajectories associated with risks" (Fergus \& Zimmerman, 2005, p. 399). This process involves the 
use of assets and resources such as mentoring that help youth sharpen their strengths and reduce deficits that may occur with exposure to difficult circumstances. Fergus and Zimmerman identified three models for understanding resilience in youthcompensatory, protective, and challenge. The compensatory model is defined when a promoting factor counteracts or operates in an opposite direction of a risk factor. They used the example of an adult monitoring the behavior of an adolescent that is exposed to poverty to prevent the behaviors of delinquency that are associated with this risk factor. This is a reactive approach. In contrast, the protective model involves the use of assets or resources to moderate or reduce the effects of a risk on a negative outcome. Fergus and Zimmerman cited the example of adult engagement of parents and/or mentors that may provide high levels of support to youth that are exposed to a negative risk. Lastly, the challenge model described the curvilinear association between a risk factor and an outcome. This model suggests that youth may potentially benefit from exposure to risks because they gain opportunities to develop their own resources to counteract the negative influences of these risks and prepare them to overcome higher risks in the future. Zimmerman et al. (2005) stated that mentoring is most closely associated with the compensatory and protective models of resilience because mentors may offer youth assets and resources such as guidance, social capital, support, and supervision.

The Pathways to Mentoring Influence Model. While youth development and resilience have been noted as potential goals for mentoring relationships, the ways in which mentors work with youth to steer, protect, and guide them toward these goals requires additional clarifying discussion. Rhodes (2002) developed the first theoretical explanation of how mentoring relationships achieve these goals-The Pathways to 
Mentoring Influence Model (see Appendix A). Rhodes' model described a series of intricate influences through which mentors leverage their relationship with mentees to achieve a wide range of benefits and outcomes in youth. These influences include: serving as a role model, enhancing social skills and emotional well-being, and improving cognitive skills through listening and dialogue. Her model also described important conditions that must be present in mentoring relationships for change to occur, including a close and empathetic bond and mutuality between mentor and mentee. Because of the diverse range of experiences and history that mentees bring with them into their relationships and the types of support they receive while participating in their relationship, The Pathways to Mentoring Influence Model highlights various moderating processes that may promote or hinder benefits for participating youth. These moderating processes include: child's interpersonal history, social competencies, developmental stage, relationship duration, program practices, family context, and neighborhood ecology. Mediating influences such as changes in parent, peer, and other relationships during the youth's relationship are also detailed. In an updated version of this model (see Appendix A), Rhodes (2005) described specific benefits that may occur for youth. These benefits include: socio-emotional development, cognitive development, and identity development. Lastly, an overview of specific outcomes is highlighted, including such changes as improved grades, problem solving, behavior, and well-being. Because of the need to more closely understand the characteristics and processes that occur within mentoring relationships, highlights from both versions of Rhodes' model are described throughout this section and further illuminated with supplemental theory. 


\section{Mentor influences: Role modeling, cognitive development, and social/emotional}

development. Rhodes (2002) argued that mentors affect youth through three important influences found in their relationships with a young person-role modeling, cognitive development, and social/emotional development. She argued that mentors that can extend their influence into one or more of these areas are most likely to foster greater impacts in youth. In order to more closely examine how and why these influences may be important for promoting benefits in youth, supplemental theories related to each of these areas are explored within the context of Rhodes' model.

The importance of role modeling as a pathway for influence in mentoring relationships may best be described through the work of Bandura (1986). Bandura theorized that observation of more experienced individuals may be an effective approach to facilitate learning, under the conditions that the learner is actively engaged, has opportunities to observe the more experienced individual in action, and the protégé can practice using new skills. In mentoring relationships, mentors may be able to act as positive role models by giving their mentee an opportunity to see new skills and traits that they wish to emulate, which holds the potential of propelling the young person into attempting to learn new ways of thinking and being (Rhodes, 2002).

S. F. Hamilton and Darling (1996) argued a mentor may be able to act as a positive role model within the context of a mentoring relationship in three specific ways: (a) mentors behave in a way that they hope their mentees will emulate, (b) mentors offer descriptions of their own experiences and reactions to difficult events and offer critiques about how they may have better handled a situation, and (c) mentors help their mentees witness the ways that thoughtful and caring adults interact with each other. While these 
three strategies provide insight into how a mentor can act as a role model, S. F. Hamilton and Darling also suggested that the motivation and desire of the mentee to recognize the mentor as a role model is critical.

Socio-emotional support is the second pathway of influence discussed in Rhodes' (2002) model. Rhodes, Keller, Spencer, Keller, Liang, and Noam (2006) stated that mentors offer youth opportunities to engage in various recreational and social interactions and access positive social experiences within a new relationship. The influence of socioemotional support may occur in three vital ways: (a) the mentor provides opportunities for fun and escape from daily stresses, (b) the mentor offers corrective emotional experiences that may generalize to and improve youths' other social relationships, and (c) the mentor offers assistance with emotional regulation (Rhodes et al., 2006). These mentor/mentee interactions may often foster new emotions: "When an adolescent feels safe and accepted in the presence of a mentor, a fuller range of feelings and thoughts, and a different way of relating and being related to, can grow" (Rhodes, 2002, p. 39).

Cognitive development is Rhodes' (2002) third pathway of mentoring influence. In order to more closely understand the ways in which a mentoring relationship may assist youth through this influence, an overview of theories that explain cognitive development is helpful.

Theories on psychological constructivism, based on the work of Piaget in the midtwentieth century, offer detailed insight into how a young person may build personal meaning through engagement with their environment. Piaget (1936) theorized that through the development of schemas, or cognitive structures, a child is able to advance to higher stages of knowledge and development. As children engage with their environment, 
they develop greater cognitive skills that allow further exploration within the environment and higher cognitive development. This process is highly informed through the act of "handling, dismantling, and generally transforming...surroundings." (Phillips \& Soltis, 1998, p. 42). This developmental process is based on the relationship between the inquirer and his or her environment.

Building from this theoretical model, Vygotsky (1978) argued that knowledge acquisition is closely connected with the guidance of more experienced individuals. In Mind and Society, Vygotsky introduced a concept of learning called the Zone of Proximal Development. The Zone of Proximal Development is "the distance between the actual developmental level as determined by independent problem solving and the level of potential development through problem solving under adult guidance or with more capable peers" (Vygotsky, 1978, p. 85). This concept of learning requires a relationship between a more experienced individual and less experienced individual, which is a key component of the definition of mentoring (Freedman, 1991).

Rhodes (2002) stated that mentors specifically offer youth a unique opportunity to gain capacity for critical thinking and awareness through Vygotsky’s (1978) model. Rhodes stated "mentors can help adolescents test their ideas and sharpen cognitive skills that they would not use on their own, or in day-to-day conversations with peers" (p. 44). By understanding the importance of Vygotsky's Zone of Proximal Development, we gain insight into potential pathways through which a formal mentoring relationship can help a young person learn, develop, and gain increased skills that will assist them in becoming more positive and healthy adults. 
Finally, Phillips and Soltis (1998) argued that adults can better understand and honor the cognitive developmental processes of youth by fully respecting the individual nature of learning, understanding the role of experience and environment in learning, and becoming more aware of the varied stages of cognitive abilities and features that each child possesses and for which he/she has the capacity. Therefore, adults can support the cognitive development of youth by recognizing that a one-size-fits-all approach will not work and that each child engages in their own processes. Adults and adult mentors can work with youth, foster positive learning environments, and offer support to further enhance the individual development that occurs. Rhodes et al. (2006) stated that mentoring relationships contribute to cognitive development by exposing mentees to new experiences, providing challenge and guidance, and fostering academic success.

Conditions: Close and empathetic bond, mutuality. While the three pathways of mentor influence offer an important understanding of the ways in which mentors can interact with mentees to foster change in youth, Rhodes $(2002,2005)$ also argued that certain conditions must be met for these relationships to fully offer mentee benefits. The mentor and mentee must establish a close and empathetic bond and feel trust with each other and the mentoring relationship must be based on mutuality.

Spencer (2004) described the importance of establishing a close and empathetic bond in mentoring relationships, linking this type of bond to those seen in psychotherapeutic relationships. In psychotherapeutic relationships, the bond that is formed between a counselor and a client is seen as central to the change process (Rogers, 1980). This bond requires empathy, positive regard, and congruence on the part of the counselor which is used as the emotional foundation for treatment. Spencer argued that 
the positive emotional bond is thought to "contribute to the client's feeling listened to and understood and experiencing the therapist as trustworthy and helpful” (p. 34). In mentoring relationships, the degree to which the mentee feels valued, listened to, and appreciated offers important implications for how trust develops in the mentoring match, ultimately increasing the potential for the mentee to positively benefit from the relationship (Rhodes, 2007).

The mentor's approach to the young person may also provide insight into how bonding occurs through mutual activities. Mentors that use developmental and/or instrumental approaches within their relationship are seen to form a stronger bond, which is hypothesized to ultimately influence the development of the mentee (Karcher, Kuperminc, Portwood, Sipe, \& Taylor, 2006). Developmental mentoring focuses: “on facilitating the relationship between mentor and mentee as a way of promoting the youth's development and reflects assumption that mentoring influences social, emotional and academic development through the creation of supportive relationships" (p. 714). This type of mentoring relationship often involves the use of games, mutual activities, and opportunities for the mentor and mentee to have fun together in a format that builds a bond in their relationship. Instrumental mentoring, in comparison, focuses on leveraging the mentor to help the mentee achieve goals such as the learning of a skill or achievement in an academic setting. In this type of relationship, often the mentor assists the mentee in accomplishing the goals of the mentee's choosing, offering advice, guidance, and opportunities for suggestions. A third type of mentor approach, prescriptive (Morrow \& Styles, 1995), is driven by the adult and involves the mentor telling the mentee what must be done without regard to developing the relationship or leveraging the goals that the 
youth has identified. This type of relationship and the activities and conversations chosen by the mentor is often viewed negatively by a young person and may compromise the formation of a bond between the mentor and mentee.

Moderating processes. In addition to the conditions of a close and empathetic bond and mutuality, Rhodes (2005) also described several moderating processes that play a role in whether and how benefits in youth are achieved. These moderating processes are child's interpersonal history, social competencies, developmental stage, relationship duration, program practices, family context, and neighborhood ecology.

A child's early relationships and interpersonal history may influence the ways in which the individual participates in and leverages support from a mentoring relationship (Rhodes, 2005). For example, Rhodes argues that those young people with a history of unsatisfactory relationships that resulted in disappointment may have a more difficult time forming bonds with a mentor at first. However, with the development and presence of a close, trusting, and empathetic bond, many of these young people may be more receptive to their mentor's emotional and social support_ - ultimately helping to foster a wider range of socio-emotional benefits over time. In contrast, young people that already possess a history of caring adults in their lives may be more likely to access and receive cognitive development support and benefits during their mentoring experience (S. F. Hamilton \& Darling, 1996; Rhodes, 2005).

The background of a mentee, including his or her race, culture, and ethnicity may also be important to consider within the context of interpersonal history, especially in light of the propensity of mentoring relationships to primarily include non-white youth. In order to more closely examine potential challenges and opportunities that may occur in 
mentoring relationships consisting of racially, culturally, and ethnically diverse youth, Sanchez and Colon (2005) presented different theoretical perspectives that explain nuances based on interpersonal history that can promote or hinder benefits in such youth. First, Sanchez and Colon argued that Ogbu's (1990) framework related to similarityattraction paradigm (Byrne, 1971) offers insight into the importance of matching mentees with mentors from similar racial backgrounds due to shared interpersonal experiences with racism. In these instances, a same-race mentor may be able to more effectively role model skills uniquely related to overcoming stigma and offer coping skills to a mentee than what can be gained through a relationship with a mentor that has not experienced racism. Second, Sanchez and Colon highlighted the importance of stereotype threat in mentoring relationships involving diverse mentors and mentees. Stereotype threat "refers to the psychological state that an individual experiences when some property of the environment reminds him or her of stereotypes held by society" (Steele as cited in Sanchez \& Colon, 2005, p. 193). In mentoring relationships that consist of matches between white and non-white youth, stereotype threat may be an important factor that can become exacerbated when white mentors are ill-prepared to work with youth from different backgrounds: "For instance, if a White mentor simply provides suggestions and points out weaknesses to a minority mentee, the mentee may believe the mentor holds negative racial biases or prejudices and be less motivated to succeed in the future" (Sanchez \& Colon, 2005, p. 193). Sanchez and Colon also argued that stereotype threat may hinder the development of trust in mentoring relationships - a key condition needed to foster benefits in youth. Cultural values are also explored as a potential force that can alter benefits in diverse youth and create tension, especially involving issues involving 
individualism and collectivism. Of note, Sanchez and Colon described the tension that may occur when White mentors work with youth from backgrounds that value collectivism:

Consider, for instance, an individualistic mentor who is paired with a mentee from a collectivistic culture. The mentee might be expected to remain close to the family and emphasize its goals over any individual's. However, the mentor might advise the mentee leave home and go away to college, thereby suggesting, in contrast to these family values, that his future is most important. (p. 194)

Because of the tensions that may occur in mentoring matches that consist of mentors and mentees from different backgrounds, a wide range of challenges may be present. These challenges may be even more pronounced for youth that have interpersonal histories that include experiences with racism, stigma, values from non-individualistic cultures, and disappointing interpersonal experiences with adults. For mentees with interpersonal histories that have been shaped by factors such as race, culture, and ethnicity, ill-prepared mentors may unknowingly perpetuate tension or harm in mentees.

Social competencies are considered to be a second moderating process. Rhodes (2005) stated that youth entering into mentoring relationships with positive temperaments and who also possess high levels of emotional regulation may have already developed social skills to access support from adult role models and may more likely be able to acquire benefits in mentoring relationships. In contrast, those youth that struggle to relate to others may have ongoing difficulty forming a close and trusting bond, which is considered an important condition for benefits in mentoring relationships.

The developmental stage of the young person may also moderate the ways in which mentoring relationships benefit a young person (Rhodes, 2005). Erikson's (1963) model of youth development holds that an individual is faced with undertaking different 
developmental tasks that must be resolved in order to move toward higher levels of development. Therefore, depending on the developmental stage of a young person, variations may occur in the activities and relational abilities of the youth, influencing how they leverage and access their mentoring relationship. Rhodes offers an important summation of this moderating influence:

For adolescents on the brink of adulthood may be less interested in establishing emotional ties with mentors, instead gravitating to peers and vocational skillbuilding activities. Older adolescents tend to be more peer-oriented than their younger counterparts and less likely to sustain their involvement in structured mentoring programs. (Rhodes, 2005, p. 36)

The developmental stage of an adolescent may alter the potential focus of activities and support that occurs within mentoring relationships, especially in regard to the youth's interest level in participating in various activities.

Another important perspective on developmental stage as a moderating influence can be found in discussion around one special population of youth—children with incarcerated parents. Bilchek (2007) argued that arrest of a parent may have an impact on a young person's ability to successfully navigate through stages of development cited in Erikson's (1963) model. For example, youth that are navigating through issues related to trust and attachment during their first two years may have impaired parent-child bonding if they have lost a parent due to his or her arrest. This may translate to issues developing close attachments with others and may contribute to difficulty forming trust in a newly formed mentoring relationship. In theory, interruptions in any stage of development caused by the arrest of a parent may have specific considerations for mentors and mentoring programs that require specific attention, actions and support for the young person. 
The duration of the mentoring relationship holds important weight as a moderating process (Rhodes, 2005). Longer term relationships may offer increased opportunities for youth to bond with and to benefit from their mentors (Rhodes \& Grossman, 2002). In contrast, shorter-term relationships and those that terminate early may actually have detrimental influences on a young person's feelings of self-worth and perceived scholastic competence and may reaffirm negative experiences regarding relationships.

A model that highlights the stages of a mentoring relationship may further provide insight into the importance of duration in mentoring matches. Keller (2005) described the various stages through which mentors and mentees form, norm, and terminate their relationship. Keller hypothesized that mentoring relationships contain five succinct stages: contemplation, initiation, growth and maintenance, decline and dissolution, and redefinition. Contemplation involves the anticipated preparation that occurs before a mentor and mentee are matched. This stage focuses on developing expectations for a relationship that is yet to form and may be highly influential in determining the initial behavior of mentors and mentees as they start their relationship. The stage of initiation begins when a mentor and mentee are paired for the first time. This stage consists of mentors and mentee becoming acquainted with each other and exploring how their prerelationship expectations compare with the actual relationship. Growth and maintenance involves regular meetings and the development of patterns. This stage may include greater self-disclosure and opportunities for trust to grow. Keller defined decline as "a reduction in the importance or level of closeness in the mentoring relationship" (p. 87). Dissolution is defined as "the termination of the relationship" (p. 87). This stage holds 
challenges within the relationship that may involve conflict or struggles between the mentor and mentee or a change in the usefulness of the relationship. Finally, the stage of redefinition involves a change in the relationship, either in terms of termination or rejuvenation. This stage may involve negotiating terms for future contact, redefining ways that the match will work together, or actually terminating the match. By understanding the stages through which mentors and mentees engage in their relationship, the importance of duration may become more transparent. In order for mentoring relationships to form closer bonds, the natural progression of the relationship may require time to build trust, which may not occur in the initial stages of a match.

Program support for the mentoring relationship is another moderating process (Rhodes, 2005). Programs that adhere to guidelines such as the Elements of Effective Practice (MENTOR, 2009) may offer mentors high quality training and feelings of selfefficacy that further their ability to build long lasting and close relationships with young people (Rhodes, 2007). Further, ongoing support of the match from program staff may help the relationship overcome difficult or challenging events (Rhodes, 2005). In contrast, programs that do not possess practices that strengthen mentoring relationships appear to have less beneficial results for youth (DuBois, Holloway, Valentine, \& Cooper, 2002; DuBois, Portillo, Rhodes, Silverthorn, \& Valentine, 2011).

Keller (2006) offered insight into how program practices may provide support or hinder benefits in youth. In the systematic model of the youth mentoring intervention, Keller argued that the mentor-child relationship must be examined within the larger context of other relationships that are proximal to the mentoring relationship, including the mentoring program. Considered within his model, these immediate environmental 
relationships include the parent/caregiver and program staff. Keller stated that this model holds a myriad of interactions, including direct pathways, reciprocal exchanges, transitive interactions, parallel sequences, and circular patterns, which ultimately emphasize that the facilitation of outcomes in youth goes beyond a mentor-mentee dyad and includes a variety of channels of influence that are filled with complexity. In addition to the mentoring relationship, these closely situated relationships such as those with program staff may hold important weight in helping or hindering outcomes that are possible for the mentee.

Keller's (2006) model also informed theory about the importance of family context as a moderating influence. Rhodes (2005) argued that support from a young person's family may be critical to the success of the mentoring relationship. Family mobility, stability, and program contact with parents may also influence the closeness and duration of a young person's mentoring relationship.

Neighborhood ecology is the last moderating process described by Rhodes (2005). Rhodes argued that young people may approach mentoring relationships differently depending on available adults in their local neighborhoods and communities. Young people growing up in poverty may not have easy access to non-related positive adult role models and may more likely benefit from their mentoring experience than youth from communities with ample adult support (DuBois, Holloway et al., 2002; Rhodes, 2005).

Many of the moderators, including neighborhood ecology, described in Rhodes' (2005) model may be directly attributable to the influence of the environment in a young person's life. Because the environment may play a significant role in moderating benefits 
for participants in mentoring relationships, further description is merited. Therefore, theories that clarify how the environment may act as an influence on role modeling (Bandura, 1977) and youth development (Bronfenbrenner, 1979) are described.

Bandura (1977) developed and explored a model that involved mutual interaction between an observer, role model, and the environment. This theory describes the importance of each of these variables in facilitating learning, including the willingness of the youth to learn, ability of the role model to promote change, and environmental factors that either promote or limit opportunities for development. Bandura's model expands the focus of social learning to reflect a tri-directional interaction between mentor, mentee, and environment - a model that emphasizes the importance of mutual engagement of different variables found within learning (M. A. Hamilton \& Hamilton, 2005).

Other theorists place even more importance on the potential and comprehensive role of the environment on youth development (Bronfenbrenner, 1979). An ecological systems model of human development explored human development in the context of interrelationships between an individual and his or her immediate and more distant environments, which he described as systems. Bronfenbrenner (1979) described these systems as microsystems, mesosystems, exosystems, and macrosystems. The microsystem is "a pattern of activities, roles, and interpersonal relations experienced by a developing individual in a given setting” (p. 22). The mesosystem consists of those relationships between microsystems - which might consist of relationships between family members, teachers, and caregivers surrounding the individual. The exosystem is further removed from the individual and includes structures that are influential on microsystems but perhaps not directly experienced by an individual (Bronfenbrenner, 
1979). An example of this may include resources for the family or parent workplace schedules. The macrosystem is the furthest layer of the individual's environment. This may include the larger cultural values or customs that surround the individual.

Darling (2005) offered three important clarifications about the ways in which this model emphasizes human development. First, the model contains "an emphasis on an active person who influences and interprets, as well as is influenced by, the environment" (p. 179). Second, the model contains a focus on underlying processes that may be part of the individual's development such as systems that may be beyond the immediate surroundings of an individual. Third, this model also emphasizes the interrelationships between and among the systems in which the individual interacts and is influenced by. Bronfenbrenner's (1979) ecological systems model more fully explains the ways in which different layers of surrounding environment may influence or be influenced by the human development of an individual.

M. A. Hamilton and Hamilton (2005) described important ways in which ecological systems theory may help to explain the influence of the environment as a moderator of mentoring benefits in youth. For example, they described the role that parents can play in allowing a mentee to access potential learning opportunities from an experience:

An apprentice, intern, or service protégé whose parents are supportive will have a different experience than one whose parents are disengaged. A young person who arrives with a strong sense of purpose and direction, based on temperament and previous experiences, may be able to take advantage of work and service-learning opportunities more quickly than one who is unfocused and lacks confidence. (p. 351) 
By better understanding this broader environmental context, mentors, through their mentoring relationship, may be able to disrupt negative influences and trajectories that are present in the mentee's life—especially those that are more proximal.

Benefits: Socio-emotional, identity, and cognitive development. When relationship conditions are met and moderating influences support growth in young people, Rhodes (2005) stated that mentoring relationships can benefit mentees in three important ways: socio-emotional, identity, and cognitive development. Rhodes argued that each of these benefits work in tandem with each other over time to influence outcomes. A further review of each of these benefits is offered, including ways in which they work in concert with each other to assist positive outcomes in youth.

Rhodes (2005) described several socio-emotional benefits for youth. First, mentors can "challenge negative views that youth may hold of themselves or of relationships with adults and demonstrate that positive relationships with adults are possible" (p. 33). Second, mentors can help youth learn how to regulate emotions through role modeling and listening to the challenges and issues that a young person faces. Third, mentors may also serve as a primary or secondary attachment figure that can provide a young person with the foundation needed to gain skills around social interactions and cognitive development.

Contained among these benefits is the importance of attachment which can also explain identity development benefits in youth. Theory from Bowlby (1982) offered insight into how attachments between individuals may influence identity. Bowlby developed attachment theory by examining the influence of early role models and figures in a child's life. Through these early relationships, a child gains vital self-impressions, 
which will have long-standing effects on his or her identity development. Barrera and Bonds (2005) stated: "Bowlby referred to attachment to explain the affective bond between an attachment figure and a child that facilitates the development of internal working models of self and others" (p. 135). For children growing up with insensitive or unreliable caregivers, Rhodes (2002) stated that they will grow up with issues of anger, disappointment, and: "they will view others as unlikely to meet their needs" (p. 39). However, for these children, mentoring relationships that are mutual, empathetic, and trusting may offer pathways for altering these deep-seated vulnerabilities.

Rhodes (2002) also argued that mentoring offers children the opportunity to alter their initial self-impression through internalizing the positive impressions of their mentor. Rhodes (2005) referred to Cooley's concept of the "looking glass self" which describes ways that attachment between individuals can promote positive change in youth: “Significant people in children's and adolescent's lives can become social mirrors into which the young people form opinions of themselves" (p. 35). Through these interactions and relationships, youth can internalize the positive impressions of others, offering these children new ways of looking at and understanding themselves in this world: "If a mentor views a youth positively, that can start to change the youth's views of herself and can even start to change the way she thinks parents, peers, and others view her" (Rhodes, 2005, p. 41). Through this attachment, Rhodes argued a youth can potentially learn new and more positive ways of understanding him or herself and their standing in the world. Mentoring relationships also contain cognitive benefits for youth. Rhodes et al. (2006) stated that youth can access cognitive development benefits through exposure to new opportunities for learning, provision of intellectual guidance and challenge, and 
promotion of academic success found in their relationship with a caring adult.

Specifically, mentors offer teachable moments through which a young person may be able to access new ways of reasoning. Mentors may also offer youth an opportunity to refine thinking skills through activities contained in their mutual relationship. Lastly, mentors can contribute directly or indirectly to academic success through leveraging the mentee's interest in instrumental activities that lead to improved academic performance or by acting as a cheerleader and supporter for student connectedness to school.

Mediating influences. In descriptions of her theory, Rhodes $(2002,2005)$ does not appear to offer a specific definition for the concept of a mediator. However, the model indicates that peer and parent relationships during the mentoring relationship may act as a mediating influence on outcomes for youth. Further, this model appears to indicate that these influences work in tandem with changes that are occurring within the mentee, allowing the mentee to further practice and refine already occurring benefits in relationships that are close in proximity. More specifically, changes in and identity development appear to offer opportunities to refine and practice new found skills, with the most positive outcomes occurring when close relationships such as those found with parents and peers permit positive reinforcement of changes.

Youth outcomes. The Pathways to Mentoring Influence Model (Rhodes, 2002, 2005) concludes with an overview of potential outcomes for youth that participate in high quality mentoring relationships. Rhodes proposed that outcomes for youth include measurable changes in grades, improvement in emotional well-being, and measurable changes in behavior. However, she also offered that many unknown outcomes may also exist and that knowledge regarding the scope and reach of mentoring for youth is still in 
its infancy. Therefore, in order to more closely describe and detail specific outcomes for youth, the next section explores various empirically-conducted research studies on formal mentoring. This exploration offers some degree of verification for various hypotheses included in Rhodes' theory and also offers timely discussion around limitations in our current knowledge, theory, and research related to this topic, especially for diverse and special populations like gay youth.

\section{Empirical Research}

While Rhodes' (2002) theory detailed important insight into the potential goals, mentor influences, conditions, moderators, benefits, mediators, and outcomes of mentoring, a limited body of empirical research has only begun to verify certain assumptions contained within the Pathways to Mentoring Influence Model. Rhodes (2005) stated that "research is limited in scope and has not addressed the nature and extent of the specific processes that are posited in this model” (p. 39). However, many core assumptions contained within this model appear to gain some degree of validity from empirical studies (Rhodes, 2005). Among these limited insights, research has begun to capture a range of potential outcomes for youth and ways in which mentoring relationship conditions are formed and contribute to strengthening youth benefits and outcomes. Empirical studies have also begun to initially understand how certain moderating influences, including program support and match duration, may facilitate or hinder outcomes. Lastly, research on diversity in mentoring relationships has indicated an important first glimpse into ways that youth from different racial and gender backgrounds participate in and benefit from mentoring. 
Youth outcomes. Research on mentoring in community settings has begun to capture a variety of measurable outcomes for youth. In the first empirical examination of the impact of mentoring, J. P. Tierney, Grossman, and Resch (1995) utilized quantitative methodology to conduct an experimental study to learn more about the ways that mentoring relationships benefit youth. This study consisted of 959 youth, ages 10-16, who applied to become mentees at eight BBBS program across the country. The experimental group consisted of mentees that were randomly assigned to mentors, while the control group consisted of mentees that were placed on a waiting list and did not receive mentors. Pre-test and post-test surveys were used to understand how the presence of a mentor influences anti-social activities, academic performance, relationships with family, peer relationships, self-concept, and social/cultural enrichment. Datum was collected from youth, parents/guardians, and the program case manager. After 18 months in a mentoring relationship, the experimental group of youth placed with mentors: were $46 \%$ less likely to initiate drug use, $26 \%$ less likely to initiate alcohol use, and $33 \%$ less likely to hit someone; skipped half as many days; showed modest gains in GPA; and reported better parent and peer relationships. These findings were statistically significant. However, no statistically significant gains were demonstrated for self-worth, selfconfidence, or social/cultural enrichment. This study provided important insight into mentoring outcomes for youth, offering explicit descriptions of how mentors working with youth can create changes in behavior and improve relationships with others. Jekielkek, Moore, and Hair (2002) also documented several important outcomes for youth participating in community-based mentoring relationships in a report analyzing findings from 10 different program evaluations. Five experimental and 5 quasi- 
experimental/non-experimental evaluations were included in their analysis from mentoring programs and programs that included mentoring as part of a comprehensive approach to youth development. This study specifically explored youth outcomes in three important areas: educational achievement, health and safety, and social and emotional development. Educational achievement results from evaluation data were noted to include: youth participating in mentoring relationships had better attendance, were more likely to access and attend college, and had better attitudes toward school. Health and Safety findings included promise in prevention of substance abuse and reduction of behaviors associated with delinquency. Social and emotional benefits included promotion of positive social attitudes and relationships with others. Yet, mentoring relationships were not found to consistently promote improvements in youth perceptions of themselves. Findings from this study offer additional confirmation for many conclusions regarding youth outcomes documented in the national impact studies of BBBS programs in both community (J. P. Tierney et al., 1995).

Herrera, Grossman et al. (2007) conducted an experimental study on school-based mentoring programs to explore the effectiveness of mentoring in educational settings. The sample included 1,139 youth grades four through nine from 10 BBBS programs across the country. A lottery was used to randomly assign half of the youth to the experimental group, thereby receiving a mentor. The control group consisted of the other half of youth that remained on a waiting list for a mentor. Data were collected from participants at three unique points during the study—at the baseline (when youth were beginning their program at the start of the school year), at the end of the school year ( 9 
months later), and again during late fall/early winter of the second school year (14

months later).

The Big Brothers Big Sisters School-Based Mentoring Impact Study (Herrera, Grossman et al., 2007) collected data from teachers, mentors, and youth in the treatment group and from teachers and youth only in the control group. Agencies were also qualitatively interviewed to answer research questions related to various functions of the program, including cost. Data included information related to youth risk-economic status and stressful life events, academic performance, school behavior and attitudes, substance use and misconduct outside of school and relationships with teachers, parents, and peers.

At the end of the first school year, Herrera, Grossman et al. (2007) found that mentored youth as compared to youth in control group had several important reported differences:

Teacher reports indicated the treatment group did better than control group in: overall academic performance, as well as in subject areas of science and oral and written language; quality of class work (correctness, neatness, and completeness); number of assignments completed (in-class and homework assignments); and serious school infractions, including principal's office visits, fighting, and suspensions. (p. 33)

In addition, youth reported improvements in scholastic efficacy, numbers of days skipped, and recognition of support from non-parental adults. These results indicated that school-based mentoring may hold benefits and specific school-related outcomes for youth participating in such relationships. Further, no overall impacts were found for youth in non-school related outcomes such as self-worth, engagement in pro-social activities with peers, assertiveness, and relationships with parents and peers. 
Results at the conclusion of the study also indicated important limitations for outcomes related to school-based mentoring. During the final data collection point, mentees reported three significant benefits: They were less likely to start skipping school, continued reporting receipt of support from a non-parent adult, and were more confident they would attend and finish college.

While these findings appear to hold several limitations about the long-term and wide-scale viability of promoting benefits for youth in school-based mentoring program settings, several important caveats must be made: First, a large number of mentoring matches did not continue into a second school year, indicating that duration of match may hold important weight in offering benefits. Second, a high proportion of mentors paired with youth in this study were college and high school age versus older adults. These two caveats create an important starting point to clarify additional conditions and moderators of mentoring benefits for youth.

Conditions. While research has begun to capture the range of outcomes available to youth participating in mentoring relationships, other studies have been able to further examine various conditions such as mutuality and the formation of a close bond described in Rhodes' model (2002, 2005). More explicitly, similarity between a mentor and mentee appears to hold important weight in facilitating a close and lasting bond (Herrera, Sipe, \& McClanahan, 2000). Second, frequency of match meetings may also assist in giving mentors and mentees greater opportunities to spend time together, which may further strengthen their bond (DuBois \& Neville, 1997). Lastly, mentors that take a developmental, rather than prescriptive approach to mentees, appear to leverage greater 
respect and interest from the mentee regarding their relationship (Morrow \& Styles, 1995).

Herrera et al. (2000) examined mentoring relationships in both school and community settings. Six hundred sixty-nine one-to-one matches from 98 programs participated in this study. Data collection involved a survey with all matches as well as interviews and focus groups with youth, school staff, and program staff from 8 programs. The study found that $85.5 \%$ of community-based programs and $66.5 \%$ of school-based programs gave great importance to matching mentors and mentees based on similar interests. Further, similarity between mentor and mentee interests was seen to be an important predictor for closeness in the mentoring relationship.

Frequency of match meetings also appears to hold important weight in facilitating a bond between a mentor and mentee (DuBois \& Neville, 1997). In a study that surveyed 27 mentors and 40 mentees in two community-based mentoring programs, DuBois and Neville found that more frequent contact between mentors and mentees corresponded with feelings of closeness and perceptions of benefits in mentees. DuBois and Neville also found that the longer the mentoring relationship, the greater the perceptions of benefits for mentees.

Another important empirical understanding of how mentors and mentees bond can be found in research on the approach the mentor uses in their relationship with a young person. Morrow and Styles (1995) conducted two semi-structured interviews (one year apart) with 82 matches supervised by eight BBBS agencies across the country. Matches were in relationships for at least 4 months but not longer than 18 months. All interviews were audio-recorded and transcribed. The results of this study indicated that mentoring 
relationships consisted of two types of relationships, developmental and prescriptive. Developmental relationships demonstrated a close attachment between mentors and mentees and focused on the needs of the youth. Prescriptive relationships were driven by the mentor and focused on the needs that they mentor assigned for the youth. Youth participating in developmental relationships reported feeling more supported by their mentors and believed that they would be there for them if needed. Youth in prescriptive mentoring relationships reported feelings of frustration and lack of satisfaction with the relationship. This research highlighted the important differences that may occur within mentoring relationships, either supporting positive outcomes or hindering them.

Moderating influences. In addition to uncovering certain features that help to facilitate a close bond between a mentor and mentee, empirical research has also begun to document ways in which moderating influences can facilitate or hinder a range of outcomes in youth. Of note, duration of a relationship (Rhodes \& Grossman, 2002), program support (DuBois, Neville, Parra, \& Pugh-Lilly, 2002; DuBois, Portillo et al., 2011), and mentee diversity based on interpersonal history appear to play important moderating influences in the mentoring relationship

Match longevity appears to directly relate to greater outcomes for youth (Rhodes \& Grossman, 2002). Using data from J. P. Tierney et al.’s (1995) study and employing quantitative methodology, Rhodes and Grossman found that mentoring relationships that lasted less than three months actually demonstrated regression in self-worth and feelings of scholastic accomplishment in youth. In addition, mentoring relationships that lasted six months showed no positive effects and indicated that mentees may actually be more likely to initiate alcohol use. However, positive benefits around initiation of drug and 
alcohol use, parent and peer relationships, and aggressive behavior occurred for those youth that were in mentoring relationships for at least one year. This study indicated the importance of maintaining relationships for longer durations and offered insight into the importance of establishing program practices such as screening mentors for commitment and providing ongoing supervision of matches to optimally promote longer duration of matches.

Qualitative research has helped to provide insight into why mentoring matches may terminate early. Spencer (2007b) qualitatively interviewed mentors and mentees that participated in failed relationships (i.e., those relationships that did not meet for one year or longer). Spencer interviewed 20 adults and 11 adolescents to better understand the reasons behind relationships that terminated early. Six key trends were uncovered about these relationships: (a) mentor or protégé abandonment of the relationship, (b) perceived lack of protégé motivation on the part of the mentor, (c) deficiencies in relational ability of mentors, including the ability to bridge cultural divides, (d) unfulfilled expectations, (e) family interference, and (f) inadequate agency support. These themes demonstrate the extreme complexity of variables within and between mentors and mentees that may play important roles in determining the longevity, termination, and outcomes for youth.

The degree of program support for a mentoring match may also act as a moderating influence on youth mentoring outcomes (DuBois, Neville et al., 2002). DuBois, Neville et al. conducted a meta-analysis of evaluations conducted on formal mentoring efforts between 1970 and 1998. Studies that were selected were based on three specific criteria. First, mentoring program evaluations selected were required to follow the explicit definition of formal mentoring contained in this paper. Second, the research 
selected had to empirically examine the effects of participation in a mentoring program (i.e., pre-post comparison or experimental comparison). Third, youth that participated in the selected mentoring program must have been younger than 19. From these criteria, DuBois, Neville et al. selected 55 studies that were used in this meta-analysis. Findings from this analysis indicated that youth that were typically involved in such programs only gained modest benefits from participating in mentoring. The estimated effect sizes were .14 and .18. Additionally, moderators of effect size were closely associated with the degree to which programs utilized best practices such as those recommended by MENTOR (2003). Programs that utilized practices such as training, support, and matching based on similar interests were more closely associated with greater outcomes for youth. Conversely, programs that did not employ these practices actually created decreases in youth outcomes. This study offered important insight into how program support may enhance benefits or further harm youth that participate in mentoring relationships.

In 2011, DuBois, Portillo et al. conducted a meta-analysis that captured a second snapshot of mentoring effectiveness over the last decade. The 2011 meta-analysis consisted of 73 independent evaluations of mentoring programs between the years 1999 and 2010. Findings from this study support effectiveness of mentoring for behavioral, social, emotional, and academic domains, with mentored youth typically demonstrating gains on measures versus declines for youth without mentoring. Moderating influences were also examined, offering insight into how characteristics of youth, mentor recruitment and selection, match criteria, and mentor role expectations play a role in outcomes. When examining variables within these moderating influences, mentoring 
programs appear to be more effective under certain circumstances. First, youth with behavioral difficulties or a personal vulnerability that leads to risk for academic failure demonstrate greater effects. Second, mentors with well-suited educational or occupational backgrounds such as teachers or other school staff are more effective in mentoring relationships. Similarities between mentor and mentee also demonstrated higher levels of effectiveness. Lastly, stronger effects were noted for programs that asked mentors to serve in advocacy roles. Findings from this study noted how differences among moderating influences promote or hinder outcomes for youth participating in formal mentoring relationships.

Research has only begun to understand how diversity within mentoring matches may act as moderating influences on outcomes for youth. Several variables such as race/ethnicity and gender of mentee may alter the degree to which positive outcomes occur. For example, Rhodes et al. (2002) used experimental quantitative research findings to explore how same-race versus cross-race mentoring matches compared on indicators found in the BBBS National Evaluation. These indicators included parent and peer relationships, initiation of drug and alcohol use, self-esteem, and scholastic connectedness. Rhodes found that the majority of outcomes were similar for all youth. However, important yet slight differences occurred for youth in same-race and cross-race matches. First, mentees in same-race matches were more likely to initiate alcohol use at the end of the study than those in cross race matches. However, for boys in same-race matches, outcomes of scholastic competence and feelings of self-worth were higher than for boys in cross-race matches. Girls in same-race matches were also more likely than girls in cross-race matches to demonstrate increases in self-esteem and school 
connectedness. These findings indicate that mentoring may create different outcomes for youth based on the race of the child and the mentor.

Issues of gender in mentoring relationships were explored in research conducted by Spencer (2007a). In a qualitative research study that interviewed 12 mentoring relationships between adult and adolescent males, Spencer found six major themes that were unique to these mentoring relationships. The first theme consisted of the mentee's appreciation for having a male figure in their lives — something that may have been missing in the mentee's day-to-day relationships. Second, the male mentors often stated that they wanted to be emotionally available to their mentees - to offer them the opportunity to have a caring male role model that was open and honest. Third, the mentoring relationships offered a safe space to show vulnerability and access support for the mentee. Fourth, the mentoring relationship provided an opportunity to forge a close and enduring bond. Fifth, the mentoring relationships offered male adolescents an opportunity to learn how to better manage feelings of anger. Lastly, the mentoring relationship offered a chance for the mentees to learn more about their own masculinity. Spencer's findings offer important insight into how males view the potential benefits of mentoring relationships with other males, but this study does not help us specifically understand the processes, characteristics, and pathways through which gender identity benefits occur within mentoring relationships.

Research on mentoring has also deciphered important differences in outcomes and potential for damage for youth that participate in mentoring relationships based on individual and environmental risks. In their meta-analysis on youth mentoring, Dubois et al. (2002) found that mentoring may potentially yield the most positive effects for those 
youth that are susceptible to environmental risks. However, for youth that have individual risk factors such as pregnancy or juvenile delinquency, this same meta-analysis revealed that such youth may be prone to more negative effects while participating in mentoring relationships, especially when programming does not meet effective practices (DuBois, Holloway et al., 2002). Therefore, extreme care has been urged when developing or facilitating mentoring relationships for youth that face individual risks (Rhodes \& DuBois, 2006).

Gaps in research. As noted, empirical research has only begun to initially validate core assumptions regarding the ways in which mentoring relationships "work" and foster outcomes in youth (Rhodes, 2005). Because of the potential for further harm and the limited knowledge about ways that mentoring may work for diverse populations of youth, a call has been sounded to increase research that better captures the ways in which vulnerable youth participate in mentoring relationships (Rhodes \& DuBois, 2006). Further, DuBois and Karcher (2005) argued that the relationship between theory, research, and practice related to mentoring needs to be strengthened, especially for special populations of youth. DuBois and Karcher argued that increased attention must be given to the ways in which diverse and highly susceptible youth participate in and benefit from mentoring relationships:

Those associations with mentoring of specialized populations of youth are illustrative in this regard. Because traditional models of mentoring may not extend directly to these groups and because they may be especially susceptible to negative impacts of poor-quality relationships or programs, research that helps illuminate approaches that have the promise of being safe and effective for such populations is critically important. (p. 9) 
By developing research that examines how diverse groups of young people participate in and understand their mentoring relationships, an initial link can be established to strengthen theory and influence program practices. Because research, theory, and program practices in mentoring have not addressed issues specifically related to gay youth, an urgent need exists to begin building insight for ways in which programs can better serve and protect these young people in their care. The next section of this paper begins to answer this call by offering important theoretical understanding around ways to offer support to this population, including the importance of developing targeted opportunities to enhance sexual-minority identity development.

\section{Support for Gay Youth}

Bernal and Coolhart (2005) stated that successful intervention strategies for gay youth must be designed to assist youth in their coming out process, which includes the important feature of forming, accepting, and disclosing sexual identity. Further, D’Augelli (2006) argued that research on gay youth must include attempts to better understand the role of supporting sexual identity development as a pathway to break cycles of victimization and stigma. Therefore, this section offers an overview of theories related to sexual identity development and the supportive roles that others, including mentors, may be able to play in this potentially life-altering process. However, before this discussion occurs, I believe it is important to more firmly differentiate between two key terms that are closely and complexly related to gay youth - the more constant and lasting sexual orientation of a gay individual and the more fluid and changing process of understanding, accepting, and sharing one's sexual orientation which is known as sexual identity development. 


\section{Definitions: Sexual Orientation and Sexual-Minority Identity Development}

Sexual orientation refers to "the preponderance of erotic feelings, thoughts, and fantasies one has for members of a particular sex, both sexes, or neither sex" (SavinWilliams, 2005, p. 28). Debate exists on the specific determinants and fluidity of sexual orientation, with Savin-Williams arguing that genetics and/or biological/intrauterine factors most likely facilitate the onset of sexual orientation during conception or during prenatal development, with immutable changes over time. However, other perspectives (Bem, 2001) stated that sexual orientation may be better explained by the Exotic Becomes Erotic (EBE) Theory which hypothesizes that individuals can become "erotically attracted to a class of individuals about whom they felt different from during childhood" (Bem, 2001, p. 53).

Similar to Savin-Williams (2005), the EBE Theory hypothesizes that biological variables may be responsible for initially determining sexual orientation (Bem, 2001). However, Bem argued that these initial genetic and prenatal determinants are not related to direct coding for sexual orientation; rather, they code for specific childhood temperaments that may predispose a child to certain gender conforming/non-conforming activities. According to EBE Theory, participation in conforming/non-conforming activities as a child directly impact the ways in which a child may feel different from opposite/same-sex peers, which, in turn, assist in developing a physiological arousal to those that they feel different from (the exotic). Thus, a gay sexual orientation includes a temporal sequence and combination of genes, prenatal hormones, non-gender conforming activity preferences, and feelings of difference from same-sex peers. This blend of biological and experiential variables assists in developing a physiological arousal and 
erotic attraction (gay sexual orientation) over the course of childhood that is different from a heterosexual orientation (Bem, 2001).

While the etiology of sexual orientation continues to be debated, most researchers agree that same-sex sexual orientation is often constant and should not be altered (Bem, 2001; D’Augelli \& Patterson, 2001; Savin-Williams, 2005). For example, conducting conversion therapy to alter sexual orientation is viewed as potentially damaging, especially for youth that may be struggling to understand and accept a natural same-sex sexual orientation (American Psychiatric Association, n.d.). Several groups, including the American Academy of Pediatrics, the American Counseling Association, the American Psychiatric Association, the American Psychological Association, the American School Counselor Association, and the National Association of School Psychologists, have taken a stand arguing that a gay sexual orientation does not need to be cured or altered (Just the Facts Coalition, 2008).

Sexual identity development has been described as the process of becoming aware of one's sexual orientation, usually through a process of questioning, exploring, accepting, and sharing an identity as a gay individual (Rosario, Schrimshaw, Hunter, \& Braun, 2006). Sexual identity development is closely associated with the colloquial term coming out, which refers to a "process during which a number of milestone events occur whereby an individual moves from non-recognition of his or her homosexuality, with perhaps a degree of sensitization of being somehow different from others, to selfrecognition that he or she is indeed a homosexual person" (Savin-Williams, 1990, p. 30). Many different theories and models (e.g., Cass, 1979; D’Augelli \& Patterson, 2001; McCarn \& Fassinger, 1996; Savin-Williams, 2005) describe the stages and processes that 
gay individuals undergo as they develop and share a gay sexual identity. In order to better understand the ways in which a solid sexual identity is formed, an overview of several of these theories is presented here, including Cass' (1979) Homosexual Identity Formation Model, Savin-Williams' (2005) Differential Developmental Trajectories Framework, and McCarn and Fassinger's (1996) Inclusive Model of Sexual-Minority Identity

\section{Development.}

\section{Cass Homosexual Identity Formation Model}

The Cass Homosexual Identity Formation Model (Cass, 1979) is widely accepted as the "standard bearer of homosexuality identity models" (Savin-Williams, 2005, p. 72). In this model, Cass $(1979,1984)$ argued that homosexual identity development is a process marked by a series of changes, growth points, and stages which are ordered and progressive. Often, the presence of certain behavioral, cognitive, and affective milestones are associated with each stage and positive progression to the next stage requires further acceptance, rather than rejection, of a homosexual identity. The stages include: (a) identity confusion, (b) identity comparison, (c) identity tolerance, (d) identity acceptance, (e) identity pride, and (f) identity synthesis.

Identity confusion. In the identity confusion stage, an individual recognizes that his or her feelings, thoughts, and actions may be considered homosexual. Previous assumptions about sexual identification are questioned and confusion about identity occurs. This often causes tension within the individual and may also lower levels of selfesteem. If the individual views the possibility of a homosexual identity as acceptable, he or she may progress to the next stage. However, if the possibility of a homosexual identity is rejected, movement to the next stage is foreclosed (Cass, 1979, 1984). 
Identity comparison. In this stage, an individual makes a comparison with nonhomosexual others, recognizing that they may be homosexual and different (Cass, 1979). The identity comparison stage is often met with feelings of alienation as the difference between the potentiality of a homosexual self and non-homosexual others is magnified (Cass, 1984). During this stage, the individual assesses whether the possibility of a homosexual self is desirable, too costly, or a temporary aberration (Savin-Williams, 2005). In order to continue to the next stage, the individual must view this possibility as positive, rather than negative or resolution is foreclosed (Cass, 1984).

Identity tolerance. The third stage consists of increased acceptance and tentative commitment to the possibility of being homosexual (Cass, 1979). This stage includes acts of making initial contact with other homosexuals and informing trusted heterosexuals about identity (Savin-Williams, 2005). Also, depending on these initial experiences, the individual may devalue or isolate contact with other homosexuals or further increase commitment to a homosexual status (Savin-Williams, 2005).

Identity acceptance. Individuals in this stage move from tolerating their homosexual status to accepting this status (Cass, 1979). Increased contact and comfort among other homosexuals exists and further selective disclosure of a homosexual identity to others occurs (Savin-Williams, 2005).

Identity pride. In stage five, an individual increases commitment to a homosexual identity, including a sense of community with other homosexuals (Cass, 1979). A dichotomy in the individual exists which distinguishes between sources of pride (being gay) and sources of anger (not-gay) (Savin-Williams, 2005). Anger at society's 
stigmatization of homosexuals is often present as well as purposeful confrontation with non-homosexuals about equality occurs (Cass, 1984).

Identity synthesis. Individuals in this stage have fully embraced a homosexual identity in all aspects of themselves (Cass, 1979). This embrace includes an integration of public and private selves and also includes the belief that homosexual identity is only one part of a larger identity (Savin-Williams, 2005). In this stage, "the person is at peace, feels self-actualized and not defensive, and has positive interactions with those that are not gay" (Savin-Williams, 2005, p. 74).

While Cass (1979) created the "standard bearer" of homosexual identity models and established the first theory regarding the ways in which an individual defines and accepts his or her sexual identity, many objections to this model have been made. First, Diamond (2006) argued that the Homosexual Identity Formation model is based on the experiences of gay male individuals and does not account for many differences that might occur in lesbians. Diamond argued that assumptions regarding exclusive attraction to same-sex individuals may not be the same for woman as they are for men. Lastly, Diamond also argued that women are more likely to continue questioning their sexual identity long after they identify as lesbian and that labels may not be a beneficial or appropriate resolution to sexual identity development.

\section{Savin-Williams Differential Developmental Trajectories Framework}

Savin-Williams (2005) also offered several arguments against using stage-based models to account for sexual identity development. First, he argued that sexual identity development is much more fluid and chaotic and often does not follow many of the linear progressions and milestones associated with stage-based models. Second, Savin-Williams 
argued that little empirical evidence is available to prove and validate any of the stagebased models. Third, Savin-Williams argued that many stage-based models do not account for differences in gender, ethnicity, and age. For example, the process and barriers experienced by individuals in the past attempting to define their sexual identity are not the same as those of young people today. Instead of a stage-based model, SavinWilliams posited that sexual identity can be better understood by what he calls the Differential Developmental Trajectories Framework.

The Differential Developmental Trajectories Framework (Savin-Williams, 2005) is built on the premise that a great deal of variability is inherent within and across individuals as they navigate through adolescence and that gay youth should not be primarily defined by the "monolith" of their sexual orientation in this process. SavinWilliams' framework consists of four assumptions: (a) Same-sex youth experience similar biological, psychological, and social influences as heterosexual youth; (b) samesex youth are dissimilar from heterosexual youth in their developmental trajectories due to their biological constitution as non-heterosexual, exposure to cultural heterosexism, and differences in psychological development regarding acceptance of attraction to samesex individuals; (c) same-sex youth may vary among themselves in their developmental trajectories, especially given differences in sexuality, gender, ethnicity, geography, socioeconomic status, and cohort; and (d) each person's developmental trajectory is different and no two people experience identity development in the same way. These four assumptions establish that great similarities and differences exist for all young people as they navigate through adolescence, with the caveat that young gay and non-heterosexuals 
may experience their own individual processes for understanding and accepting their sexual identity.

Savin-Williams (2005) offered an important alternative to many stage-based sexual identity development models. However, the Differential Developmental Trajectories Framework has several limitations. First, Savin-Williams minimized differences between same-sex attracted youth and heterosexual youth. He stated that same-sex attracted youth are generally indistinguishable from other teens. While differences in biology, psychological development, and tension with a dominant heterosexual culture may create some differences between gay and non-gay youth, SavinWilliams argued that many of these differences are secondary because differences in sexuality are often overemphasized in research and theory that describe an individual's experience. Second, this framework argued that difficulty in adolescence is a universal experience and that gay youth are not exposed to heightened risks and struggles beyond what heterosexual youth experience. Both of these arguments are in direct conflict with well-documented research on stigma, victimization in school and community settings, and heightened levels of social interaction anxiety in gay youth (D'Augelli, 2006; D’Augelli \& Patterson, 2001; Garafolo, Wolfe, et al., 1998; GLSEN, 2008; Gibson, 1989; National Gay and Lesbian Task Force, 2007; Safren \& Pantalone, 2006). Third, this framework emphasized sexual-identity development as an individual process and fails to account for the ways that others may assist or work with gay youth to develop a healthy sexual identity. Because of these limitations, the Differential Developmental Trajectory Framework may not be the most appropriate framework to describe the ways 
in which sexual identity is uniquely developed in gay youth or socially supported by others.

\section{McCarn and Fassinger's Inclusive Model of Sexual Minority Identity Formation}

In contrast to the Differential Developmental Trajectory Framework (Savin-

Williams, 2005), McCarn and Fassinger's (1996) Inclusive Model of Sexual Minority

Identity Formation offered specific details into the unique processes and potential struggles that diverse non-heterosexual individuals experience as they develop a sexual minority identity. Several key components of this model addressed several shortcomings of previous sexual identity development models. First, McCarn and Fassinger argued that sexual identity development consists of phases, instead of stages, emphasizing the fluidity of development. Second, the Inclusive Model of Sexual Minority Identity Formation included discussion around the conflict in individuals as they embrace a sexual identity that is often met with societal stigma. Third, this model addressed both individual and social phases of sexual identity formation. Fourth, disclosure of sexual identity is not viewed as a resolution for sexual identity development. Because of these differences, the Inclusive Model of Sexual Minority Identity Formation answered many previous critiques about the processes involved in developing a solid sexual identity as well as the potential role that social interaction may hold for assisting diverse gay individuals.

The Inclusive Model of Sexual Minority Identity Formation (McCarn \& Fassinger, 1996) consists of eight phases: (a) Individual Sexual Identity: Awareness, (b) Individual Sexual Identity: Exploration, (c) Individual Sexual Identity: Deepening/Commitment, (d) Individual Sexual Identity: Internalization/Synthesis, (e) Group Membership Identity: 
Awareness; (f) Group Membership Identity: Exploration, (g) Group Membership Identity: Deepening/Commitment, and (h) Group Membership Identity: Internalization/Synthesis.

Individual sexual identity: Awareness. During this phase, an individual becomes aware of being and/or feeling different from the heterosexual norm. Individuals are likely to experience confusion, fear, and/or bewilderment (McCarn \& Fassinger, 1996).

Individual sexual identity: Exploration. In the exploration phase, an individual explores attraction to people or an individual of the same-sex. Often, a person may experience longing, wonder, and excitement as increased discovery of unknown sexuality occurs (McCarn \& Fassinger, 1996).

Individual sexual identity: Deepening/commitment. This phase includes a deepening of self-knowledge related to sexuality and emotions. Also, choices around sexuality occur, including recognition of intimacy preferences with same-sexual individuals. Individuals in this phase may encounter emotional conflict due to increased exposure and awareness of stigma associated with heterosexism and homophobia (McCarn \& Fassinger, 1996).

Individual sexual identity: Internalization/synthesis. In this phase, the individual internalizes same-sex love as part of his or her overall identity, which allows for a sense of internal consistency. Individuals in this phase may also feel a sense of pride regarding their choices (McCarn \& Fassinger, 1996).

Group membership identity: Awareness. This phase includes a new awareness that there may be different sexual orientations in other people. Group Membership 
Identity: Awareness also includes acknowledgement of the existence of heterosexism and experiences and often includes feelings of bewilderment and confusion related to increased awareness (McCarn \& Fassinger, 1996).

Group membership identity: Exploration. Individuals in this phase actively explore attitudes and beliefs about gay/lesbian people as a group through increased engagement with others. Further, individuals assess their potential membership within that group and their interactions. Anger, anxiety, and guilt are present due to increasing awareness of heterosexism. Yet, increased exploration of gay/lesbian people may also bring newfound excitement, joy, and curiosity (McCarn \& Fassinger, 1996).

Group membership identity: Deepening/commitment. Greater and deeper involvement in the gay/lesbian community occurs during this phase. This involvement may also bring increased awareness of consequences that may occur due to stigma of gay/lesbian people. Further, a combination of pride, rage, excitement, and intense identification with other lesbian/gay people may occur (McCarn \& Fassinger, 1996).

Group membership identity: Internalization/synthesis. In the final phase, a gay or lesbian individual has internalized his or her membership in an oppressed group into his overall self-concept. This internalization allows for a synthesis of identity across many different contexts. Disclosure of sexual identity may or may not occur in this stage, depending on the circumstances of the individual (McCarn \& Fassinger, 1996).

This model offers an important examination of both the individual and social nature of forming a sexual identity. In McCarn and Fassinger's (1996) model, individuals must assess their attitudes toward self, other lesbian and gay people, and non-gay people during each phase of sexual identity development. Further, because of this model's 
emphasis on group membership, the importance of social interaction gains traction for understanding ways in which others may potentially support or negate the facilitation of a solid sexual identity. Examples of ways that others can support sexual identity development are provided in the next section, including the promising potential of providing one-to-one mentoring support for gay youth.

\section{Supporting Sexual Identity Development in Gay Youth}

Why is support for sexual identity development important, especially for gay youth? Rosario et al. (2006) argued that many gay individuals are often unprepared, unsupported, and stigmatized in their search for a sexual identity. They argued that incongruence in an individual's affect, behavior, and cognitive processes during sexual identity development may create psychological tension and struggle. Further, gay youth that have successfully developed a solid sexual identity show no significant difference in self-concept or self-esteem from heterosexual youth, despite the many negative risks that they face (Bernal \& Coolhart, 2005). Gay youth are seen to actually increase their resiliency by successfully navigating through the coming out process (Savin-Williams, 1990). In research that explored self-esteem and degrees of being open and out with regard to understanding and telling others about one's sexual orientation, Savin-Williams found that gay youth actually demonstrate increases in self-esteem and are less likely to engage in behaviors associated with risks. Because of these findings, increased attention has been given to the importance of offering targeted programming to gay youth that provides a safe climate and social resources to help them navigate through their sexual identity development process. 


\section{Strategies for Support: Educational Settings, Mental Health, and Community}

As documented, gay youth face significant stigma, victimization, and negative social sanctions. In addition, many gay youth are often unsupported as they define their sexual identity (D’Augelli, 2006). Because of the importance of developing targeted support and intervention strategies to address these needs, various approaches have been used in schools, mental health and counseling settings, and in the community. Yet, many of these approaches typically involve group and/or professional support which may be different from yet complementary to the range of potential benefits found in one-to-one formal mentoring relationships. Descriptions of each of these support strategies and their potential strengths and benefits for gay youth follows.

Educational settings. In educational settings, research has indicated that gay youth can benefit from inclusive and safe school climates (Lee, 2002; Szalacha, 2003). Gay-straight student alliances have offered important ways for students to gain vital resources, promote visibility and learning needs, and strengthen relationships between students that might otherwise feel isolated and alone (Szalacha, 2003). Gay-straight student alliance participants report that they felt more comfortable with their sexuality, described improvements in their relationships with other gay and non-gay students, and expressed feeling more supported during their coming out process than before participating in the gay-straight alliance (Lee, 2002). These findings demonstrate that a safe climate in a group setting can yield many promising and diverse benefits.

An Evaluation of the Massachusetts Safe Schools Program for Gay and Lesbian Students also found important benefits for gay youth were created by expanding school policies and programming to include protective and supportive climates (Szachala, 2003). 
The Safe Schools Program for Gay and Lesbian Students was created in the early 1990s to respond to the oppressive learning climate of gay and lesbian youth in Massachusetts' schools (Governor's Commission on Gay and Lesbian Youth, 1993). This mandate stated that schools should: (a) protect gay and lesbian students from harassment, violence, and discrimination; (b) offer training to school personnel in crisis management and suicide intervention; (c) support the establishment of school-based support groups for gay and lesbian students such as a gay-straight alliance; and (d) provide school-based counseling for family members of gay and lesbian students. A three year mixed methods study of this program indicated that the presence of any of these four elements correlated with student perceptions that their schools were safer than schools that had not implemented these suggestions. Because safety is such an important need for gay youth that struggle with verbal and physical harassment within many educational climates, findings from this study indicate that proactive policies and programming may hold great promise to assist perceptions and assist in making gay youth feel more comfortable and secure in school settings.

Mental health and counseling settings. Targeted support to sexual identity development in gay and lesbian individuals is also recommended in mental health and counseling settings (Bernal \& Coolhardt, 2005; Finnegan, McNally, Anderson, \& Shelton, 2001; Hershberger \& D’Augelli, 1995; Lemoire \& Chen, 2005). A provider's guide to mental health issued by the United States Department of Health and Human Services (Finnegan et al., 2001) described the need for mental health providers and counselors to create inclusive counseling environments that respect the uniqueness of each individual's sexual identity development process. In order to achieve this milieu, 
Finnegan et al. suggested that counselors familiarize themselves with specific risks facing gay and lesbian populations and to use inclusive language, acknowledge significant others of clients, and self-monitor heterosexist norms. These suggestions are fundamental for offering clients a safe place to explore struggles that may occur during the sexual identity development process.

Raskin and Rogers (2000) described a client-centered approach to counseling that includes unconditional positive regard, congruence, and empathy. Lemoire and Chen (2005) expanded these criteria for gay youth, stating that counselors should also encourage the client's locus of evaluation, emphasize the youth's notion of self-concept, and believe in the client's ability to grow. By providing client-centered approaches to counseling that reflect the unique needs of gay youth, important resources and tools can be gained to assist in navigating through their coming out process. Lemoire and Chen further argued that counseling using this approach may not be enough to fully provide benefits to gay youth; they also recommended support groups, community services, and opportunities for gay youth to benefit from influences of similar others. Through this composite approach, gay youth can gain vital opportunities for validation of their personal struggles as well as learn strategies to better gauge the risks involved in disclosing their identity to others (Lemoire \& Chen, 2005).

Community settings. Research on resilience in gay youth further emphasizes the power of building relationships and support services in community settings, offering accounts of ways that gay youth have benefited from holistic services that center specifically on their needs (Brown \& Colbourne, 2005). The Gay, Lesbian, and Bisexual Youth Project is an important example of how composite services may work to promote 
benefits in gay youth. This agency provides confidential individual and family counseling, safe housing, HIV testing and counseling, an ally identification program, and bi-weekly support groups. Important benefits have occurred for youth that have participated in this project, including opportunities to form connections, improvement of grades, access to safe housing, completion of school, and reports of feeling safe and belonging to a group (Brown \& Colbourne, 2005). Findings from this qualitative study indicated that gay youth possess great potential to overcome barriers, especially when supportive environments are in place. One of the important suggestions from this study involves offering gay youth opportunities to engage with role models that can help them access services and navigate through challenges associated with their coming out process.

Formal mentoring relationships for gay youth. While support for gay youth in school, mental health, and community settings appear to offer important benefits, a little utilized strategy for support—formal mentoring relationships — may potentially yield additional and complementary benefits for youth. While no previous study has captured the ways in which gay youth participate in and benefit from these relationships, Ross (2005) explored how mentoring for college-age students supports a range of identity development outcomes that might be available for gay adolescents participating in these relationships.

Ross (2005) utilized qualitative research methodology to examine how mentoring relationships between gay mentors and mentees in college settings offer support for sexual-minority identity development. Seventeen self-identified gay male university students in formal and informal mentoring relationships participated in interviews and surveys. Findings from this study indicated that participants in mentoring relationships 
gained skills that were useful in their process of developing and strengthening a solid identity as a sexual minority. In addition, many other benefits appeared such as increases in well-being, improvement as a college student, and commitment to give back to the gay community. These results offer an impressive array of potential benefits that work to ameliorate risks and offer targeted support for sexual identity development.

In order to explain the ways in which the social interactions within one-to-one mentoring relationships work to facilitate sexual identity development, Ross (2005) developed a conceptual model based on his findings (see Appendix B). His model states that several key pathways exist through which sexual identity development and cultural competence as a sexual minority are fostered. In his model, mentees engaged in a step of learning and unlearning — a process through which their own assumptions about sexual identity were challenged and redefined. This learning and unlearning process involved tasks essential to sexual-minority identity development, at both the individual and group membership levels. For example, mentors were seen to assist mentees in the coming out process, offered socialization opportunities to meet other gay individuals, helped mentees gain perspective about dating and relationships, and offered assistance in navigating through religious conflict. Further, Ross identified other important roles that mentors often played in offering support to gay mentees. Mentors were seen to be positive role models for mentees, helping them to navigate into the gay community while serving as a "cultural" guide, actively challenging misconceptions mentees might have related to being gay, and often dispelling myths found in heterosexism. These newfound influences appeared to curtail environmental risks as well as offer increased internal skills to more successfully navigate through phases of sexual-minority identity development. 
Ross' (2005) study offered an important first illustration of the possible roles that mentors might be able to play in the lives of gay youth. Specifically, Ross offered confirmation for a range of positive outcomes found in mentoring relationships that include many socio-emotional, cognitive, and identity development benefits such as improved relationships with other gay people, increased feelings of self-worth as a gay individual, improvements in academics, and opportunities to gain support during the process of strengthening sexual minority identity. Further, his results appeared to offer insight into the ways that mentoring may support individuals in overcoming stigma and victimization that have been described as important elements of offering targeted support to gay individuals (D'Augelli, 2001). Ross' study offered important hints for ways in which one-to-one mentoring relationships may offer unique and targeted support for gay individuals. However, because the study's participants were college students, important differences may occur for younger adolescents which are not yet understood.

Because of the landscape of challenges facing gay youth and the potential for formal mentoring relationships to offer a range of positive outcomes, additional research must be conducted to better understand the characteristics, scope, and potential for this promising development strategy. The next chapter details the methodology for this study. However, before the details of this inquiry are described, I feel it is essential to complete this chapter with a description of queer theory — a theoretical framework/grounding that assisted me in better understanding the literature that I have presented and further guided me in my dissertation. 


\section{Queer Theory as Theoretical Framework/Grounding}

In order to more completely and thoroughly describe this study and to alert my readers to the lens through which I am undertaking my inquiry, I have chosen to use this section to define and justify my use of queer theory. Specifically, this section situates my working definition of queer theory among the complex and nuanced definitions cited in previous literature. Further, a justification for selecting this framework/grounding is offered, particularly related to the process of conducting an inquiry on a group of individuals that have often been marginalized in research and society due to being gay. By offering this overview, I seek to strengthen my inquiry by more clearly articulating my reference point for conducting and facilitating this study and better prepare my readers to understand decisions regarding my research methodology and design in the next chapter.

\section{Defining Queer Theory}

Queer theory emerged as an attempt to reframe binaries that have structured the world into heterosexual and non-heterosexual (Plummer, 2005). Plummer stated that queer theory is difficult to define, arguing that this theory holds many different meanings depending on the ways that one interprets the word queer. To further examine this point, Plummer cited six different variations on what queer and, therefore, queer theory means:

Sometimes it is used simply as a synonym for lesbian, gay, bisexual, and transgender (LGBT). Sometimes it is an "umbrella term" that puts together a range of so-called "non-straight positions". Sometimes it simply describes nonnormative expression of gender (which could include straight). Sometimes it is used to describe "non-straight things" not clearly signposted as lesbian, gay, bisexual, and transgender but that bring with them a possibility for such reading, even if incoherently. Sometimes it locates the "non-straight" work, positions, pleasures, and readings of people who don't share same sexual orientation as the text they are producing or responding to. Taking it further, Doty suggests that 
"queer" may be a particular form of cultural readership and textual coding that creates spaces not contained within conventional categories such as gay, straight, bisexual, and transgendered. Interestingly, what all his meanings have in common is that they are in some way descriptive of texts and they are in some way linked to (usually transgressing) categories of gender and sexuality. (Doty as cited in Plummer, 2005, p. 365)

While these six variations promote important discussion around ways that sexual minorities, including gay individuals, are defined, understood, and represented, other theorists provide alternative perspectives of what queer and queer theory are.

Pinar (1998) defined queer as separate and distinct from labels such as gay or lesbian. Queer is a fluid term that is used to disrupt assumptions and understanding of who named sexualities are, how they see themselves, and how they are seen by others. Using Pinar's definition, queer is a term that complicates the binary between gay and straight and reconfigures assumptions of identity through the reclamation of a word that once was, and still is, held negatively by many of those in power in society.

Other theorists (Morris, 1998; Shlasko, 2005) argued that queer is more complex than language and should be defined by the subject position, politic, and aesthetic of an individual or group. The subject position involves one's location in reference to the norms of society. Individuals that identify as queer have undergone a tension between what is considered normal within dominant societal standards and have become part of the "other," usually as a result of their sexuality or gender identity. This identification shapes and defines their subjective location and understanding of the norms of society. As a politic, queer challenges the very idea of normal and promotes an assertion that disrupts the constructed norms which have marginalized and oppressed. These assertions may seek to break down socially constructed barriers that protect and police the 
boundaries between normal and other. The third part of this definition, the aesthetic, refers to the seeking of "subversive content in cultural texts of any media, from academic research papers to television advertisements to graffiti" (p. 124). Through these three components, queer moves beyond the umbrella term for individuals that identify as either gay, lesbian, bisexual, transgender, inter-sexed, or same-gender loving and into a collective group that asserts, challenges, and redefines what it means to be normal or different through seeking to visibly represent their presence, ultimately subverting the assumed norms of society (Shlasko, 2005).

Using this understanding of queer, queer theory becomes the actual examination of the tension between normal and "other"- a study of and from the viewpoint of people who are outsiders in terms of gender and sexuality (Shlasko, 2005). In addition, this theoretical framework could include the critique of normalcy and "the processes through which the borders of normal are defined and policed" (p. 125). According to W. Tierney (1999), this act becomes a process of destabilizing positions and "the de-centering of complex social meanings" (p. 452). Through these features, queer theory ultimately engages in an attempt to remove and deconstruct boundaries that oppress and discriminate, which are central features of a related theoretical perspectivecritical theory.

\section{Implications for My Study}

As a researcher and queer theorist, I contend that visibility is an essential feature of creating opportunities for all sexual minority populations. Because gay youth have not been represented in research or theory on youth mentoring, I attempted to use this study to disrupt the current dialogue by giving such young people a voice. Secondly, and more 
specifically, my inquiry offers an understanding of how gay youth wrestle with and overcome tensions found in their "otherness," exploring descriptions of how they have been able to benefit and learn from their relationships with mentors that share a similar sexual orientation and sexual identity. This inquiry most closely examines how a youth might engage in and perceive processes of development found within his mentoring relationship. Third, because I am a gay man and I am studying an issue of importance for others that are similar to me, I also see this framework as a way of expressing my personal, political, and aesthetic commitments. Through this inquiry, I sought to better understand, capture, and, ultimately, facilitate change in the hopes of moving gay youth away from the cultural margins of our society and move them into the center of hope and possibility in a field and a world that I care deeply about. 


\section{CHAPTER 3}

\section{METHODOLOGY}

This chapter describes theoretical choices and methodological decisions made for this inquiry. First, an overview of guiding paradigms is given, offering a high-level description of ways to understand different types of worldviews and research. This overview is given to situate my selection of queer theory within the paradigm of critical theory — an important research paradigm that takes into account historical realism and seeks to disrupt dynamics of power that marginalize groups of individuals. Second, this overview also describes qualitative research methodology and provides context for understanding Interpretative Phenomenological Analysis (IPA), the methodology I chose for this inquiry. Guiding principles for conducting IPA research studies are described here as well as a rationale for why this type of methodology was chosen for this inquiry. This chapter concludes with an overview of the research design, with details on study participants, data collection, data analysis, and data integrity and study limitations.

\section{Guiding Paradigms and Inquiry}

As Guba and Lincoln (1994) argued, a guiding paradigm assists in selecting methodology through which an inquirer examines and explores reality. Guba and Lincoln defined paradigm as "the basic belief system or worldview that guides the investigator, not only in choices of method but also in ontologically and epistemologically fundamental ways" (p. 105). They argued that the acceptance of a paradigm carries particular beliefs about the nature of reality (ontology), the relationship between knower or would-be-knower and what can be known (epistemology), and the ways a knower or inquirer can go about inquiring about reality and knowledge (methodology). Guba and 
Lincoln argued that basic beliefs are established through four main paradigmspositivism, post-positivism, constructivism, and critical theory-which lead to various strategies of inquiry, including qualitative and quantitative methodology.

The critical theory paradigm most clearly relates to this research inquiry. This paradigm and its connection to queer theory is more fully described below.

\section{Connection Between Critical Theory and Queer Theory}

Critical theory and queer theory hold similar belief systems about reality and the nature of disrupting power. According to Guba and Lincoln (1994), the critical theory paradigm is based on historical realism, which is reflected in the belief that knowledge is created through social, political, cultural, economic, ethnic, and gender values that are inherently rooted in individual and social experience. Critical theory research, which evolved in postwar Germany as a response to the oppressiveness of capitalism and empirical paradigms of objectivist thought, holds basic assumptions about the distribution of power and privilege in society and seeks to announce bias related to a desire to change the world (Kincheloe \& McLaren, 1994).

Kincheloe and McLaren (1994) cited seven assumptions inherent to critical theory research:

1. Every society gives privilege to certain groups and oppresses others.

2. The oppression experienced by an individual is an interactive combination of the various oppressions generated by that individual's nonprivileged identification.

3. Cultural texts are probably the most powerful means of expressing and maintaining differences in privilege.

4. Every human act, creation, or communication can be interpreted in relation to the cultural context of capitalist production and consumption. 
5. All thought is mediated by socially and historically constructed power relations.

6. Facts can never be isolated from the domain of and prevailing assumptions formed by values.

7. Mainstream research practices help produce systems of oppression that are based on race, gender, class, and other cultural categories.

Employing these assumptions, an inquirer attempts to utilize research to disrupt power and social norms and to promote greater opportunities and equality among those who are marginalized. For queer theorists, this inquiry most typically focuses explicitly on those persons who have been marginalized due to their nonheterosexual identification (Plummer, 2005).

Thus, while critical theory and queer theory carry similar assumptions about the nature of power, privilege, and oppression, queer theory more explicitly focuses its lens on those who have been excluded due to differences in sexuality (Plummer, 2005). One difference between queer theory and critical theory may be seen with queer theory's employment of and relationship to issues of standpoint. Generally, standpoint theory, like critical theory, challenges the ontological and epistemological assumptions of positivism (McCorkal \& Myers, 2003). In addition, standpoint theory holds the view that persons who are marginalized by society may actually hold a more complete view of that society due to their marginalization (King, 1999). Employing standpoint, queer theorists note their deviance from heteronormativity as the basis for their marginalization. Further, queer theory employs visibility of nonheterosexual individuals to disrupt assumptions and promote change. 


\section{Qualitative Research}

In close connection with my decision to leverage the lens of queer theory for this inquiry, I have also selected to conduct this study using IPA, a qualitative research methodology. Denzin and Lincoln (1994) defined qualitative research as

.... a situated activity that locates the observer in the world. It consists of a set of interpretive, material practices that make the world visible. These practices transform the world. They turn the world into a series of representations, including field notes, interviews, conversations, photographs, recordings and memos to the self... (p. 3)

Bogden and Bilken (2003) stated that qualitative research has five succinct characteristics. First, qualitative research is naturalistic. This type of research is concerned with understanding the context and setting of a particular investigation.

Second, qualitative research contains descriptive data such as words and pictures that help to show nuances and details beyond numbers. Third, qualitative research has a concern with process that can be used to explore how something occurs rather than the end results or outcomes. Fourth, qualitative research is inductive and facilitates the development of theories, allowing a researcher to explore possibilities rather than proving or disproving hypotheses. Lastly, qualitative research can help to explore how people make sense of their lives by investigating meaning, resulting in rich, thick descriptions.

\section{Types of Qualitative Research}

While qualitative research holds these five succinct characteristics, different types of qualitative methodology can be used. Merriam (2002) suggested that eight approaches are most common: basic interpretative qualitative study, phenomenology, grounded theory, case study, ethnographic study, narrative analysis, critical qualitative research, 
and postmodern research. Each of these types of qualitative research carries different purposes and strategies for inquiry.

Of these methods, the use of a phenomenological approach seems most appropriate to explore a participant's experience and understanding of a lived situationtwo central concerns that I wanted to explore in this study. Phenomenology has been described as an "attempt to understand the meaning of events and interactions of ordinary people in particular situations." (Bogden \& Bilkin, 2003, p. 23). This approach is deeply rooted in philosophical questions related to intentionality of consciousness and has been influenced by Husserl, Heidigger, Sartre, and Merlou-Ponty (Creswell, 1998).

IPA. IPA is a type of phenomenological inquiry (Smith, Flowers, \& Larkin, 2009). IPA holds that experience is "a lived process, an unfurling of perspectives and meanings, which are unique to the person's embodied and situated relationship in the word" (p. 21). Within phenomenology, this approach pays specific attention to the ways that people create meaning or understand an experience. In addition, IPA also openly embraces two additional theoretical underpinnings - hermeneutics and idiography (Smith et al., 2009).

Smith et al. (2009) described hermeneutics as the theory of interpretation. First, IPA recognizes that the researcher plays a role in interpreting the phenomenon lived and shared by a participant: "IPA is concerned with examining how a phenomenon appears, and the analyst is implicated in facilitating and making sense of this appearance" (p. 28). IPA also contains an iterative focus_-guiding a researcher through different ways of thinking about, breaking down, and interpreting data: "The idea is that our entry into the meaning of a text can be made at a number of different levels, all of which relate to one 
another, and many of which will offer different perspectives on the part-whole coherence of the text." (p. 28). Interpretation is ongoing and sustained throughout the IPA approach, giving prolonged opportunities for the researcher to think about, present, and engage in new ways of understanding an explored phenomenon.

Idiography — the concern with the particular — is the third underpinning for an IPA approach (Smith et al., 2009). IPA uses this underpinning in two ways. First, idiography guides IPA toward detail, supporting in-depth accounts of an event in order to facilitate interpretation of that account (i.e., contains rich, thick description). Second, this underpinning focuses IPA on the specific, suggesting that unique experiences, events, and relationships are suitable for inquiry. Such an underpinning holds that individuals who have experienced a phenomenon are best able to share their relationship with that phenomenon.

Thus, IPA is a research approach that focuses on understanding the meaning of an account of an experience. It is shaped by phenomenology, hermeneutics, and idiography and provides an important pathway toward understanding an individual's or group of individuals' meaning related to a particular phenomenon.

Methodological considerations using IPA. IPA describes a series of methodological choices regarding participants, data collection, and data analysis, offering tools, guidelines, processes, and opportunities for a researcher. With regard to study participants, IPA recommends the purposeful selection of a sample or samples who can most closely speak to a lived experience (Smith et al., 2009).

Data collection in IPA typically involves in-depth, semi-structured interviews with participants (Smith et al., 2009). Transcripts are created, typically using a verbatim record 
of what was said. However, IPA does not require noting details related to the rhythm, stress, and intonation of speech because of the focus of this approach on content.

Smith et al. (2009) stated that analysis in IPA usually involves guiding processes and principles that are not rigidly set; however, the authors offer important structures for a researcher to employ when reflecting, engaging, and interpreting meaning related to what participants are sharing about their experience. This process is iterative and can be done with one or multiple cases.

IPA analysis is also complex and requires a significant amount of time to create sufficient detail required for this type of methodology. Suggested pathways for IPA analysis include: (a) reading and rereading, (b) initial noting, (c) developing emergent themes, (d) searching for connections across emergent themes, (e) moving to the next case, and (f) looking for patterns across cases (Smith et al., 2009).

Step one involves reading and rereading the transcript so that the researcher can immerse in the data (Smith et al., 2009). This stage of analysis is meant to give the researcher a prolonged relationship to the text, giving him or her chances to see emerging pieces of the data. In addition, IPA researchers are encouraged to keep analytic memos to capture initial observations, feelings, and thoughts about the experience during and beyond this stage.

Step two in IPA analysis suggests taking initial notes on the transcript to highlight a wide variety of thoughts and reflections about how a participant talks about a lived experience (Smith et al., 2009). During this stage, the researcher is encouraged to note initial thoughts on the transcript (with suggestions to create a column next to the raw data 
for these notes to appear alongside of the account). Descriptive comments, linguistic comments, and conceptual comments can all be included in this stage.

Step three in IPA analysis encourages the researcher to construct and write down emergent themes from the text (Smith et al., 2009). In this stage, the researcher continues to read over the transcript (and initial notes) and begins to generate thematic comments that more broadly capture the researcher's initial interpretation of what is happening from the data. Usually, a third column is included on the transcript for this purpose. Then, the themes are written chronologically, following the flow of the text, to create a list of all the themes through time and across the transcript(s).

Step four suggests searching for connections across emergent themes (Smith et al., 2009). The researcher can examine the chronological list of themes for patterns that include abstraction (patterns between emergent themes), polarization (oppositional relationships), contextualization (temporal, cultural, and narrative themes related to key moments), numerization (frequency with which a topic is discussed), and function (the role something serves within and beyond the transcript). This step concludes by creating a graphic representation of the structure of themes, usually in the shape of a table.

Step five is moving to the next case. While Smith et al. (2009) stated that a single case is acceptable in IPA, they also note that the previous steps can be repeated for each additional case.

Step six suggests looking for patterns across cases (Smith et al., 2009). Doing so includes looking for broader themes across cases. The researcher can approach this step by exploring strategies that work best for him or her-including building upon themes used in the original case or assembling new emergent themes across cases. 
Although these six steps are typically suggested for analyzing IPA, Smith et al. (2009) also stressed that analysis continues well into the write-up and reporting stages as new themes and connections may emerge when an account is reassembled during this phase. Hence, as the researcher re-presents data in different contexts, analysis continues well into the written documentation of the inquiry.

Rationale for selecting IPA. IPA appeared to be a good fit for this study for a number of reasons. First, this approach and its methods have previously been used to better understand topics of concern to gay populations, including identity (Smith \& Osborn, 2008). Because the present study shared experiences from a mentoring match between an adult and a youth from the gay community, I was drawn to a methodology that had been used previously to examine and understand these situations. Second, IPA allowed for smaller sample sizes while also requiring that chosen participants be able to speak to and answer selected research questions with rich detail. Doing so was essential for me because I was unable to locate additional matches during my outreach (see below). Third, I was drawn to the processes and structures that this type of analysis allowed for, given its opportunities to gain insight from participants while also recognizing that I was playing a role in interpreting that data.

\section{Research Design}

This section describes the research design used during this study. A description of the research participants, data collection, data analysis, data integrity, and study limitations are provided. 


\section{Research Participants}

One mentoring match from a formal program that sponsors relationships between gay adults and gay youth was selected to participate in this study. The mentor, who chose the pseudonym "Daniel," is currently 28 years of age. He is Caucasian and self-labels as "gay." The mentee, who chose the pseudonym "Tony," is currently 19 years of age. He applied to participate in the program when he was 17 years old. The mentee is biracial and currently self-labels as "queer." The pair has been matched since January 2011.

Tony and Daniel were purposefully selected to participate in this study because they met the following criteria.

First, they were participating in a formal mentoring program that sponsors one-toone relationships between nonheterosexual adults and youth. A mentoring program that focuses on support for gay youth is distinct from other youth mentoring programs in that it has created specific layers of support—program intake, case management, match training, and program support — designed to be inclusive of this population. I also selected this mentoring program setting because it appeared most likely to sustain relationships focused on giving this population support around the coming-out process as well as opportunities to individually connect with other members from the gay community in a positive setting.

Second, Daniel and Tony have now been matched for over two years. Because duration of match has been connected to degree of benefits in a young person (Grossman \& Rhodes, 2002), I wanted to locate a match that had been together for at least a year.

Third, I was interested in selecting matches that worked closely with and were familiar to program staff, because staff awareness, ongoing case management, and 
interaction with matches appear to be closely related to the presence of benefits in youth (DuBois, Holloway et al., 2002; Dubois, Portillo et al., 2011). Tony and Daniel were identified by program staff as having developed a close bond and were also recognized for participating in a range of program activities.

Fourth, I had hoped to locate a match between a youth who identified as gay and an adult who also identified as gay. Because the processes of navigating through sexualminority identity development may be different for males and females, I wanted to establish clear parameters to better understand how one subgroup of the gay community_-gay male youth—-leveraged support for this process through relationships with similar others. While Daniel, the mentor, self-labels as gay, Tony currently describes himself as queer.

Although Tony's use of "queer" may not fit the exact terminology that I used in my research question, I highlight two important justifications about why this match was finally selected to participate in my study. First, Savin-Williams (2005) argued that most youth today — whom he calls "the new gay teenager"-are often opposed to the use of binary labels and may choose to express their sexuality and orientation differently than older cohorts, to which I belong. The term queer is one way that nonheterosexual youth might express their lack of conformity to a dominant paradigm. This personal decision for many youth parallels the intent and use of the term queer theory in academic settings. Second, my outreach process demonstrated just how difficult it was to find one-to-one formal mentoring programs serving the gay community and to gain access to communitybased matches that included gay males. 
Program outreach. The breadth and depth of that outreach process is included here to more fully illuminate just how difficult it was to find this match or other matches that held similar, if not quite exact, characteristics that were described in my list of criteria. I offer this further description of outreach not only to justify the choice of participants, but also to contribute to a broader understanding of the state of the field during recent years.

My outreach efforts to locate potential programs and participants for this study started in 2010. These efforts included:

- Using the National Mentoring Database at MENTOR, which contains listings for more than 4,000 high-quality mentoring programs that follow the Elements of Effective Practice (MENTOR, 2009)

- Reaching out to LGBTQ community centers across the country

- Contacting the national office of BBBS

- Conducting online searches using Google and other search engines

- Posting requests for assistance on a national listserve used by mentoring researchers and practitioners

- Contacting various State and Local Mentoring Partnerships Through searches of the National Mentoring Database and personal correspondence in 2007 with Barajas (2004), author of Mentoring Gay, Lesbian, and Transgender Youth, I was able to locate three mentoring programs that sponsored formal mentoring relationships between gay adults and gay youth. A fourth agency was located through a Google search using the search phrases programs and mentoring for gay youth. These agencies were all located in urban areas, and each was initially contacted to assess its 
interest, availability, and access to potential participants. Three of the agencies initially agreed to work with me, and all three stated that they had participants who met my stated criteria. The fourth agency stated that they did not have mentoring matches who met my stated criteria.

After approval of my dissertation proposal and subsequent approval of my human-subjects review, none of the three agencies I had initially identified ended up participating in this study for varying reasons. One agency abruptly closed down, a second stopped returning calls during initial outreach efforts, and a third agreed to send out letters of consent to potential participants and then stopped responding to my calls and emails.

Because none of these three agencies participated, I expanded my outreach efforts to include various gay and lesbian community centers in urban areas across North America to explore whether their services to youth might also include one-to-one mentoring relationships. During this phase of my outreach, I learned that most support services in these settings consisted only of group models, mental health/counseling, peer counseling, and drop-in support; no adult-youth one-to-one mentoring programs were in place. Despite conducting searches in 2010, 2011, and 2012 with these types of agencies, I was unable to locate any one-to-one formal mentoring programs within these settings that met my stated criteria and were also willing to work with me to identify potential dyads for my inquiry.

In 2012, I decided to explore an expansion of my selection criteria to include gay youth located in any type of mentoring agency, even those without the mission of sponsoring formal relationships between gay adults and gay youth. At this time, I 
conducted outreach to the nation's largest mentoring organization, BBBS (2012), which serves over 200,000 children nationwide. During correspondence with staff from various agencies and with the national evaluation director, BBBS stated that its national tracking system did not identify the sexual orientation or identity of mentees, but a few of its regional affiliates were beginning the process of collecting such information. Three agencies were identified: BBBS of Puget Sound, BBBS Columbia Northwest, and BBBS of Central Ohio. However, after email and phone contact with each of these agencies as well as a fourth affiliate, BBBS of the Bay Area, none reported matches between gay adults and gay youth. Further, none of the agencies had implemented a formal tracking system to determine whether a youth identified as gay before he or she was matched. One agency, BBBS of Puget Sound, noted that it was beginning the process of tracking this kind of data on youth.

In addition to conducting outreach to BBBS, I also sent notices and information requests to State and Local Mentoring Partnerships and to a national list serve of researchers and leading practitioners in the mentoring field. None of these requests resulted in the identification of a mentoring match involving a gay adult with a gay youth-or even a heterosexual mentor with a gay youth who had started the mentoring relationship when he or she was 18 years of age or younger. This outreach experience, and my struggle to locate accessible and identifiable formal matches who met my criteria, must be noted, as my inquiry parameters ultimately required slight modifications.

I would also like to note here that while I had difficulty locating established mentoring programs that were sponsoring long-term relations between gay adults and gay youth, my outreach started to indicate interest and a growing number of start-up agencies 
that are seeking to provide these specific services. For example, a June 2012 article in the Washington Post (Buerger, 2012) highlighted a program in Washington, DC that was in its infancy and was looking to become the first agency of its kind in the Beltway area. After facilitating a series of national webinars and trainings on mentoring gay youth, I also received phone calls and emails from participants in Nebraska, Montana, Florida, and Pennsylvania letting me know that were exploring strategies to create formal mentoring relationships for queer and questioning youth. While this increase in program type is notable, none of these programs have been around long enough to sponsor or support long-term mentoring matches. Therefore, they were unable to support my request for participants.

In May 2012, I once again contacted the fourth mentoring program, which initially reported no long-term matches between gay male participants. Previous contact with this agency revealed that no matches between a gay male adult and a gay male youth had been together for a year or longer. However, as my outreach process took multiple years to complete, during this follow-up call, I learned that they had a match that met most of my criteria. This program was the source for Tony and Daniel.

Informed consent. After the dissertation committee approved my study, an application was submitted to Portland State University’s Human Subjects Research Review Committee (HSRRC) and was approved. This HSRRC application included detailed information about steps to protect participant confidentiality, study interview protocols, letters of consent for participants, intended analysis, and outreach materials.

In May 2012, after my initial correspondence with staff from the fourth identified mentoring program, I mailed outreach materials to the program manager. Materials 
included an outreach flyer for the mentor (see Appendix C), an outreach flyer for the mentee (see Appendix D), letter of informed consent for the mentor (see Appendix E), letter of informed consent for the mentee (see Appendix F), and a script for program staff to follow that described the HSRRC's approved steps to solicit participants for the study (see Appendix G).

Following the prescribed steps for participant outreach that the HSRRC had approved, program staff initially asked Tony, the mentee, if he was interested in participating in the study. He was given the outreach flyer and letter of informed consent. Once Tony agreed, signed the form, and returned the form to the program staff, Daniel was given the outreach flyer and letter of informed consent. He in turn returned his materials to the program staff.

This specific process was used in order to make sure that the mentee did not feel coerced by the mentor to participate. Once all materials were submitted, program staff mailed the materials to me. I then contacted both mentor and mentee electronically, discussed the study, and set up a time to meet for the first interview.

\section{Data Collection}

In June 2012, the first in-person interview with the mentor and the mentee took place. This interview occurred at a private office at the mentoring program site during a time when no other program activities or matches were present. While no other youth or mentors were on site at this time, the mentor-program coordinator was present; the coordinator introduced me and then left the room to make sure we had privacy during our conversation. Before the interview began, I verbally read the letters of informed consent to the participants and had them sign and respond verbally that they understood. 
Following suggested data-collection methods for IPA (Smith et al., 2009), a semistructured interview protocol was developed and used (see Appendix H). The first 75minute interview protocol—which was conducted at the mentor-mentee pair's 17-month match point — consisted of questions that attempted to learn more about the characteristics of the relationship and how both parties viewed its benefits and drawbacks. In addition, an activity asked the match to draw a timeline illustrating milestones, highlights, and other meaningful events from their relationship over the previous year and a half.

In November 2012, a second in-person interview took place with both the mentor and the mentee at a private office. This interview was also semi-structured and included protocol prompts that contained stem questions related to sexual-minority identity development (see Appendix I). The interview also involved an opportunity to member check cited milestones and the timeline for the relationship. The interview lasted 60 minutes. Following the formal interview, I walked with the match around the neighborhood for nearly three hours. Analytic memos and field notes captured data from this unplanned opportunity.

\section{Data Analysis}

Following suggestions from Smith et al. (2009), both interviews were digitally audio-recorded and then transcribed using a verbatim account. In order to maintain consistency across interviews, specific transcription conventions were developed and used to guide all transcription activities. These conventions required me to listen three times to the audio recording before the transcription was finished. Guidelines for spacing, the use of line numbers, and notations for speech and expression were defined. In 
addition, I only used pseudonyms to identify participants in all written transcripts and analytic memos.

Further, all audiotapes were kept in a locked drawer in my home office, where I will retain them, following suggested security measures from the HSRRC, for 3 years. Password protection on my computer was also used to make sure that the recordings remained private.

Between the first and second interview, I engaged in a thorough analysis of the data following guidelines suggested by Smith et al. (2009). First, I read over the transcript three times during step one of the analysis, writing initial thoughts and comments. Second, I read over the transcript three additional times to assemble themes that were emerging from the initial comments and notes. Third, themes were listed in chronological order. Fourth, I used a large surface to visually assemble and arrange written themes in clustered categories. Then I clustered groupings into larger, superordinate categories about the mentoring relationship. Fifth, I created a table with superordinate categories, themes, and specific examples. These initial analysis categories were used to develop additional follow-up questions for the second interview.

After the second interview, I followed the same steps suggested by Smith et al. (2009) by first creating an individual analysis of this interview and then merging both analyses together in the same manner as described above. Further analysis occurred between the construction of the table and a written account used here.

\section{Data Integrity}

In order to strengthen the integrity of my qualitative study, the following measures for credibility, transferability, dependability, confirmability, and authenticity 
were taken. These measures demonstrate steps the researcher took to support data integrity throughout this study.

Credibility. Credibility refers to the congruence of findings with what is observed (Imel, Kirka, \& Wonacott, 2002). Building credibility into a qualitative study often includes "prolonged engagement in the field, persistent observation, collection of sufficient data, triangulation (use of multiple raters, cases, theme interpreters), peer review, member checks (confirmation by participants) and a search for negative instances that challenge emerging hypotheses and demand their reformation" (p. 5).

This study built credibility by conducting two separate interviews five months apart that included both the mentor and mentee in discussions. The selection of both mentor and mentee as participants offered a chance to triangulate different perspectives at different times in their relationship. Further, interview protocols included opportunities for participants to describe limitations and challenges within their relationship, offering me the ability to gain insight into potential negative instances that challenged emerging hypotheses during this inquiry. Member checks were also incorporated into the study, with chances for the match to clarify the timeline of their relationship and other milestones during follow-up.

Transferability. Transferability refers to detailed and rich descriptions that offer the opportunity for others to make informed judgments of findings (Imel et al., 2002). In order to provide readers with sufficient information to judge the applicability of my findings, detailed, rich descriptions taken directly from participant interviews are included in the analysis and in the findings. 
Dependability. Dependability refers to the consistency between results and collected data (Imel et al., 2002). In order to retain dependability, the research uses an audit trail that fully documents the steps taken to reach study conclusions. Demonstrating that my results are consistent with my data collection methods, I ensured dependability by documenting the methods, procedures, and sample selection requirements by keeping a qualitative researcher log that recorded the steps taken during this study. This log can be used to assist other researchers in understanding the exact processes that I used to conduct my study and will allow them to follow my procedures if they choose to conduct a similar study in the future.

Confirmability. The term confirmability often includes self-reflection and disclosure of the worldview that has shaped the inquiry (Imel et al., 2002). The trustworthiness of my study was established through the use of analytic memos written during my data collection and analysis phases, which documented my theoretical orientation, assumptions, biases, values, and epistemological stances. These memos assisted me in acknowledging dilemmas that were encountered and gave me the space to document any ethical concerns and issues that might have arisen while I conducted my inquiry. Further, a description of my researcher orientation through queer theory has been offered during my study. That description was meant to offer insight into the ways in which I see a connection between my work and how it might offer voice to a marginalized group of individuals.

Authenticity. Authenticity involves opportunities to present a range of perspectives to ensure that a fair representation of a phenomenon has been conducted (Imel et al., 2002). In order to provide a range of perspectives regarding the phenomenon 
of mentoring relationships involving gay adults and gay youth, this study employed the perspectives of participants over a five-month period of time. Further, the types of questions asked of participants provided insight into both the benefits and drawbacks of their participation in these unique relationships. By securing this range of perspectives, a greater and more authentic understanding of this phenomenon was achieved.

\section{Study Limitations}

While the selected methodology appeared to work well for the goals of this inquiry, I would also like to address potential limitations. First, IPA is a relatively new methodology, only emerging within the last 20 years (Smith et al., 2009). While it has grown in use, especially in Europe, IPA may still require additional explanation. Larkin, Watts, and Clifton (2006) argued that IPA has wrongly been viewed as simple descriptive methodology that is less demanding and rigorous than other types of research approaches. However, this approach requires skill, balance, and a comfort with uncertainty that may not be present with other, more established, qualitative approaches (Larkin et al., 2006).

A second limitation lies in the execution of this approach. Although IPA offers suggestions and guidelines for inquiry, this approach recognizes that each study will be different and that a researcher should be able to make individual decisions regarding its use. The balance between following suggested guidelines and opening up the process to researcher prerogative requires skill and balance, something that only comes with practice. As a novice researcher, this approach was challenging and often laced with uncertainty. However, by following the suggested guidelines of Smith et al. (2009) and by recognizing the idiographic, hermeneutic, and phenomenological underpinnings of 
this approach for my inquiry, I attempted to ground my inquiry with the process as well as the voices of this study's participants.

\section{Chapter Summary}

This chapter provided insight into theoretical and methodological decisions for this inquiry. An overview of guiding paradigms, justification for the choice of qualitative methodology, and an in-depth overview of the specific approach for this study-IPAwas described. Lastly, this study's data collection, data analysis, data integrity, and potential methodological limitations were detailed. 


\section{CHAPTER 4}

\section{FINDINGS}

After we finished our second interview, Tony, Daniel, and I spent an afternoon walking around the gay district not too far from the office of the mentoring program. As we walked, we passed groups of laughing gay men, rainbow flags in storefronts, coffee shops, clubs, bookstores, and gay bars. The neighborhood felt alive and bustling on an atypically warm but overcast Sunday in November.

Daniel told me how they took walks just like this when they were initially matched nearly two years before. Tony would commute 40 to 50 minutes into the city and Daniel would set up and give "lessons" about the community. Daniel would point out resources, share stories of his coming-out experience, talk about the trials and tribulations of dating men, introduce Tony to his friends and boyfriend, and connect him with answers about being safe and being queer.

Two years on, the two of them walked along like old friends. Sometimes they walked in silence, keeping pace with each other as they cross an intersection. Other times, conversation would bubble up: Daniel shared a story about a "cleanse" he recently finished and described how dramatic it was to get through 10 very long days without eating sugars and carbohydrates. He emphasized the words dramatic and very long to the effect that both Tony and I started laughing with him. A few minutes later, Tony excitedly shared how he saw a drag performance at one of the clubs we passed on the main strip, saying that he was impressed with the way the girls choreographed their show. His respect for the drag queens' show was notable because Tony spends most of his free time engaged in performance and dance. 
Our walk took us by the arts center where they went to shows together, the street corner where Tony watched his first Pride parade, and into the same bookstore where Daniel helped Tony pick out his first piece of gay literature so he could learn more about life as a gay man. As we walked into the small bookstore, I noticed shelves with titles such as "Gay Relationships," "Gay Literature," and "Lesbians With Children.” There were newspapers and magazines, postcards, community flyers, and other customers browsing in silence.

Once we made it through the entryway, the three of us walked to different parts of the store, exploring on our own. As I walked around, one of the books I saw in the back of the store was Becoming a Man by Paul Monette. This was the first piece of gay literature I read shortly after moving to Portland in 1996, just a month or two after I came out to my mom. For a moment, I was taken back to that time- before the television show Will and Grace, with its strong gay characters; before the tragic murder of Matthew Shepard for his gayness; before I started this doctoral program; before the Internet was easily accessible. My eyes welled up with emotion as I saw the cover of that book for the first time in years.

Tony came over to see what I was looking at, and I asked if he had read it. He said no, and paused for a few minutes to look at the cover. "What was it like?" he asked. I realized that his question went beyond just reading the book.

I shared with him how I read that book in one sitting, that it was the first time I connected with the story of someone who was similar to me. I said it was written in a different time, but that it was a book that meant a lot to me when I was figuring myself out. Tony listened politely for a few minutes, flipped through the pages, and put the book 
back on the shelf just as Daniel walked over to see what would be the next stop for our time together.

The description of our afternoon walk together offers insight into what a longterm formal mentoring relationship between a gay adult (Daniel) and a queer youth (Tony) "looks like" and provides a snapshot of the benefits and unique support that Tony has received since being matched with Daniel. Although the descriptive story above gives a glimpse of a moment in time shared with both of them, themes that emerged during the analysis of interview sessions conducted over a five-month period provide depth, nuance, and richness related to how the two perceive the phenomenon of their unique relationship.

Chapter 4 explores selected themes from major areas in Daniel and Tony's relationship. These superordinate themes:

- Characteristics and processes

- Benefits and limitations

- Unique support for sexual-minority identity development

In each major area, findings are described first; they are followed by a researcherdiscussion section, which functions as a summary and a space for initial connections of the findings to scholarly theoretical frameworks and empirical research. These research discussions do not, however, replace a broader discussion of assertions, recommendations, and contributions contained in chapter 5 , but act as an intermediary between the findings and broader discussions of meaning and implications.

Before the findings are presented, I would like to highlight that the superordinate themes described below should not be viewed as an exhaustive representation of Daniel 
and Tony's relationship. Nor should the written structure of themes and findings presented here be meant to imply succinct separations and distinctions among sectionsespecially because support for sexual-minority identity development seems to permeate many characteristics, processes, and benefits that Tony and Daniel described about their relationship. Given these considerations, the structure of this chapter and these written words are only meant to offer a vehicle through which to view a glimpse of a much deeper, nuanced, complex, and moving phenomenon: a long-term formal mentoring relationship between a gay adult and a queer youth.

Themes within the superordinate theme of "characteristics and processes" are the following:

1. Before they were matched: Confusion and coming-out stories

2. Greater involvement in community: A key motivation

3. The "firsts"

4. From mentorship into friendship

5. Similarities, mutual interests, and differences

6. Changes in frequency and types of contact over time

Themes within the superordinate theme of "benefits and limitations":

1. Support for Dating: A relationship about relationships

2. Greater comfort meeting people from the gay community

3. Space to work through family issues

4. Limitations of time

5. Dealing with attraction and boundaries 
Themes within the superordinate theme of "uniquely contributing to sexual-minority identity development":

1. Unique and individualized space to access support

2. Ongoing and responsive mentee-centered approach to identity development

3. Leveraging the relationship to raise awareness in others

\section{Processes and Characteristics}

Daniel and Tony offered me an in-depth look at what their long-term mentoring relationship "looks like" and the milestones they experienced since they were first matched. At the 22-month mark as mentor and mentee, Daniel and Tony provided insight into how they experienced this relationship, highlighting specific ways that they have both grown over the course of their relationship. These included a series of "firsts" and milestones, a description of the events that moved them from a mentoring relationship into a friendship, identification of ways in which they were able to form a deeper bond, and strategies for how they have maintained closeness through social media. In addition, this superordinate theme captures the individual stories of Tony and Daniel before they signed up for the program — offering insight into their coming-out stories and their initial motivations for participating in a mentoring program that matches gay adults with gay youth.

\section{Before They Were Matched: Confusion and Coming Out}

Tony and Daniel shared stories about their motivations for participating in a mentoring program that matched individuals from the gay community. These 
motivations, and their coming out stories help to provide important context for how their mentoring relationship developed, grew, and evolved over time.

Tony: "Because I was really confused." Tony was 18 when he was matched with Daniel. During our conversations about what led him to sign up for the mentoring program, Tony described a series of events that eventually propelled him to seek out support. These events and milestones included early moments of recognizing he was different, his initial attempts at self-labeling, and how he used his appearance to share who he was with other people. Tony reflected on feeling different and how he found a term that captured what he was feeling:

I knew that I liked guys from like really young-really young, actually. Maybe like eight. Um. But, I like knew my sexuality was different in like tenth grade and that was just because I was really confused. I didn't know what bisexual was. Actually I didn't know that that was a thing. I knew that I liked girls. And I knew that I liked guys and that was confusing for me so I knew that I wasn't gay because I like I still liked girls. Ahm. And so when my friend like introduced the idea and like asked me "are you bisexual?" I'm like "What is that?" (Short laugh) and she explained it and I was like yeah. That sounds right. That feels right to me so. Yeah. Ah. Around I'd say like 15.

In his reflection, Tony noted the presence of being confused about what was happening inside from a young age. He especially described a struggle to find language that captured how he was feeling. When his friend helped him in this process, Tony appeared to gain a new way of seeing himself, a lens that gave him greater clarity and what appeared to be a sense of relief.

While Tony was trying to figure out how to define himself, he also brushed up against issues related to when and how to share his sexuality and identity with others. He noted that sharing with others was not a negative experience, especially because he used his outward appearance and dress to convey who he was: 
I didn't get any negativity to be honest. I was never bullied or made fun of. Mainly because I was so involved already in school. I mean like everybody already knew me. Coming out to people was not really an issue but if they asked I told. And it wasn't like I went out and made an announcement. But, no ... so it was not weird at all. Most people were like "I think had already like made that assumption," especially like once I came to terms with my bisexuality I started dressing differently so it was no more like really baggy clothes and baggy shirts so I think it just became ... I think it became like really evident to people what was happening there. So it was fine in school.

In his account, Tony described how he depended on his choice of clothes-his appearance - to convey who he was to others. In this same sense, Tony also seemed to wait for others to ask him about his sexuality instead of proactively and openly using language that helped to identify him to others. Yet, although Tony highlights the ease through which he conveyed his outward appearance, during our first interview he also hinted that there were indeed internal struggles underneath the veneer:

I was feeling really depressed at that time. Um, school was going OK, um, I had friends and everything like that. Not the greatest of friends, but I was just really confused about life, and I didn't really understand. 'Cause I knew that I liked girls and I'd dated girls, but I always ended relationships because I felt like I didn't really understand what bisexual was, and then, that's when I was like my best friend, still my best friend, came to me and asked me if I was bisexual. And I really didn't know what that was. I'm like "gay/straight." And then she explained it to me and I'm like, um, that's the closest thing that I connect to. I'm not even sure that's what I'd apply to myself right now. But it's the closest thing that I connect to, and the best way to explain how I feel towards intimate relationships.

Although Tony described feeling at ease with sharing his sexuality with his peers, he also seemed to struggle internally. He described feeling depressed and also seemed to lack close friendships. These struggles, along with a desire to learn more about the gay community, ultimately led him to seek out support from other external resources such as the mentoring program. 
Daniel: "I needed to come out with it and just be open about it." Daniel's

coming-out process seemed similar to Tony's experience-Daniel described having an early awareness of being different, noted previous experiences dating women, and also had internal struggles trying to define who he was:

I always knew something was up sexually. Like I was always drawn to guys and didn't really have any desire to be with women or I found them to be very attractive and I was in a relationship with a woman for five years so that just kind of really distracted me and I was really in love with that person and we developed a wonderful relationship. Ahm and it was toward the end of that relationship and when I moved downtown when I turned 20 that ahm I was in and around this neighborhood a lot and I felt like I belonged and like I knew what it was and it made sense and it just lined up and it was like "Whoa!" this is what this is.

In his reflection, Daniel described how he had an early awareness of being gay but also attempted to have a relationship with a woman. He also shared that it was not until he moved closer to the gay neighborhood that he was able to finally have a sense of belonging and connection that seemed to be missing from his life before. His move downtown also appeared to open his world to new possibilities while forcing him to face any previous denials about being gay: "This is like real. This is not like something in your imagination. And yeah, so it was. I did not know what it was until or I did not want to believe."

Daniel said that once he realized that he was gay, he needed help trying to process the changes that he was going through. He eventually accessed counseling support at his university:

I went to therapy for a while. While I was in college, they offered free counseling services and I literally felt like I was going mental so I thought it was... it was probably my first year of school...at the root of it all was I needed to face that I was gay and I needed to come out with it and just be open about it. 
Daniel hinted at the difficulty of this experience and that he needed to find external support for processing what this might mean for him. When he had not yet enrolled in therapy, he did not seem to have opportunities for support around his struggle: "I really just buried myself in my room and tried to figure it out on my own."

After trying to figure things on his own, Daniel decided to get external supporthe went to the counseling center at his university to talk to a therapist. However, he described his initial experience working with a counselor to be quite negative:

I remember the first counselor that I was seeing, and we talked about career paths and stuff for about six months and then I went in and then I was also just like "And then I am also gay" and like.

She responded, "Well. I am not trained to deal with this."

And I was like, "What do you mean 'deal with this'?” And I got really defensive about it.

Although this experience seemed to leave Daniel self-protective, he continued to seek out counseling and support, eventually finding a counselor who offered him what he was looking for-specific tools to use to work through coming out:

And then I got to see this wonderful man for about two years. Um. This older gay man who was probably in like his late sixties. Actually, um, who provided a lot of support. He was like a mathematician to me. He was like- - so, this is a formula. And this is where you are and this is how we are going to calculate and this is how we are going to work through it. So, when you are feeling lost or stuck somewhere just go back to this. And just being rational about something is I guess the best kind of advice that I give as well.

Being able to access support from someone who understood seemed to be a very important resource for Daniel. The rational approach he gained to navigate through his coming-out experience appeared to offer him a specific tool to move past where he might have felt stuck and seemed to propel him to higher levels of acceptance. Even now, 
Daniel indicates that this is advice that he holds closely for himself and shares with others.

\section{Greater Involvement in Community: A Key Motivation}

In addition to Tony and Daniel's individual experiences of coming out, their shared motivation to participate in a mentoring program that matches gay youth with gay adults also holds an important place in understanding the starting point for Daniel and Tony's relationship. Both of them described a similar motivation for wanting to sign up for such a program: the opportunity to connect with others from the community.

For Daniel, the motivation to volunteer as a mentor was about wanting to give back. He wanted to offer a younger person the support he struggled to access:

And I heard about the program online and I just wanted, just needed to do something new. Number one. And I wanted to get involved with something that was um part of the community.... when I read about the program it just sounded so appealing because I thought I could be a mentor at the time. Basically, because I wanted to get involved with the community a bit more and there was no guidance for me when I was coming out myself.

This quote seems to highlight how Daniel wanted to channel his own struggles and challenges with his sexuality into a way to benefit a younger, less experienced person during the coming-out process - a key motivation for why he signed up for this specific program.

When he applied to be a mentor, Daniel had just met the minimum age requirements for the program and said that he wanted to help a youth feel comfortable and learn more about the gay community. At one point, when describing his motivation to be a mentor, Daniel even said that he felt like if he had a mentor "I don't think it would have taken me as long to feel comfortable with myself." 
At the other end of the spectrum, Tony, just 17 when he applied to the program (18 when he was matched), wanted to learn more about what being gay and being part of the gay community was like. "I actually didn't know anything about the queer community like at all," he said, adding, "I needed somebody to make me like aware of how to get involved in the community, what to do in the community, and what the gay community looked like.”

Such a starting point seemed to offer a foundation for the range of activities, opportunities, and learning - the characteristics and processes - that were built into much of their formative months as mentor and mentee. Both Daniel and Tony seemed to want to find a greater connection with their community, and their choice to participate in a mentoring program strongly reflects this desire.

\section{The "Firsts"}

Once Daniel and Tony were matched, much of their early relationship offered a number of "firsts" for both of them. During our conversations, they identified many different experiences that were new or different for each of them, including the first meeting, Daniel's initial approach toward his new role as a mentor, and Tony's introductory experiences entering into and learning more about the gay community.

Daniel and Tony had their first match meeting in the winter of 2011. They met at the mentoring program office and, according to Tony, talked "for like three hours." Both identified their first meeting as an important milestone in their relationship, as there seemed to be an instant connection between them. Yet Tony and Daniel described different feelings around the experience. 
Tony said that he felt like it went well: "Well, I thought it went quite well. Ahm. I don't know we just met in the room over there and we talked for like the longest time." Later in the interview, Tony added that he was able to open up to Daniel pretty early in that first meeting: "I think it was like from the first conversation where I was talking about my family and those type of expectations and like talking about school pressures and stuff like that."

Daniel described a much different experience. He described being "terrified" when they first met:

Interviewer: So what happened during your first meeting?

Daniel: $\quad$ Terrifying. (Both Daniel and Tony laugh)

Tony: $\quad$ Really? (Group laughter)

Daniel: $\quad$ For me, I was thinking: "What am I doing? Oh my god!"

Tony: I thought it went over quite well.

Daniel said these fears and uncertainties extended into how he began to approach his new role as a mentor with Tony during their early meetings:

At first, I just felt that like I needed to help this person. I am doing this because this person needs help. But everybody needs help. So, it's just being there when someone does and not feeling like they do all the time or that's what the relationship is about. So, once I let that go, then I could listen a lot more. But at first it was "I needed to give good advice and all the time be positive and not swear and lead by example."

Daniel's description indicates an initial set of expectations around how he thought he should behave as a mentor. He later added how he would approach these concerns:

So I have to, you know, approach it really delicately or just make sure I know what I'm talking about. Um, and was kind of distant and thought it was a teacherstudent kind of thing. So, I was like all right, let's talk about the community then, 
let's not make it personal, let's not make it about friends or family. Let's just make it a lesson about the culture and the environment that exists in [this city].

While he had these concerns, Daniel appeared to find ways to help reduce his anxiety about being a mentor and to shift his thinking about his role in the relationship. One way he did this was to create structure around their first in-person meetings together: "So we did these specific windows of time. So, like we are going to hangout from 12-4 today so it doesn't get awkward." Daniel also focused the match meetings on what Tony said he wanted to do - to learn more about the gay community:

We set up a few ahm dates I remember in public where we were gonna like walk around. He was like "let's walk around the neighborhood. I don't know the neighborhood or some of the history behind the neighborhood or the community." So we walked by. We went to the community center. Then we went to the bookstore.

This exposure to different resources, experiences, and institutions in the gay community seemed to leave an impact with Tony. When asked about the milestones of their relationship, Tony highlighted a number of firsts that he experienced with Daniel during the early stages of their relationship, including his first gay book, going to his first Pride parade, first drag performance, and his first real "like" of another guy.

These early characteristics of their relationship — the firsts — included, as described above, what seemed to be moments of uncertainty, differences in perspective, and opportunities to explore new things during this formative stage of their relationship. These experiences also appear to have offered them the space to get to know each other better, which ultimately helped their relationship grow from a mentoring match into a friendship. 


\section{From Mentorship Into Friendship}

Twenty-two months into their relationship, Daniel and Tony shared similar language when they talked about each other. Both of them used words like friendship and companionship, which hinted at a relationship that is familiar and close. For example, Daniel said that Tony "is the most patient, soft, not loud or abrasive person you can imagine." He added that Tony has such incredible strengths that include empathy, directness, and honesty. Tony said that he has a "hard time trying to separate" Daniel "as a friend" from Daniel "the mentor." These descriptions convey a close relationship that has grown since they were first matched.

“It's [been] more of a transition to companionship. [Now] it's more of a friendship," Daniel responded five months before when asked what their relationship looked like at the 17-month mark. He elaborated: "like it is someone who I don't have to see or I don't feel pressure to see all the time but then when we do have conversations we just picked up from where we left off or it is just really easy-going."

At the 17-month mark in their relationship, their interactions seemed to show them at ease with each other, often peppering humor into their conversations, even when they were talking about subjects that could be difficult and painful, like the end of a relationship, sharing struggles about coming out, or dealing with issues with friends or family.

A good example of how comfortable they felt talking about difficult and personal issues appeared during our first interview, when Daniel and Tony were asked to reflect upon and identify important milestones in their relationship: 
T: Hmmm. Well, “Daniel breakup” was like huge. (Tony laughs)

D: Yeah, well, so were these. (Daniel points to the word "firsts" listed on the paper.)

T: Well, like "first love" but I don't think it was love. I think it was...

D: Describe it for me.

T: $\quad$ OK. I am going to say infatuation. I was like I really really liked him as opposed to like other times where I just kind of...

D: $\quad$ First love like? OK?

T: $\quad$ OK. Let's say that.

D: Ahm. These were all like really highs. Like this was like manic depressant. Erm. Depressive. And this was like amazing.

T: Just confusing moments for me. (Tony gives a short laugh.)

D: And this was like this (Writing down the words on the paper)

T: $\quad$ OK (Tony laughs.)

D: Well. This was good.

T: $\quad$ It was? (Tony laughs.)

D: Wasn't it? Not really?

T: $\quad$ Ahm. But I ended up breaking up with him for a reason. (Tony gives a short laugh.)

D: Yeah. But there was clarity at the end of it all. Remember?

T: $\quad$ Yeah. Yeah there was. That was the whole...

D: $\quad$ You learned something. So I say that is a positive.

T: $\quad$ It is. Don't date people you're not that attracted to. (Tony laughs.)

At the 22-month mark, conversations between them continued to contain similar layers of what could be seen as openness and humor. During our second interview together, Tony shared a story of how he recently broke up with a guy he was dating: 
T: $\quad$ Yeah! I was like, oh my god. And it was over like stupidness. I think, like, one time we were supposed to meet up. You know, we met up, he brought his friend. I'm like oh, so you want to go over to your friend's house and like hang out with your friends again? I'm like, oh, how bout you guys go do that? I'll go meet up with my friend and then we'll meet up for karaoke later. He's like, OK, sure. And then he messages me. He's like, 'OK. Um, I'm a little too tired to meet up'. I'm like 'OK, I'm just going to keep hanging out with my friends. By the way, I went to the movies.' And he's like we were supposed to watch movies earlier, but he didn't want to go to the movies, so I'm like, OK. So we went to the movies, and then he got pissed. He's like, so you went to the movies without me? You decided that you wanted to hang out with your friends instead of me? I'm like, didn't we agree on this? You wanted me to go hang out with your friends all day but I wasn't into it. And then he, like, at one in the morning, he's like, "Hope you have a good life, it's over." I'm like...

D: $\quad$ So dramatic. (Group laughter.)

T: $\quad$ So dramatic.

D: Was the movie good at least? (Group laughter.)

T: $\quad$ Yes, it was. It was perfect. I had a great time.

These personal moments offer an opportunity to see real-world examples of what Daniel described as a "a good give-and-take relationship." He added: "I think that things are good where they are right now. And they work for the two of us, and it's nice to ... it's just a great relationship."

When asked how they got here, how they transitioned from mentorship to companionship and friendship, both Daniel and Tony described a significant event in Daniel's life that served as a milestone for their mentoring relationship. This event was the ending of a long-term relationship for Daniel. He had been living with his boyfriend of three years, and the relationship suddenly ended when his boyfriend cheated on him with one of their friends. Daniel shared the story about how that experience shifted his relationship with Tony: 
I was in a long-term relationship for like three years and we lived together as Tony mentioned. Ahm. And so I had like the perfect home and all this and everything was going to run so smoothly and ah when all that collapsed was when [Tony] would come over and I just I just needed help and that is when I realized that he was someone who had become a friend. That I could share a lot with...He could see that I wasn't somebody that was on a higher pedestal that which...I... you know I was just another person who needed some advice as well. And so it was that. That that prompted me to kind of unleash and just know that it was a duality...

In the aftermath of the breakup, Daniel appeared to be aware of how his role as a mentor was no longer viewed as one-directional. In fact, because he was in need of support and because he had different expectations about how he was supposed to act as a mentor, he wondered if he should continue to volunteer:

And the tables really turned at that point in time, too. Um... where I felt like actually giving up. Like being part of this program because I felt like I um couldn't give anything. I didn't want to be a mentor anymore. I just felt very depleted. And I was just like I can't lead by example like everything had you know and that is when you get caught up in those kinds of moments. You know like what can I give? But in those moments of of ahm like complete loss or whatever you are, you can give. You know you can give more advice or better advice or you reach a common ground.

As Daniel reflected on his breakup, he seemed to view this event as an opening that helped to facilitate a more mutual, authentic, and open relationship with his mentee. His reflection indicated that he had found a new way of thinking about his role as a mentora role that allowed for greater disclosure of personal struggles and difficulty. Daniel was not alone in his thinking about this change. Tony also agreed: "That's when it shifted from like a mentorship to a friendship."

In the aftermath of Daniel's breakup with his boyfriend, Daniel and Tony seemed to recognize a "duality" in their relationship — one that appeared to redefine their expectations of their roles as mentor and mentee. Daniel described this shift: "Then it 
went from more of an education-community-type lesson plan to more of a personal journey through the community and how the community has served me." He added: "So me having gone through a relationship and having...meeting people after the relationship. It was new territory for me, so we were kind of working through it together. So it was nice to have that common ground."

\section{Similarities, Mutual Interests, and Differences}

In addition to the concrete example of how Daniel's breakup with his boyfriend helped Tony and Daniel's relationship move from a mentorship into a friendship, there also appeared to be other factors that helped them to form this bond, including similarities, mutual interests, and a desire to learn from each other. These shared interests seemed to offer opportunities for them to bond in a variety of ways beyond their shared identification with the gay community.

When asked about what their relationship looked like and how similar they were, Tony shared that they both have a love of arts and described hours talking about performances, books, dance, art, and community events. Both joked about how they listen to music together and talked about different artists they dislike and like.

Tony on Britney Spears: "Yeah, I was like, no, the girl can’t do anything."

Daniel on Adele: "I hate Adele."

Both on Rihanna: "We love her."

They told me they go to live music together and forward details to each other about events the other might want to see. Their relationship appeared to be built on a mutual love of the arts that has given them the space to explore music and performance that they both enjoy. 
Their differences also seem to offer additional and nuanced ways for them to explore and grow. When asked about how they see their differences, Daniel and Tony offered insight into what they might have learned from each other. Daniel shared how he learned to listen and to relax more because of Tony's more focused yet laid-back approach: "He can get to the point a lot quicker than I can, and he is very self-directed. But I often speak way too much and he will go offline a lot." He added:

Like I overanalyze like everything and you (looks at Tony) are just like sorry I forgot to call you like three days ago. WHERE have you been? Did you die? What is going on? No it is like no I've just been busy. Like why didn't you just call?

In sharing this story about their differences, Daniel used humor — as he often does — and made light of his tendency to become overprotective with a more independent Tony.

For his part, Tony offered a slight indication of the differences in socioeconomic and family background that they experienced. He also noted that Daniel had a very different experience navigating through his sexual-minority identity than he did: "Like the major difference is obviously family is different. And he has a closer connection to his family than I do. Um, he came out like later than I did. Definitely."

Even while describing their differences, both Tony and Daniel made a point of qualifying that these differences were not something that either one of them viewed as negative. Tony said, “I don't think there was like any moment where like there was a complication due to differences." Daniel added, "No, no. Maybe like food differencessomething like little. Like my view of he likes ketchup and I like mustard.”

In addition to being part of the gay community, similarities and mutual interests between Daniel and Tony seem to have helped them build a bond. Because they enjoy the 
same activities, they seem to have greater opportunities to connect in a number of shared interests. They also seemed to be willing to use that bond to be able to learn from each other-recognizing their differences as a positive and not something that has been a challenge.

\section{Changes in Frequency and Types of Contact}

At the time of our second interview, when considering a mentoring relationship that was almost at the 2-year milestone, Daniel and Tony seemed to be adjusting to a number of changes in both frequency and types of contact. When they were first matched, they had consistent in-person meetings. At the 17-month mark, Tony said they talked on the phone every couple of weeks and texted "frequently." At 22 months, Daniel described a shift that relied more on social media and technology:

D: I think our relationship has evolved over social media.

T: $\quad$ A lot of text messaging.

D: A lot of messaging. Email. Text. Um, that's the way it goes.

Daniel shared more about what this looks like:

I honestly, like when we opened the meeting up today I thought about it on my walk over, and I really honestly do think that social media has helped us stay in contact, really. Like, I don't know if we couldn't text or send a Facebook message or send an email, even though like Tony doesn't sometimes check it that often or whatnot, but to know like from my end that there is a message out there and then for me to like text him, "Did you get it?" Or we try calling, and knowing that we don't just have to meet up or like have a two-hour conversation though we both appreciate talking in person or over the phone as opposed to just having lengthy text descriptions, um, it has helped knowing that someone has extended an arm and that like, their thoughts, and they're like thinking of you, and that they're still there in some other world, and um as opposed to not having that? Like, I could just see that he would post something and then he'd pop in my mind. And, if that wasn't there, there might be lengths of time like three or four months where I didn't see a picture of him, I didn't know what was going on. So, it didn't create a dialogue in my head and create me to, you know, respond in some sort of way. 
So, I think subconsciously it's really helped ahm maintain some sort of foundation in a weird way, though we both don't use it. Like, I use it often, but he doesn't use it that often, like, to check things and such, but it really helps in terms of communicating, especially for me. Because I know that we're so busy. And, I know that even if he doesn't respond that it's still there, that there's still an effort, or to know that he exists because of posts, as odd as it sounds, you know, it's comforting.

Daniel's description helped to convey meaning around how social media and technology keeps them and their relationship connected. While both said that they do not see each other as much now as they did during the early stages of their relationship, they also appeared to be relying more and more on virtual connections to stay present in each other's lives. Status updates on Facebook and text messages appeared to offer reminders and encourage follow-up questions, especially when they were able to see each other again.

Their shared dependence on virtual communication seemed to be accepted by both of them for this moment in their relationship. While it did represent an apparent shift, both emphasized that this reliance was not necessarily a bad thing. For example, Tony said that he does not mind that they do not see each other as frequently: "I actually kind of like that sometimes we don't talk for long periods of time, because it just lets us build on the experience that we have and that when we do talk there is like a lot to talk about." Daniel agreed:

Like it has sort of become someone who I don't have to see or I don't feel that pressure to see all the time but then when we do have conversations we just picked up from where we left off or it is just really easy-going, which is what I like most of my friendships to be like. 
Even with a change to a more virtual and remote relationship, there was a sense that they both were still committed to their relationship and that they trusted in the future of having each other in their lives. For example, Daniel offered:

I think that things are good where they are right now. Ahm. And they work for the two of us and it's nice, too. It's just a great relationship. Like it's nice. Like if we don't talk for a month. Like I feel good when we spend like two hours on the phone or like three hours or I feel good when we finish talking. Like it is nice to hear about all the projects that he is doing and if things aren't going so well then to talk through it but like it always ends fairly positively. Ahm. It's just a really humbling kind of experience.

This quote appears to highlight the connection that has carried on, regardless of the frequency of contact. This quote also describes a level of comfort with not seeing each other as much as in the past. Daniel added that their new rhythm also seems to work, stressing that he feels positive about their future: "And I think it will only get easier."

\section{Researcher Discussion for Characteristics and Processes}

Using IPA analysis, multiple themes for characteristics and processes emerged from Daniel and Tony's account of their mentoring relationship: (a) Before they were matched: Confusion and coming out stories; (b) Greater involvement in the community: A key motivation; (c) The "Firsts"; (d) From mentorship into friendship; (e) Similarities, mutual interests, and differences; and (f) Changes in frequency and types of contact over time. These themes offer a glimpse into what their relationship has "looked like" over time as well as the specific activities and events that appeared to be most significant to them.

The comparison of findings from this IPA study with literature on the characteristics and processes of long-term formal mentoring relationships offers an opportunity to view and interpret Tony and Daniel's relationship through additional 
frames of orientation. This discussion also helps to contrast unique nuances found in their relationship against the backdrop of other empirical evidence and theory. With these explicit goals for discussion, I speak to notable threads between the themes contained within the inquiry of this first research question.

Rhodes $(2002,2005)$ identified the presence of trust in a mentoring relationship as a key condition for youth to access and leverage opportunities for social-emotional, identity, and cognitive growth. As described in the findings for this research question, a core characteristic of Daniel and Tony's mentoring relationship is a shared sense of closeness and a bond that has lasted almost two years. They describe each other as friends, laugh and enjoy similar activities, and appear to have a genuine investment in each other's well-being.

Daniel and Tony described a number of activities that might explain how they were able to form their bond. One potential pathway toward trust in Daniel and Tony's relationship could be explained by Daniel's approach to the mentoring relationship. Daniel spent time getting to know Tony's goals and interests and leveraged these goals and interests to help move him closer to his stated desire of learning more about the gay community. Daniel initially played an introductory role in this process - showing Tony resources in the community, having conversations around his own coming-out experiences, and working with him to process his feelings about dating other men. Later, Daniel interactively supported Tony as he opened up and shared relationship issues with his family.

Daniel's approach in this mentoring relationship appears to be instrumental in nature. An instrumental approach builds opportunities for a mentee to use the mentoring 
relationship to work toward his or her stated goals (Karcher et al., 2006). This approach has been seen to facilitate bonding between mentors and mentees as they work together toward achieving these goals.

Similarities between Daniel and Tony also appear to have played a role in how the two of them have been able to bond and form a lasting relationship. Before they enrolled in this program, both struggled with their sexual orientation and expressed moments of confusion and struggle. They both attempted to date women, and both seemed to have an important need to connect with physical spaces in the gay community as they navigated through moments of trying to figure out the role of their sexual orientation in their lives. In addition to their shared sexuality, both Daniel and Tony have a real and passionate connection to the arts - they can have hours-long conversations about music, performance, theater, and dance. In addition, the two of them have a broad range of similarities, ranging from a shared sexual orientation to a shared enjoyment of activities. Similarity between mentor and mentee seems to be a critical ingredient for facilitating a close and lasting bond (Hererra et al., 2000).

As described in my discussion, trust appears to be a central characteristic of the mentoring relationship between Daniel and Tony. Daniel's instrumental approach as a mentor and the similarities they share seem to hold important weight in how that trust was established. Using Rhodes' (2002, 2005) Pathways to Mentoring Influence Model as a guide, the presence of trust in the mentoring relationship would appear to positively encourage social, emotional, cognitive, and identity development benefits in Tony. 


\section{Benefits and Limitations}

When asked about how Tony benefits from having a gay mentor, Daniel immediately said that they have a relationship about relationships - a space for Tony to think through dating experiences and how to be safe and intimate with someone of the same sex. Many of the other benefits they describe also appear to be related to relationships. Tony has gained support for meeting new people in the gay community and has also learned new strategies to process his feelings related to his family. These benefits, highlighted through themes described below, offer important insight into how Tony has gained opportunities to develop new social and emotional benefits. Most importantly, it also seems to give Tony benefits related to exploring and sharing his identity.

In addition to these identified benefits, Daniel and Tony shared limitations about their relationship, for instance, they do not have enough time to be able to see each other as much as they would like. They also offered insight into how mentoring relationships between gay mentors and gay mentees may struggle due to issues of attraction and boundaries.

\section{Support for Dating: A Relationship About Relationships}

Daniel and Tony described that their mentoring relationship held the benefit of offering a unique space to "process" and talk through other relationships in their lives. Notably, this included talking about dating and sharing thoughts about romantic experiences with someone of the same sex. In regard to this topic, Daniel said:

I guess our relationship has a lot to do with relationships themselves and how to identify like when you are in lust or when you are in love or how to go out and find someone or do you meet someone online or do you meet face to face? So 
ahm how do you find somebody? How do you trust somebody? There has been a lot of that kind of stuff, too.

This quote hints at the range of ways Daniel supports Tony as he explores same-sex romantic relationships and tries to build intimacy, giving him the space to talk about how to meet other people in the gay community, trust, and explore what it means to be in love with another person.

A concrete example of how this space was used to process romantic relationships occurred during our second interview, when Tony opened up about his fears around how he should behave and think when he is with another man in a romantic way. Daniel worked with him to think through what this might mean for him:

T: $\quad$ I just realized that I don't really treat guys the way I should. I feel like I don't have the ability to love somebody properly right now, so I just needed a break to figure out how I can learn how to love somebody.

D: Well, that will just come when it comes. Right?

T: Yeah.

D: It will. If someone comes around...you'll like learn to...you'll just change without even realizing it. And "Oh look, I have a heart."

T: $\quad$ No. I feel like you've got to be open to it at this moment or not.

D: $\quad$ You do. It's true.

T: $\quad$ Yeah. But to be open to it I feel like I hear about so many bad relationships. I'm kind of even afraid of the idea of falling in love with somebody. So it's not really happening right now. I need to work on that.

In this example, Tony appeared to open up to Daniel about his fears and his concerns about being involved romantically with another person. While Tony shared his concerns, Daniel seemed to listen and respond to him in order to offer support, affirmation, and encouragement. This back-and-forth felt direct and nonjudgmental, giving the impression 
that both mentor and mentee were working together to actively find resolution for Tony's concerns. Daniel seemed attuned to Tony's needs.

In addition to their discussions about love and intimacy, Tony appeared to internalize lessons learned from watching Daniel. For example, Tony described how Daniel served as a role model for him and helped him to see a future life as a gay individual he might not have visualized for himself before:

T: Um...there was a lot of conversations around like...well...He was telling me about the relationship. Um, it was like very reflective for me because his relationship was like the first long-term relationship I had heard of with um...queer folks and...(to Daniel) do you mind if I say it?

D: $\quad$ You talk. (Daniel gives a short laugh.)

T: $\quad$ To just hear that like he cheated with his friend and I was like oh, OK. This does happen. Because I was so in the idea that they are in this longterm relationship and it is just going so beautifully and maybe I can have that at one point which I am not doubting that that could happen. I just also now see where there is a reality where it is not everything is so black and white. So, I don't know, it was just very reflective for me looking in terms of really looking at relationships for me in very objective way. In terms of advice I gave to Daniel about that I think it was trying to reassure him that he is a great person.

Tony seemed to be highlighting just how important it was for him to be able to see his mentor have a long-term relationship with another man. Before he met Daniel, he had never seen that before. Daniel's role modeling appeared to help him better visualize that possibility for himself. Even though he watched Daniel's relationship end, Tony also appeared to indicate that the breakup did not cause him to outright reject that possibility for himself, but he began to recognize how complex a relationship can be, with shades beyond good and bad_-giving a more authentic and realistic view of what a relationship might look like. 


\section{Greater Comfort Meeting People From Gay Community}

According to Tony, a second benefit of the relationship with Daniel was support around connecting with other friends in the gay community. When reflecting on what his experiences were like in the community before he was matched with Daniel, Tony said, "I wasn't sure you could make friends here." His doubts appeared to be related to previous negative experiences when he first tried to connect with other youth:

I didn't really talk to a lot of queer people, especially since like the one queer person I did talk to when I was like 16 was kind of a jerk. He like made me feel like some of the things they said about queer people is really true and that I just didn't want to be a part of the community.

His story about what happened during this initial encounter offered insight into how this experience felt for him:

S. told me, because she was a mutual friend, um, that he was for sure gay, that he's gone up to her. So I went up to him and was talking to him, and I asked him, "Are you gay?"

He's like, "What? Why would you ask me that?"

I'd be like, "Oh. I just wanted to know if you like wanted to go out to eat or something like that."

And he's like, "No, are you gay?" And then he started yelling and was like "Eff you!" blah blah blah, "I'm not gay."

I'm guessing he's been bullied a lot for it. And at that time, I'm kind of dressed pretty straight, so I'm pretty sure he didn't get what was coming across. Um, and he was very abusive with his language. And I just felt like extremely defeated and ugly, and I don't, I don't know. Once again, I was just like extremely ashamed and embarrassed, so I didn't talk to him again. And it was hard, because we were both student leaders, and like in a lot of clubs together, so we would go to meetings, but like we wouldn't talk or look at each other or anything like that.

Um, I told S. about it, and that was about and she was just like, "Oh, you shouldn't be bullied like that and I'm just not sure what was happening there or why he was being such an idiot. I'll go talk to him." 
I'm like "Don't talk to him. That's the past and I just want to be over it." Tony's account highlighted a difficult first attempt to connect with other youth from the gay community. His experience offered an unflinching look at how vulnerable the process of trying to reach out must have felt and how it left him with a negative impression filled with embarrassment and shame. This impression appeared to last until he had the chance to have more positive connections with other people in the community, especially by being able to connect with Daniel.

Tony said that Daniel helped him rethink his initial, negative first impressions and to help him dispel the idea that other gay people might treat him like the guy from his school:

I felt like maybe that was true and then I didn't want to be part of the community and Daniel made me see that that isn't really the case and that's why I am comfortable making friends with other queer people and I am like comfortable going into all these other queer spaces which I tend to do a lot.

Tony elaborated, directly attributing how he has benefitted from being matched with Daniel:

So, knowing that I was able to make friends with Daniel allowed me to be able to make friends with a lot of other people and that's why I have so many queer friends right now in my life right now just because Daniel made me comfortable with talking to other queer people.

Tony's remarks indicated how his relationship with Daniel might have helped him feel more at ease and comfortable with other people, especially peers, from the queer community. This also seems to show a change in trajectory in his thinking about other people in the community; Tony appears to have used his positive experience with Daniel to open himself up and become more engaged with other gay and queer people. 


\section{Support to Work Through Family Issues}

The mentoring relationship also seemed to give Tony the benefit of a unique space to process and work through issues he was having with his family. During our first interview, Tony described the difficulty he was experiencing at home and how hard it was for him to address issues directly with his family:

When my sister was staying at my house and I just felt like my space was really invaded and I was just feeling really toxic up here because I have a hard time. I don't have a hard time expressing myself with other people but when it comes to family it is really hard for me to like talk to them even though like I feel semimore comfortable, I still have a hard time talking to them. So, I tend not to say much to them.

Tony seemed to recognize a barrier to communicating with his family. He described his difficulty in being able to ask for what he needs from them-in this case, space. Yet Tony also described having difficulty accessing support from people outside his family in order to process his feelings about his home situation: "There was just times when I wanted to talk and I just didn't feel like talking to any of my friends about it, especially when it came to like the family."

Yet, his relationship with Daniel appeared to make him feel comfortable enough to share his feelings, vent, and process in ways that other supportive relationships may not have. As Tony said:

Usually, I just don't talk that much about my family with anybody. I'm (short pause) just 'cause I just never had a deep connection with family so I never thought it was something to talk about. I just rather not talk about it and talk about other things that are going on in my life. So, um, the point where I was able to talk to him about family and feel OK with that...I was like "OK. I feel really safe talking to him." 
Tony's comfort with Daniel and his willingness to share more about topics he had difficulty sharing with other people speaks to how the mentoring relationship has created a unique space for him to access support on issues related to his family. He shared that the space to talk with Daniel helped tremendously: "But after venting, I kind of didn't feel so overwhelmed anymore."

Tony said he even used Daniel to help him process whether to move out of his mother's house:

Yeah, I think at that point I was contemplating moving out. And also like moving in with my dad, moving in with my friends, and then I don't know. At some point after the venting, because I often don't do that, and then coming to a conclusion and letting that conclusion be to stay.

By working with Daniel to talk through, "vent," process, and explore options, Tony decided to stay at his mother's house. This strategy for working with another person to talk through a problem seemed different from previous ways that Tony had typically handled issues, which was on his own.

When I checked in with Tony five months later about his relationship with his family, he said it had markedly improved:

Oh, yeah um, for me, like, I've recently put family at the forefront and like I'm talking to a lot less friends because I used to be like really social where I would talk to every and anybody. But now I just talk to, like, a few, and my connection with my family has grown quite a bit just because I spent like two weeks or something like that just at home. Like, around my family, so I am closer with like my sisters and my mom. I'm really close to my mom.

Tony's improved relationship appears to be the result of how he has made them a bigger priority in his life, especially by committing to spending more time with them. This is a marked difference from our first conversation five months before and can be attributed, in part, to his relationship with Daniel. 


\section{Limitations of Time}

One of the limitations that both Daniel and Tony noted about their relationship involved time. When asked about what the drawbacks of their relationship were, both Daniel and Tony identified that they did not have enough time to spend together. This concern started when they were first matched, as Tony wondered whether they would be able to make the commitment to connect:

T: We both realized that we were extremely busy people, and I'm like, OK, so when is this going to work out?

D: Yeah.

$\mathrm{T}$ : $\quad$ Because I was like in every club, performing at school, doing, like, everything, so I'm like, I don't have time on these days.

D: Yeah.

Even 17 months into their relationship, at the time of our first interview, Tony remained busy. When asked how often they were able to connect, Tony said:

We are both like really busy people. As in...we like get into a lot. And then like...I think we get into too much. (Tony laughs.) Like I was just really busy the past couple of weeks rehearsing for dancing and singing and doing presentations in school. It was like ah OK too much work.

Daniel also described challenges with time:

But it would be nice to be able to go see each other's work because we are both very artistic and he does a lot of dance and singing and stuff like that and we get involved in so many projects but it is very difficult to...kind of schedule everything in.

Although both lead hectic lives, they also indicate that they are not bothered by not seeing each other as frequently as they would like:

D: But I know that that opportunity will come again at some point. It's just not at the moment, which is fine. It just is what it is. Right. 
T: It's not like something that bothers. I don't think it bothers either one of us just because we both are actually really busy. Like I said we both load our schedules pretty heavy. So like this week...so that like I decided to take this week off and not do much of anything. Which I don't like (laughing).

D: Right. That's...

T: $\quad$ So, like next week. I am starting to record new music. I am starting another dance project. Well. Two dance projects and then I am going back to working.

The fact that both lead busy lives may have also helped Daniel to recognize that Tony was self-sufficient and able to ask for help as needed. As Daniel recounted:

[When] I realized that he was self-sufficient or what the relationship was, or what he needed out of from me coming to [the mentoring program], it was a lot easier and I trusted him and knowing that he would if he had a problem that he would just call or if he would want to hang out that he would just call and it wasn't just all on me it was a lot easier.

While Daniel and Tony describe hectic schedules filled with activities and events, they also seem to indicate that this limitation has not detracted from their ability to remain in each other's lives and to continue to have a bond. While they identify limited time as a drawback, this potential challenge also seems to be something that they have actively worked to overcome in their thinking about the relationship and each other.

\section{Concerns About How to Address Boundaries and Attraction}

Tony and Daniel described concerns about how to address attraction and boundaries in mentoring relationships between gay adults and gay youth as a potential drawback and limitation. When they were first matched, Daniel said that he paid close attention to potential signs that Tony was developing an attraction toward him, especially because he was still trying to figure out his own boundaries about sharing his personal story with Tony: "And I was on the lookout for things at first and was just trying to 
navigate through because I just didn't know what was going on.” The program had given each mentor specific training and one-to-one support on this issue and had conducted a home visit to assess risk. Even with this support, Daniel still worried: "Hopefully, no sexual tension arises."

Although both of them say this was not an issue in their relationship, Daniel and Tony shared thoughts and concerns about how other relationships in the program were struggling with attraction and boundary issues. Tony, for example, shared stories about other mentees "falling for their mentors" and described peers who had issues around controlling their feelings:

I know that that is actually happening, because a lot of my friends are like, "Oh, you are in the program" and I am like, "Yeah, you should go and try it out" and then they like ask for like a 27-year old and...they don't know what to do cause my friends are sometimes like introverted and then it's just weird, especially because they don't have as much control. So like they say, "I am really attracted to my mentor." I'm like, “that's your mentor. You can't."

Tony's description indicates that several of his friends have struggled with their attraction toward their mentors, especially mentors who are younger and closer in age to the mentee. He also seemed to express a clear line around what is and is not acceptable when thinking about a mentor in a romantic way_it should not be done.

Although his peers may have been struggling with issues of attraction, Tony clarified why this was not an issue for him:

But they just kind of fell for their mentors and it just wasn't right, there was no connection there. Um, for me, I think it was the fact that I kind of went in purely to ask questions. I just wanted to know about the queer community, and I felt that somebody who'd been in the queer community could help me do that. And so that's why I kind of wanted a mentor. 
Tony appeared to draw contrasts between mentees who may have other intentions for enrolling in the program and his focused desire to learn more about the community. He seemed to know what he wanted out of the relationship right from the start — and that did not involve meeting a mentor to find a date.

Although Tony offered what appeared to be a general criticism of the role of his peers in creating an uncomfortable situation in their mentoring relationship, he also seemed to express concern about one of the other mentors not being able to diffuse the tension in a way that was respectful to the mentee:

Not just that but I felt like if you were going to have a mentorship position that you should be in that position where you are trying to make that person feel comfortable in a sense, so obviously the mentor wasn't making him feel comfortable and he wasn't able to open up so I just felt like it was a fail on the mentor's part.

Tony's expression of these challenges seemed to highlight a concern about making sure that mentors are able to address mentee issues, including attraction, in a way that is respectful and positive. He specifically worried about younger mentors not being able to accomplish this:

Sometimes I think it has to do with age. I find that a lot of the younger mentors actually aren't doing so well with this just because usually like the mentees will request a younger mentor but they don't exactly know what to do.

As he described his concern, Tony appeared to offer caution about finding the right mentors to work with mentees, including mentors who are prepared and able to handle these difficult situations.

From a mentor's perspective, Daniel agreed that dealing with attraction might be an important challenge for mentors to address appropriately with their mentees. In circumstances where a mentee expressed an attraction to the mentor, Daniel argued that 
mentors would probably require additional support; he worried that some of them might quit as a volunteer because of the intensity and commitment involved:

And I am not quite sure if a lot of people don't just give up. A lot of people don't, like, they just don't have anything really invested in it and they do it and they get matched and they probably do it for like three months and it is like six months of their lives and then they just drop off the face of the earth. But so I am just wondering if there's like more help that can be had like I don't know if [the mentoring program] has services at all for that. Like I don't know if there is help available or there is follow-ups that happen.

Daniel's observation seemed to indicate that he believed mentors in relationships between gay adults and gay youth could benefit from additional support, especially targeted support from program coordinators around how to address issues of attraction and boundaries. He appeared to note that, without ongoing support when needed, mentors may end up terminating their relationships early.

\section{Researcher Discussion on Benefits and Limitations}

IPA analysis of interviews with Daniel and Tony uncovered numerous themes for perceived benefits and limitations. Themes for benefits and limitations consisted of: (a) support for dating — a relationship about relationships, (b) greater comfort meeting people from the community, (c) support to work through family issues, (d) the limitations of time, and (e) concerns about how to address boundaries and attraction.

Comparing findings from this IPA study with other literature on mentoring benefits and limitations may offer additional insight into how to understand the ways in which Tony has been able to benefit from this mentoring relationship as well as describe key concerns about their relationship. This understanding is of central concern to the second research question. 
Tony identified numerous ways in which his relationship with Daniel was beneficial to him. He described the importance of being able to have the space to vent and process and to learn ways to problem-solve with his family. He talked about how Daniel gave him new ways of thinking about friendships and relationships that ultimately helped him to see people from the gay community more positively. Tony also described seeing Daniel as a role model. Tony said that seeing Daniel in a long-term same-sex relationship offered him a glimpse of that possibility for himself. As these stories indicate, most of Tony's identified benefits appeared to be related to social relationships and the way he thinks and feels about his place with others.

Social, emotional, and identity development are cited as a key benefits for mentees in trusting relationships (Rhodes, 2002, 2005). Access to positive role models, formation of healthy attachments, and new ways of thinking about possible selves have been cited as aspects of the pathways through which a young person can benefit from a mentoring relationship.

Tony and Daniel both described the limitation of time in their mentoring relationship as well as concerns about setting boundaries and receiving program support related to issues with attraction. Tony and Daniel talked about not having enough time to spend with each other and said that this had been an evolving problem for them since the beginning. While they described this as an issue, they also talk about how they have been able to create strategies to address their concerns - depending more on social media, for example, and reflecting on how the passage of time can actually give them greater opportunities to connect when they meet in person. 
Meeting consistently and frequently appears to promote opportunities for mentors and mentees to bond (DuBois \& Neville, 1997). Also, longevity and duration of mentoring relationship are closely linked with enhancing positive outcomes (Rhodes \& Grossman, 2002). Although Daniel and Tony may not have as much time to meet regularly and consistently like they did during the early months of their relationship, both indicate that they frequently text and continue to make in-person time with each other.

Because they are in an evolving and changing relationship, Daniel and Tony's concerns about the limitations of time may also be reflective of the current stage of their relationship. With the passage of time, their relationship has moved through different stages. Keller (2005) might describe their relationship at the maintenance stage — where they both have a sense of reliability and trust that their relationship will continue. This stage is often ripe with opportunities for growth, disclosure, and familiarity.

A second concern that Tony and Daniel express is related to attraction and boundary setting. This limitation is important for both of them as well as for several of Tony's peers. Tony talked about concerns related to mentor preparation and mentee preparation for their roles. Daniel also described a real targeted need to offer program support around these specific issues.

Program support for mentoring relationships has been seen as a key element for fostering close and safe relationships (Dubois, 2002). Programs that have strong screening tools and provide training and ongoing case management are seen to be associated with the greatest outcomes for youth. Tony's and Daniel's concerns around this issue seem to be closely linked with the need for program support for all mentoring relationships. Yet they also hint at specific needs that might need to be addressed for 
mentoring relationships involving gay adults with gay youth, including additional training for mentors and mentees and closely supervised case management.

As described in my discussion, Tony noted a number of benefits from his relationship with Daniel. While most of these benefits included opportunities to increase social relationships, Tony also described new ways that he was able to see himself and his identity through Daniel's role modeling and new ways that he was able to solve problems through Daniel's support. Both mentor and mentee also highlighted specific concerns related to training and program support for match duration-including the need to train and provide ongoing case management around issues of attraction.

\section{Unique Support for Sexual-Minority Identity Development}

Support for sexual-minority identity development seemed to permeate much of the characteristics and benefits identified in Daniel and Tony's relationship. They both described how Daniel worked with Tony to introduce him to resources in the gay community, act as a positive role model, help Tony feel more comfortable meeting other queer people, and process his emotions about dating and experiencing rejection. In addition to these important characteristics and benefits, Daniel and Tony also identified how their mentoring relationship offered unique types of support that Tony may not have been found in other settings.

Findings within this superordinate theme offer insight into how mentoring provided Tony with a unique, individualized and comfortable space to explore his identity; a mentee-centered approach that built in opportunities for Tony to instrumentally work toward his goal of learning more about the gay community; and 
support how Tony used his mentoring relationship with Daniel to shift his family's way of thinking about the gay community.

\section{A Unique and Individualized Space to Access Support}

Between the time he initially labeled himself as bisexual and the time he enrolled in the mentoring program, Tony described a number of ways in which he tried to gain support related to his sexuality, including searching online:

I ventured online to figure out more about my sexuality after I figured out what the hell was going on with me. Um, I dated quite a bit of girls between, too, but like those are...yeah... OK, so after I found out [about the term bisexual] my friend told me that I should search online and figure things out. So I did and I found I think it's called [website name]. Um, it's a website just for youth to go online and talk to other youth. So I just went on a lot of forums and like read what they were saying. Um talked to quite a few people and made a few friends on the site.

Tony noted that he used the resource to learn more about the gay community. He especially noted how he was able to use this online support as a way to try to connect with his peers - other gay and bisexual youth from the community. Yet, he noted, these experiences were not always positive for him:

T: Um, at one point...there was like this like really cute guy, and um I had a black-and-white picture and because I am of mixed race I put "mixed" and then we were talking for like a week and then he's like "Oh, send me another picture." And I showed him a picture of color and he's like, "Oh, you're black." I'm, like, "What?" Like yeah. And then he blocked me on everything, and I'm like...

D: Oh, you told me this story.

T: OK. Hmmm. I don't know how to process this right now. Um, so I told nobody actually, because I am like oh my god this is so embarrassing. It reminded me of the first time I had been rejected, which I think was a couple months prior to that. 
Tony's experience feeling embarrassment while receiving support in this online space brought up other feelings of rejection, ultimately causing him to stop using this resource.

He described keeping these emotions to himself, not knowing how else to handle some of his initial encounters with other people from the gay community.

After taking a break to "focus on school and not on my identity," as he said, Tony eventually tried to connect with other people in the gay community again. He said he tried again because he wanted "to know about the actual community. I'm like this cannot be the only place where I can meet other queer people." So, he attempted to gain support from an in-person community center in the area.

However, his experiences with the community center did not give him what he was looking for, either. “They had a bunch of programs, but I didn't like any of the programs that they have," he said.

Tony also tried to attend a peer support program. Again, he decided this was not the right fit for him, saying that he did not feel like he connected to other youth there:

T: $\quad$ When I went to these meetings and stuff like that. Um, I didn't really like the youth there. Um, they weren't bad or anything like that. I was just, like, you know, I just didn't feel comfortable.

I: With other, like, with other people around? Instead of having just like one other person that you could spend time with?

T: $\quad$ Yeah. Because it's like when I went there, a lot of them knew each other and they were friends and stuff like that. And I'm just like, I don't know how to approach any of these people. And then like I just the first time I went there I remember I went there by myself. Um, I just kept thinking, who you are in my head through the whole meeting, cause I'm like OK, just go and be yourself, and it doesn't matter if they don't like you like that, you're not looking for a relationship with them. Hopefully they don't think you are. Just talk to somebody. 
Tony's description offers insight into how he felt like he did not belong, even when he was trying to connect with other young people from the gay community. He shared how uncomfortable it was trying to break into an established group and also indicated that he was worried about being judged by them. After attending a few more meetings at which he felt uncomfortable, he decided to try another approach at gaining support—he applied to be part of the mentoring program.

As previously described in "The Firsts," Tony talked about how his first meeting with Daniel felt "comfortable." They ended up talking for three hours, and Tony identified feeling "safe." The contrast between his experience in the mentoring program and his previous attempts trying to connect online, in the community, and with other queer youth is notable. His mentoring relationship appeared to be the one support that he chose to continue. This was also the one support that he linked with feeling comfortable and safe.

In addition to providing Tony with a safe and comfortable space, Daniel offered additional insight into how their mentoring relationship was a different type of support:

I mean it's just like getting to know somebody else through the community in a very different context, which is something that I am happy about. Not just meeting a friend or there to be any like sexual energy going on or like going out and meeting somebody. It just has something to do with this specific community which is really nice for me and it grounds me and gives me a sense of purpose and a place and that there is good in the world, and you know what I mean? I mean like so for me it encompasses all of those types of things so ahm yeah. And knowing that there is a place where we can connect that is safe. I like that that is where it started off. And it is nurturing and there is a place for it to grow. So, I am glad that there was.

Daniel offers his view about how a mentoring relationship in the gay community is different from other relationships - especially in how this type of relationship offers a 
safe and purpose-filled space for individuals to get to know each other in a platonic way. For Daniel, like Tony, the opportunity to form a mentoring relationship in the community is unique and seems to be a solid foundation for the strong relationship that they developed.

\section{Ongoing and Responsive Mentee-Centered Approach for Identity Exploration}

Tony shared his struggles and confusion around how to label himself and his sexuality before he signed up to receive a mentor from the gay community. He described not having language that he could use to define who he was until a friend told him about bisexuality. While he adopted this term, he also stressed that it was the "closest thing I could connect to at the time."

At the start of their mentoring relationship, Tony continued to label himself as bisexual. While he retained this term to describe himself, he admitted that he was still trying to figure out whether it was the best definition. His struggle for self-definition related to sexuality is something that continued well into his relationship with Daniel. During our first interview, at the 17-month mark in their relationship, Daniel and Tony talked about this:

D: $\quad$ Because you were questioning your sexuality when we first met, too. You weren't fully a gay male. You were still bisexual in a sense or you were still exploring that then. I don't know if you still are.

T: $\quad$ I am. (Tony laughs.)

D: I can see that in your eye. You are like...well...(laughter)

Tony began to clarify, offering Daniel a more complete explanation of his thinking about his sexuality at that moment: 
To clarify, I am bisexual still. I just like am currently at a point where I had dedicated like 16 years to just dating girls and I think it is OK to talk to guys for a while. I also came to this realization that I thought that I couldn't commit to a relationship to a girl because I never explored that other part of my sexuality as being a bisexual man and that it isn't true that I just can't commit to a relationship (Tony laughs).

In Tony's explanation, he highlighted how he wanted to understand the part of him that he had not had the chance to fully explore before. This part- his attraction for men-was something that Tony was trying to learn more about and was one of the main reasons that he was looking for support from a mentoring program that matched gay adults with gay youth, indicating that he wanted to find someone that he could work with to process his sexuality and to learn more about the possibilities of the gay community. Tony elaborated by saying that he "wanted someone that was comfortable sharing their experiences" and that he wanted the "chance to explore gay sexuality through conversations."

As described in earlier themes ("the firsts", support for dating: a relationship about relationships, greater comfort meeting other people from the gay community), Daniel initially responded to this request by creating targeted and structured opportunities for Tony to explore the community. For example, Daniel supported this goal by going with Tony to the bookstore to pick up gay literature for the first time, taking him to the Pride Festival for the first time, holding conversations about dating and relationships, and helping Tony feel more comfortable so that he could eventually connect to resources and opportunities within the gay community on his own. These activities all focused on Tony's initial interest in learning more about himself and the community. When reflecting on why these activities were important, Daniel said he felt like it was important 
"to make others aware that there is a community and that it's available if you are just open to it."

After Daniel initially introduced Tony to these community resources, the mentee ended up going back to these places on his own. For example, Tony talked about returning to the bookstore they had visited a year and a half earlier and recently rereading the book he had bought there:

D: Oh the bookstore. The bookstore was very...

T: Oh yeah. I got my book there.

D: You got your first book. You first piece of literature at the bookstore.

T: $\quad$ My first piece of gay literature.

D: Right.

T: I don't know if you have ever been back?

D: I have. Have you?

T: Yeah. They have the remodeling thing there...

In addition to going back to the bookstore on his own, Tony also shared how he frequents "queer spaces" more often, something that he did not feel comfortable doing on his own when he first started to seek out resources.

As Tony gained access to new experiences in the community, he also started to change the way he labeled himself. During our second interview, nearly 22 months into their relationship, Tony began to label himself as "queer" instead of "bisexual." He then described what this word meant for him:

Well, they ask me, um, are you gay? I'm like, OK, this is how I feel. I'm queer. Meaning, whatever that means to me. So that just means that I like guys, I'm 
sometimes attracted to girls but not as much as I'm attracted to guys. And right now for me that just means talking to whoever I like.

His use of this term seems to parallel his exploration of the gay community; he seems to have started to construct his own language for himself whereas before he internalized language that others helped him to find, such as his use of "bisexual" after his friend's suggestion.

During that second interview, Daniel also reflected on the changes that Tony has undergone through the course of their relationship. Daniel also described how the role he has played in the mentee's process has also given him the opportunity to reflect and benefit:

It is different from other relationships for me in that it allows me to kind of speak from a different place and reflect on my coming-out experiences, especially more at first when you (Tony) were asking questions and you were unaware of the community and all that. It forced me to go back and think about what I thought about my first relationship or how to navigate through that or what it was like to hold somebody's hand for the first time and or actually feel something for a guy for the first time and what that really felt like. And it made me go back and really reflect on what those experiences were like for me so I could kind of talk about them, so it was kind of therapeutic in a sense. And it was free.

Daniel's comments highlight the growth that both of them have experienced over time and the ways in which he offered ongoing and responsive support to Tony by remembering his own coming-out process.

At the 22 month mark in their relationship, a shift in conversation topics seemed to prevail-Daniel and Tony openly discussed issues and challenges related to dating. These exchanges seemed more interactive in nature and far removed from earlier conversations when Daniel explained ways to meet and get to know other people from the community. During our second interview, Daniel seemed to continue offering advice 
and guidance to Tony but now offered reassurance as well—-helping Tony process new events and experiences that were part of his exploration of being gay. This represented a marked change from their early moments walking around the neighborhood, introducing Tony to difference resources.

The shifting and ongoing support that Daniel providing Tony over 22 months highlights a unique way that Tony seems to have been able to access shifting support that has responded to his needs over time. In the early months of their relationship, Tony and Daniel's activities seemed to be filled with introductory lessons and explorations. Tony appeared to undergo internal shifts in the ways he labeled himself and interacted with other people in the gay community, Daniel's approach seemed to shift as well—creating a more interactive space for both of them to process, problem-solve, and work through challenges they both faced. This ongoing and shifting response- this mentee-centered approach - appears to offer a unique way for Tony to leverage support.

\section{Leveraging the Relationship to Raise Awareness in Others}

When Tony applied to be a mentee in the program, he had not told his family about his struggles trying to define himself. Although he discussed being open with his classmates, Tony was still not open with his family. In fact, he did not come out to them until about a year into his mentoring relationship with Daniel. He described how they handled it:

Oh, um, the first bit was just like ignoring it. And then recently they ask me about stuff like whether where I'm going is a queer space but they won't say queer space but like "Is this a gay thing?" Um but yeah, usually that's what they're asking. They're asking me about relationships, although I'm not that open. Especially not...I'm not really. I'm open with my sisters just because they're open with me. Not so much my mom because there's like still that sense that she 
doesn't exactly want to hear it quite yet. But we've talked about like some of my relationships. Just not really in depth. Definitely not in-depth.

When asked if and how his family relationships had shifted over the last year, Tony described that they had become more supportive:

T: $\quad$ It has gotten a lot better, to be honest. Like, even my brothers are asking me about it, asking me about my sexuality, and we've warmed quite a bit.

I: Like how do you explain it to them? What do you-what do you say? And how, like, have they been supportive of, like kind of reaching out to learn more, like, or have they kept it, like, not talked much about it?

T: $\quad$ Oh, no, they want to go to clubs and stuff and want to go to all the queer events and I'm just, like, sure. (Group laughs.)

Although Tony said that his family has been accepting of him, he also described the complex reactions that they may hold toward other people who from the gay community.

On one hand, he shares that they have been accepting of him:

T: $\quad$ They're accepting of me, but I don't feel like they're accepting of queers in general, just because, well, I'm their brother. So they get like offended if somebody makes fun of, like, somebody who's queer or uses gay as like a derogative.

On the other hand, he also notes that they may not be completely comfortable with other people that identify as gay:

T: $\quad$ But for the most part, like, even my sister's like, I'll go to the club but I hope no lesbian comes up to me because I ain't into that. I'm like, you know you could just tell her, "No." Like, if a guy came up to you, what would you say to him?

I: $\quad$ Yeah. Right.

T: $\quad$ She's like, well, “I would tell him no, too, but it's different.” I'm like, "It's not different."

As Tony processed his sister's comment, he also highlighted how he reacted to her - trying to give her another way of looking at the situation. Tony appeared to be 
educating his sister and raising awareness of how her views differentiating gay and straight people may be hurtful.

Tony's example is even more remarkable for the level of difficulty he previously shared about being able to relate, confront, and talk to his family about things that have been bothering him until after he had been able to vent and process with Daniel. These opportunities seem to be made more available as Tony described gaining skills related to strengthening his relationship with his family.

In addition to practicing new problem-solving skills that he practiced with his family, Tony appeared to use descriptions of his mentoring relationship with Daniel to educate and raise his family's awareness of the gay community:

T: Yeah. I've mentioned him to my mom and my sisters, but they haven't met him.

I: And what have you said about that to them, and how did they react to it?

T: $\quad$ Um, at first they were like, so what do you and your mentor do? I'm like not sex, but he has talked to me about safe sex and stuff like that, but I already knew and was like not really sexually active when we first started talking and so it didn't really matter so much, um but most of it was just getting to know the community. Um so I just explained to them that he basically shows me around the neighborhood and tells me kind of what gay life was like.

Tony also seemed to be trying to confront his family's assumptions about what it means to be gay—especially his concerns that they might have assumptions that because he is gay, he is more likely to be engaged in sexual activity with other men. By talking about his mentoring relationship, Tony appeared to educate them that being gay was more than and different from the sexual behavior attached to it. This differentiation seemed to be important for Tony to share with his family. 
As Tony gained problem-solving skills from Daniel and also progressed in his openness with his family, he seemed to feel more confident educating them and helping them find greater comfort in his sexuality and his affiliation with the queer community. In addition to learning more about the gay community from Daniel, Tony also seemed to be sharing that gay community with his family_educating them and helping them to gain a more realistic view of what it means to be gay.

\section{Researcher Discussion on Support for Sexual-Minority Identity Development}

Using IPA analysis, findings for unique contributions for sexual-minority identity development were presented: (a) A unique an individualized space to access support, (b) Ongoing and responsive mentee-centered approach to support identity development, and (c) Leveraging the relationship to raise awareness in others. These findings highlight ways in which Tony and Daniel describe how the mentoring relationship appears to have offered unique support for Tony as he engaged in the process of exploring his identity within the gay community. Previous literature on sexuality in gay youth and support for sexual-minority identity development offer important starting points to understand these findings.

However, before this discussion occurs, an important reminder regarding the interwoven structure of themes within this study must be made-support for sexualminority identity development seems to undergird large portions of what this relationship "looks like" as well as areas that Tony and Daniel most visibly describe benefits. Because so many described features and key milestones of their relationship appear to be linked with support for Tony's process of exploring his identity and the gay community, this theme truly provides a foundation for many parts of their relationship. Themes contained 
within this superordinate theme help to explain unique ways that support occurredthrough access that might not have been previously available, through an ongoing and changing support during their 2-year relationship, and through the ways that Tony reached out to change and alter the opinions of his family to modify and "retrofit" systems of support available to him.

In order to understand how Tony might be accessing support for exploring his sexual minority identity through his mentoring relationship with Daniel, literature and research on teen sexuality offers an important starting point to understand what Tony may be experiencing during this moment of his youth. Savin-Williams (2005) argued that sexuality is difficult to define, especially for the "new" gay teenager growing up today. Many youth, like Tony, do not self-label as gay but engage in same-sex sexual attraction and same-sex sexual behavior. When they do use labels, these labels may shift and change. According to Savin-Williams, this period of adolescence is quite fluid —and reflects a difference for this cohort of youth compared to earlier cohorts that experienced greater levels of struggle. Further, the cultural landscape continues to change- -with greater acceptance of gay individuals. This acceptance seems to pave the way for a new generation of young people that do not have the same stigma nor the difficultly experienced by previous generations. This also has reduced the need for labels (SavinWilliams)

Although Tony has not defined himself as gay, he described having a same-sex sexual attraction and is currently only engaged in same-sex sexual behavior. In addition, the labels that he has chosen to define himself have shifted over time-from bisexual to queer. These changes underscore an important shift that is going on within him. During 
this shift, Tony opened up about feeling confused and uncomfortable. Tony also shared how he is continuing to find a self-label that feels "right." Because of these important clues, a further examination of ways of understanding Tony's fluidity and changing understanding of self is merited. In addition, literature that offers insight into how Daniel might be helping Tony through this process is also vital.

McCarn and Fassinger (1996) described sexual-minority identity development as a series of phases that include both internal and group identification. These phases start at awareness and exploration and include a series of emotions, internal feelings, actions, and social interactions that promote or hinder opportunities to navigate toward a synthesized identity. In McCarn and Fassinger's model, an individual explores their sexual minority identity internally as well as through their interaction with others. As noted, Tony is undergoing an important internal shift that yields important clues for how he has moved from awareness into identification phases. In addition, his interactions with Daniel seem to have also shifted Tony's group identification — giving him a more positive view of what it means to be a member of the gay community.

Tony's positive interactions with Daniel seem to have offered him the space to more positively engage with other people from the gay community. In his past, Tony offered harrowing stories of feeling rejected when he reached out to peers in the gay community. Tony's relationship with Daniel seemed to be the first time that he positively connected with someone from the gay community and that connection seemed to give him openings to explore, build confidence, and see positive possibilities for his future as a member of that community. The role that Daniel played in the process seemed to alter 
and change Tony's trajectory. Ross (2005) offers insight into how Daniel might have offered support.

Ross (2005) stated that mentors can play a role in supporting a mentee's sexualminority identity development by helping the mentee in the coming out process, gaining support for dating and relationships, serving as a cultural guide, challenging misconceptions, and dispelling myths. The mentor plays a role that supports positive social exchanges with other sexual minorities as well as opportunities for the mentee to internalize and think differently about his or her place within the sexual minority community.

In their account of their relationship, Daniel and Tony highlighted a number of benefits and pathways associated with the model developed by Ross (2005) - including learning more about dating, gaining opportunities to learn more about the gay community, and offering the chance to reflect on previous misconceptions about what it means to be in a long-term same-sex intimate relationship. These benefits seem to align with how Ross might identify the ways in which support for identity development occurs in mentoring relationships between gay youth and adults.

Tony also expressed a number of concerns about feeling judged when he was trying to secure support for his identity. These concerns appear to be closely related to social interaction anxiety (Safren \& Pantalone, 2006) which often hinders opportunities for young people to be able to access support, even when it is available. The individualized nature of the mentoring relationship may have been a key way for Tony to overcome this barrier - as he shared that he felt comfortable with Daniel the first time they met. This was in contrast to his stories about peer support programs and online 
resources. Having access to a mentor seemed to give Tony a viable option that ultimately allowed him to achieve the benefits he was looking for.

Support for sexual-minority identity development also offered Tony skills to start to "retrofit" family systems by educating his sisters, brothers, and mother about what he was learning from his mentoring relationship. In addition, Tony seemed to be using problem-solving skills he gained in his relationship with Daniel to rework other relationships in his life. Rhodes $(2002,2005)$ might view these activities reflecting important mediating effects in her model. In this case, Tony appeared to be using what he was learning in his mentoring relationship to promote new ways of thinking in others, thereby creating stronger relationship structures for support in the future as he was directly addressing societal issues related to homophobia and heterosexism in his more immediate family system.

As noted here, this long-term formal mentoring relationship appeared to hold numerous ways that a young person has been supported in his process of figuring out and exploring his identity as a sexual minority. Internal and social support and the unique opportunities contained within a one-to-one model seem to have given Tony a range of perceived benefits. Further, Tony leveraged these benefits to start changing the ways that others may view him and his community, ultimately creating a wave of change that can potentially move beyond the family system. These noted benefits hold important contributions for the facilitative role a mentor might be able to provide around sexualminority identity development. 


\section{Chapter Summary}

Findings from this study have offered insight into what a long-term formal mentoring relationship between an adult and a youth from the gay community "looks like." Key superordinate themes of characteristics and processes, benefits and limitations, and unique support for sexual-minority identity development were described. Of importance, support for sexual-minority identity development seemed to be woven throughout Daniel and Tony's description of their relationship. In addition, unique ways that this relationship gave Tony access to explore and share his identity with others over time were also described — highlighting insight about how support for sexual-minority identity development may occur. The next chapter offers assertions, implications, and recommendations based on these findings. 


\section{CHAPTER 5}

\section{ASSERTIONS, DISCUSSION, AND RECOMMENDATIONS}

Significantly, this IPA study contributes a baseline understanding of a long-term formal mentoring relationship involving an adult and a youth from the gay community. At its core, it addresses longstanding concerns from DuBois and Karcher (2005) about the lack of empirical research that captures the ways in which gay youth participate in formal mentoring relationships. With the inclusion of this study, research on formal mentoring finally includes the voice of gay and queer individuals that have participated in this unique type of relationship - ultimately disrupting a pattern of silence and neglect in research, theory, and practice in the mentoring field. This study also shows what is possible in such relationships - drawing from the experiences and learned lessons of a purposefully-selected match that has been together for two years - giving insight into how long-term benefits for a young person occurred and more specifically providing a detailed look at the pathways through which sexual-minority identity development is supported.

This chapter provides the following: a description of study assertions based on findings from the inquiry, a discussion of this study's contributions to relevant theoretical frameworks and guiding constructs, key recommendations, and a final personal reflection. This chapter is broken down into the following four sections: The first part summarizes the study, including an overview of the research questions and methodology, findings, assertions, and study limitations. In the second part, I discuss three theoretical frameworks, empirical research, and constructs that guided this study and to which the study now contributes; they are formal youth mentoring, sexual-minority identity 
development, and queer theory. Part three examines implications and offers recommendations for future programming and practice, policy, research, and educational leadership. The fourth and final conclusion describes personal insights and reflections gained during this study along with ways that I see my role as an educational leader being influenced by this experience.

\section{Summary of the Study}

The purpose of this study was to build a baseline understanding of the phenomenon of long-term formal mentoring relationships involving an adult and a youth from the gay community from the perspective of the participants. Three primary research questions focused this inquiry:

1. What are the most important characteristics and processes of long-term formal mentoring relationships between gay adults and gay youth from the perspectives of the participants?

2. How, if at all, do mentors and mentees perceive potential benefits and limitations for gay youth participating in formal long-term mentoring relationships with gay adults?

3. How, if at all, do mentors and mentees perceive their mentoring relationship uniquely contributing to sexual-minority identity development in gay youth?

IPA was chosen as the approach to explore these research questions. As an approach, IPA "is concerned with understanding personal lived experience and thus with exploring persons' relatedness, or involvement in, a particular event or process (phenomenon)" (Smith et al., 2009, p. 40). In the past, this approach has been used to explore topics related to the "othering" of people, including inquiries on sexuality and sexual identity (e.g., Smith et al., 2009). 
A purposeful sample of one mentoring match between an adult and youth from the gay community was chosen. This match met the following criteria: They were enrolled and supported by a formal mentoring program that held the mission of matching gay adults with gay youth in one-to-one, community-based relationships; the mentor and mentee had been matched for over one year; the male mentor self-labeled as gay, while the male mentee self-labeled as "queer." Program staff assisted in the selection of the match based on Tony and Daniel's ongoing and active participation in program activities and the program's case-management oversight.

The process for selecting a match for this inquiry took nearly two years because very few mentoring programs hold the mission of specifically promoting relationships between gay adults and youth in one-to-one relationships. Furthermore, no other gay and lesbian community center or quality-assured mentoring program was identified that either sponsored such relationships or possessed mentoring relationships between gay individuals that were longer than one year between the years 2010 and 2012. This identification process included using the MENTOR database of nearly 4,000 programs across the United States; conducting an inquiry with BBBS, the nation's largest network of mentoring programs; using internet search engines with the terms "mentoring" and "gay youth;" and seeking support from a national listserve of mentoring researchers with more than 600 subscribers.

Once a dyad was located, I conducted two in-depth, semi-structured interviews with both participants over a 5-month period. The first in-person interview with the match occurred in June 2012, at the 17-month mark in their relationship. The second in- 
person interview with the match occurred in November 2012, at the 22-month mark in their relationship.

\section{Findings}

Using data-analysis strategies described by Smith et al. (2009), I interpreted three superordinate themes related to long-term formal mentoring relationships involving an adult and youth from the gay community: characteristics and processes, benefits and limitations, and unique support for sexual-minority identity development. These themes provided an important first glimpse into how such mentoring relationships are perceived and also shared insight into the specific pathways through which benefits might occur, especially related to how a youth can access support for sexual-minority identity development.

A range of notable characteristics and relationship processes were raised up through my IPA data analysis. At its foundation, this was a relationship that provided a safe space and a number of opportunities for a mentee to explore his emerging identity as a member of the gay community. Initially, the mentor introduced the mentee to the gay neighborhood - showing him resources, taking him to events, and offering him the chance to meet other gay and queer- identified people. Over time, these activities shifted, responding to changes in the mentee by giving him more interactive opportunities to share and process his own experiences with dating, coming out to his family, and becoming more integrated into the gay community. A key condition — trust—was identified by the match that appeared to allow these explorations, activities, and learning opportunities to occur. 
My analysis also highlighted a number of benefits for both the mentee and mentor. First, the mentee gained a role model. This relationship provided a chance for the mentee to observe, engage, and interact with a more experienced member of the gay community — offering him the chance to learn more about what his life and his relationships could be like. Second, this relationship gave the mentee a space to think through, process, and examine how to share and be open about his sexuality with others, including his family. Third, the mentee secured support as he navigated through dating challenges with people of the same-sex, having conversations with his mentor around issues of trust and intimacy. In addition to benefits for the mentee, the mentor also benefitted from this relationship — he gained a valuable opportunity to reflect on his own coming out experiences and share insights and openness about the challenges of being in a relationship. The mentor also found a way to give back by sharing advice, highlighting his own learned lessons, and encouraging the next generation of his community.

Limitations involving mentoring relationship between adults and youth from the gay community were also noted in this study's findings. The mentor and mentee described difficulty with finding time to sustain their relationship because both lived busy lives. The lack of time available for in-person meetings was identified at the start of the relationship and continued until the 2-year mark of their match. Yet, despite this obstacle, both the mentor and mentee remained committed to staying in touch and ultimately relied more and more on technology and social media to sustain their relationship.

The match also spoke at length about struggles they witnessed other mentoring relationships in the program face-especially related to issues of attraction and boundary setting. The mentor and mentee described situations where youth became attracted to 
their mentors, ultimately causing challenges and tension. The mentor and mentee suggested additional training for mentors and mentees in such relationships and also described the need for targeted case management from program staff to make sure that these situations were resolved in ways that were not harmful to mentees - especially because of the potential of harm to a mentee's self-esteem. These limitations appear to hold important insight for key practices needed to ensure mentoring relationships between adults and youth in the gay community are safe and effective.

Lastly, findings from my IPA study provided a clear picture of the activities, strategies, and opportunities that a formal mentoring relationship can offer a young person as he explores his identity as a sexual-minority. Unlike more widely available supports such as online, peer, and drop-in options in community centers, this mentoring relationship was a unique resource — giving a comfortable, long-term, and individualized space for a youth to explore his identity and his community.

Themes and findings from this inquiry have provided an important baseline glimpse into what a long-term formal mentoring relationship between an adult and a youth from the gay community looks like. The next section of this chapter offers assertions based on my interpretation of those results.

\section{Assertions}

Based on the findings from this inquiry as summarized above, I offer the following four assertions:

1. This long-term formal mentoring relationship between an adult and a youth from the gay community shared numerous and important similarities with other high quality mentoring relationships. 
2. This mentoring relationship between an adult and a youth from the gay community offered insight into how to create individualized and long-term support for sexual-minority identity development in youth.

3. This mentoring relationship between an adult and a youth from the gay community represents an important but unrealized type of support.

4. Complexity exists in using language and self-labeling to define, inquire, and provide support to individuals from the gay community - especially youth.

First, this long-term formal mentoring relationship between an adult and a youth from the gay community shared numerous and important similarities with other high quality mentoring relationships. This relationship met a number of conditions that have been described to foster benefits in a young person: frequency and consistency of contact over time, opportunities to engage in mutually enjoyable activities, and an approach from a mentor that instrumentally helped a young person achieve his goals. Like other mentoring relationships, a mentee in a long-term relationship with a gay adult gained opportunities to access problem-solving skills, process feelings and work through emotions, and improve and strengthen relationships with his parent and peers over time. Lastly, much like other mentoring relationships, a match between an adult and a youth from the gay community followed "stages of a mentoring relationship," moving through contemplation, initiation, growth and maintenance, and redefinition. With these examples, a mentoring relationship between an adult and youth from the gay community holds many of the same key conditions, benefits, and opportunities contained in most mentoring relationships. In essence, this type of relationship can create positive benefits in a young person in much the same way as other relationships offer benefits more generally for youth — especially when care and high quality practices have been followed. 
Second, I assert that this mentoring relationship between an adult and a youth from the gay community offered insight into how to create individualized and long-term support for sexual-minority identity development in youth. This targeted relationship offered a safe space for a young person to process internal feelings and emotions about his sexual identity. His mentor acted as a positive role model helping his mentee envision possible selves as a healthy and well-adjusted member of the gay community. In addition, a gay mentor helped the mentee feel a sense of belonging and affiliation, which can counter feelings of "otherness" that many gay youth experience in school and community settings. Lastly, a gay mentor apparently targeted his approach to specific phases of a mentee's sexual-minority identity development, helping to scaffold him to different phases over time. This type of identity development scaffolding can occur by fostering internal insights during awareness and exploration phases, such as introducing the mentee to the community, and then adjusting to more interactive support as the youth moves farther along in his process of navigating through his identity development.

Third, based on this study, I assert that this mentoring relationship between an adult and a youth from the gay community represents an important but unrealized type of support for other gay youth. As I discovered during my search for participants for this study, very few mentoring agencies across the country are promoting and supporting relationships that include openly gay youth. In addition, few agencies appear to be addressing the needs of gay youth in earlier stages of identity development-youth between the ages of 10 and 14-that are struggling with feeling different but have not yet reached out for support from others. This invisible population of youth may be most in need of caring supporters to help them feel comfortable taking first steps in accessing 
resources for exploring their identities. However, as the mentoring field appears to have failed to respond to the diverse circumstances of gay youth along the spectrum of coming out, a need exists to help examine how these relationships can work and make a difference. This study has been a first step in that process. Yet, arguably more research and understanding needs to be completed.

Fourth, I assert that complexity exists in using language and self-labeling to define, inquire, and provide support to individuals from the gay community, especially youth. Because individuals typically shift and change as they go through their processes of defining who they are and share their identity with others, their language may also change as they gain new terminology and ways of thinking about themselves. These changes may create challenges for inquiry because of the difficulty of locating such participants - especially because many younger people may view sexuality more fluidly and do not easily adopt labels that have been accepted by earlier generations (SavinWilliams, 2007). As this study has demonstrated, conducting inquiry on youth and sexuality continues to require the establishment of clear definitions, while also understanding that fluidity and change are inherent in defining someone undergoing processes of shifting identity development.

\section{Study Limitations}

Although these findings and assertions offer important new insights into what a mentoring relationship between an adult and a youth from the gay community "looks like," several study limitations must be noted in order to place these findings and assertions into context. First, terminology used to select and describe participants created noted challenges. Because my chosen definition for the term gay for this inquiry included 
a broad pattern of self-labeling, same-sex sexual attraction, and same-sex sexual behavior and male, I had difficulty securing participants that met these criteria. For example, members of the gay community might also include persons who self-identify as lesbian, bisexual, transgender, intersex, queer, and 2-Spirit. My attempt at narrowing the parameters for this inquiry excluded these groups, although my purposeful selection of one match allowed me to offer detailed, rich, and complex insight into one specific type of relationship from this community.

A second limitation involves my choice to meet with both the mentor and mentee at the same time for both in-depth interviews. Although this approach seemed to offer a vital chance to see the phenomenon as a participant observer and to jointly build trust with the participants, I may have lost access to individual accounts and perceptions that potentially could have given additional insights about the phenomenon. I would like to note, however, that I was able to connect one-to-one with the mentor to obtain additional insights, but due to geographical distance and difficulty reaching the mentee outside of the scheduled interview sessions, I was not able to meet separately with the mentee.

\section{Contributions to Theoretical Frameworks and Empirical Research}

The results of this study offer an important first glimpse into what a long-term formal mentoring relationship between an adult and youth from the gay community “looks like." The study's findings and assertions also provide an entrée to re-examine and contribute to understanding conceptual and theoretical frameworks of mentoring, strategies to support sexual-minority identity development, and queer theory. 


\section{Formal Mentoring}

Rhodes' (2002, 2005) Pathways to Mentoring Influence Model highlights the conditions and processes through which mentees appear to access benefits while participating in a mentoring relationship with a caring adult. Mutuality, trust, and empathy are seen as key conditions that need to be present to support a range of socioemotional, cognitive, and identity development benefits.

This study provides an example of how these conditions work within a long-term mentoring relationship between an adult and a youth from the gay community. The mentor and mentee in this study described a relationship filled with mutuality and trust. Further, a deep bond seemed to have been formed between the mentor and mentee around the shared experience of coming out. In fact, the mentor was empathetic toward the mentee based on his own coming-out experiences and a real desire to foster opportunities for support that the mentor had never had. These bonds were created through similarities of belonging to the gay community as well as similar interests and the instrumental approach of the mentor that created opportunities for the mentee to focus on his goal of learning more about what the gay community could offer him.

Rhodes $(2002,2005)$ described specific benefits that occur in mentoring relationships. These include socio-emotional, cognitive, and identity development benefits. This study also describes potential opportunities for youth to gain socioemotional and cognitive benefits. The mentee specifically cited opportunities to improve family and peer relationships with the help of his mentor. The mentee also described the importance of having space to process, vent, and gain problem-solving opportunities 
within the mentoring relationship. These benefits mimic findings for other youth related to these outcomes (J. P. Tierney et al., 1995).

Role modeling is seen as one way in which benefits occur for youth in mentoring relationships (Rhodes, 2002, 2005). A mentee can observe how his mentor interacts with the environment, gaining opportunities to emulate the ways in which a more experienced individual performs a task, handles a problem, or shows resilience. This study showed how a gay youth observed the ways in which his mentor accessed resources, developed relationships, and coped with struggles and interpersonal difficulty. Learning from his mentor's example, the mentee in this study was able to see his positive future life as a member of the gay community, visualizing possibilities of having his own long-term same-sex relationship. The mentee also learned from his mentor's struggles, recognizing that asking for help when needed can be an important and positive step for overcoming adversity.

\section{Sexual-Minority Identity Development}

Further, findings from this IPA study provide insight into how an individual shifts, changes, and shares his identity as a sexual minority over time. McCarn and Fassinger (1996) described various phases of sexual-minority identity development, including individual and group membership phases. Individuals move through different phases of awareness, exploration, identification, and synthesis of their identity on a personal and group level. When an individual has positive and affirming experiences within a phase, he is able to gain opportunities to move to a different phase. In contrast, when an individual has a negative experience, he may become stagnant in his processor even revert to previous phases. 
This study showed how a youth gained positive opportunities to work through phases of exploration, awareness, and identification as a member of the gay community. With a mentor's support, the mentee gained a safe and positive space to explore his feelings and to process encounters with people he met from the gay community. At first, introductory opportunities gave the mentee access to new resources and opportunities to explore his sexual identity. Later, these activities became more interactive with the mentor working alongside the mentee as he navigated through relationship issues. The role that mentoring has played in this relationship can best be explained by Ross (2005).

Ross (2005) examined relationships between gay mentors and gay college students, specifically attempting to understand how such relationships support sexualminority identity development. In his study, Ross noted that mentors played a role in helping mentees "unlearn" negative assumptions about being gay and the gay community as well as "learn" tasks specifically related to sexual-minority identity development at both the group and individual levels. Ross's study also demonstrated that mentors supported the coming-out process, helped the mentee meet other gay people, and served as a role model and "cultural" guide in the gay community. Findings from this IPA study were very similar; the mentor supported the mentee in a range of opportunities to unlearn assumptions about dating and "the gay lifestyle." The mentor also served as a positive role model and helped to connect the mentee to resources within the gay community.

In addition to showing an example of many of Ross's (2005) findings, this study also provided new layers of thinking about the ways in which mentoring supports identity development over time. Because this relationship lasted nearly two years, the inquiry was able to explore how the match responded to changes in the mentee as the relationship 
progressed — especially as he was becoming more and more immersed in his identity as a sexual minority. Activities moved from introductory to interactive, giving the mentee chances to scaffold his experiences. The mentor also took an instrumental approach, creating opportunities within the mentoring relationship for the mentee to achieve goals related to learning more about himself and the gay community. These nuances - along with disclosure, empathy, and openness on the part of the mentor - appeared to offer an important view of the ways in which support for identity development occurs within such relationships.

This study also provides new insights on a unique strategy that can work alongside various peer supports, online, and community center options that are currently available. Young people such as the mentee in this inquiry have an important need to feel comfortable accessing support, especially related to internal struggles around sexuality and sexual-minority identity development. This necessity may be especially true for youth struggling with social interaction anxiety. Although a number of opportunities exist for young people to gain support in peer-to-peer, group, and online settings, this particular type of support - a one-to-one formal relationship between a gay adult and a gay youth — was the only approach with which this particular mentee felt comfortable. This finding is notable, especially because the mentee had been able to access this support for nearly two years, whereas other opportunities to connect were met with early termination due to the mentee feeling uncomfortable.

\section{Queer Theory}

Moreover, this study offers an important example of how inquiry can help to disrupt patterns of marginalization. With a growing body of research on mentoring that 
spans well over 25 years, this study is the very first time that the voices of nonheterosexual individuals participating in a long-term formal mentoring relationship have been raised. This baseline understanding breaks through systems within research and inquiry that have a heteronormative slant $—$ often focusing on larger-scale trends and generalizations rather than recognizing the outlying groups, especially those that struggle for visibility. Because of this study, the voices of gay individuals will be heard, and research on mentoring will finally include them when talking about how mentoring "works" for all youth.

\section{Recommendations}

Results of this study hold important opportunities to inform future programming and practice, policy, and research related to mentoring relationships for gay youth. Starting with programming and practice, these recommendations are detailed below.

\section{Programming and Practice}

Currently, gay youth have limited opportunities to receive one-to-one formal mentoring support with adults in community settings. Although peer support groups, online forums, and community drop-in centers are widely available, targeted mentoring to this population of youth has not been available through formal mentoring programs and through LGBT community centers.

With more than 4,000 mentoring programs serving nearly 3 million young people across the country, fewer than five agencies in the United States currently hold the mission of providing one-to-one mentoring services to gay youth. Although this number appears to be slowly growing, this statistic highlights a disproportionately low number of agencies that provide targeted support to this population. Further, very few mainstream 
mentoring agencies have begun to create inclusive and intentional services for this population, which could leave scores at risk of further harm if programs neglect to provide safeguards.

In addition to the lack of inclusion from formal youth mentoring programs, LGBT community centers have also been slow to adopt mentoring as a complement to existing services. Peer support, counseling services, support groups, and online resources seem to represent a large majority of approaches to support gay youth. However, these approaches may limit access for certain groups of youth who feel uncomfortable in group or peer-to-peer settings - especially those struggling with social interaction anxiety. Because so few opportunities exist for such what kind of relationships at this time, many young people who could benefit are not given access to a type of support that might truly make a difference. Therefore, based on this study's conclusions, important program recommendations for program planning and design, mentee screening, mentor screening, matching, training, and ongoing case management are provided:

Program planning and design. A series of established guidelines are available for agencies that seek to start and implement a mentoring program. For agencies that are new to mentoring, MENTOR's Elements of Effective Practice (2009) describe key strategies to design and plan a program. A first step in this process is to conduct a needs assessment that captures insight into the populations of youth served by the proposed mentoring program.

For an agency that plans to serve gay youth, a needs assessment used to plan and design a mentoring program should capture data about victimization, bullying, and health risks as well as identify potential resources in the community that can provide more in- 
depth counseling and mental health services for this population. In addition, agencies are advised to also conduct an analysis of their internal climate and ability to provide such services to gay youth. By understanding the scope of external and internal barriers, challenges, and opportunities in designing a mentoring program that focuses on or includes gay youth, greater care and intentionality can help to make sure no additional harm is caused by well-intentioned but misguided attempts at inclusion. In addition, care regarding specific program operation practices should also be addressed. Screening, matching, training, and case management recommendations are described next.

Mentee screening. Not all youth are ready or able to access the support found in formal mentoring relationships with adults. Therefore, agencies are encouraged to develop and utilize mentee screening criteria to better assess whether the mentoring program is an appropriate space for a young person to access support. Characteristics like mentee motivations, previous experiences with victimization or negative social sanctions, and phases of sexual-minority identity development are important to assess during intake and screening. Because not all young people are ready to access this type of support, they should not be forced to participate given that motivation and engagement appear to be key indicators for longevity and bonding in such a relationship. Collecting intake data on these indicators could also provide clues into the range of social support options available to the youth as well as whether he might have difficulties trusting a mentor.

Mentor screening. In addition to screening considerations for mentees, agencies are also advised to use caution when selecting volunteers to serve as mentors. Not every gay volunteer is equipped or prepared to serve in this role. Mentors must have the relational skills and the ability to bond with a young person. In addition, mentors who 
work with gay youth will need to express empathy, demonstrate a stance as well as skills that allow for an instrumental approach, and communicate long-term commitment to making a difference. In addition to these universal criteria for all mentors, gay mentors that have a healthy and synthesized identity as a member of the sexual-minority community might best be suited to providing support because of their potential to role model skills needed to navigate through phases of sexual-minority identity development. Age, stage of identity development, ability to commit to the program, coming-out experiences, and suitability would be important volunteer screening areas to assess.

Matching. Another program recommendation focuses on the matching process. Although this study demonstrated that a match between a gay adult and a youth offers a range of benefits, the pathway to these benefits may involve more than just matching based on a shared identity as a sexual minority. In addition to having a shared sexual identity, the mentor and mentee also identified a range of similar interests, which seemed to give them opportunities to bond, engage in mutual activities, and create a solid foundation that helped to foster benefits. Because a shared sexual orientation and similar interests seem to hold weight in these relationships, agencies may need to consider a range of factors that support the development of a bond that goes beyond simply matching based on whether a volunteer or a mentee identifies as a member of the "gay" community. For instance, agencies can ask about interests and hobbies, educational and career experiences and goals, and other key areas around which a youth and an adult can bond in addition to sexual orientation and identity.

Training. Because issues related to boundaries and attraction were identified as potential limitations for mentoring relationships involving gay adults with gay youth, 
agencies that sponsor mentoring relationships for gay youth are likely to need to develop training and specific policies and procedures related to boundary setting and dealing with attraction issues. Training could potentially offer support by building mentor efficacy and providing a range of specific tools for how to address such concerns before the match has been made. Including specific training for new mentees on boundaries and attraction issues can also help to make sure that young people are not embarrassed or feel uncomfortable with their feelings, both of which could potentially hinder the development of the relationship.

Match support and ongoing case management. Mentors and mentees can benefit from program-supported materials that help the match bond, while also strengthening opportunities for mentees to learn more about the gay community and themselves. A program handbook given to mentors that includes resources from the gay community, information about phases of identity development, and targeted questions and suggested activities they can use to help youth navigate through each phase is suggested. Mentors can use this type of reference to gain a valuable tool they can use over time and to learn a common language to employ when speaking with program staff.

In addition to providing resources and activity suggestions, program staff should regularly and frequently conduct check-in calls with the match. Check-in calls should consist of targeted questions to learn more about how the relationship is bonding, the types of activities they have been doing, and ways in which the youth is gaining support related to his identity and should be done individually with the mentor and mentee to triangulate their experiences. Programs should also regularly assess boundary setting and attraction issues when they conduct case management check-ins. Because of the potential 
for harm that can occur when boundaries are crossed, program staff must make sure a number of safeguards have been created to identify such issues before they endanger trust in the relationship or the safety and well-being of the mentee. In-depth, targeted, and frequent case management offers support for handling issues before they grow into a potential liability.

\section{Policy}

Because very little programming and research have focused on how mentoring might work for gay youth, this study offers important national policy implications that highlight the need to offer guidance for agencies seeking to implement, support, and create safe and effective relationships for this population. As this study offers a baseline of insight into how mentoring "works" for gay youth, policy can play an important role in helping to bridge the current landscape with future opportunities to more fully leverage mentoring as a possibility for support for gay youth. Because little is known about the potential risks that might endanger these relationships as well as risks related to gay youth participating in mentoring, policy guidance can offer a more intentional and incremental approach that supports growth in the quantity of gay youth served by mentoring while also creating quality safeguards for participating youth. For example, policy guidance on effective practices of mentoring — screening, matching, training, and support — should be widely available to agencies new to mentoring. For mentoring agencies already familiar with these best practices, policy can play an important role in offering guidance on how to create safe spaces for gay and questioning youth as well as funding for wide-scale training to create awareness of the needs, risks, and approaches that respect the unique circumstances of youth. 


\section{Research}

There are a number of suggestions for future research related to this topic. First, additional qualitative inquiries are recommended to gain baseline information about how a number of populations of youth under the umbrella of the gay community-lesbians, bisexual-identified youth, young transgender men and women, as well as 2-spirit and intersex youth—respond to and benefit from mentoring relationships with similar adults. Second, an important need exists to examine mentoring relationships between volunteer mentors who identify as straight and gay mentees in order to gain insight into the baseline landscape of characteristics, processes, limitations, benefits, and support for sexualminority identity development in these relationships. Third, unique opportunities for quasi-experimental studies exist. Pre- and post- examinations of sexual-minority identity development using an inventory created by McCarn and Fassinger (1996) can help to assess whether changes have occurred in youth and also examine if these changes correlate to other outcomes important to positive youth development. These initial types of studies can build upon insights gained in this study and promote new opportunities to understand how to best provide mentoring services to this population as well as assess the types of difference these services could make on a larger scale.

\section{Educational Leadership}

This study holds important recommendations for educational leaders. First, this inquiry highlights how leaders can work in school settings to create more inclusive opportunities for gay youth. School-based mentoring programs, for example, might use findings from this study to gain insight into the potential use of an additional strategy for support that can be leveraged for gay youth under their care. While gay-straight alliances 
are becoming increasingly present in school districts across the country, youth who do not feel comfortable accessing these types of group or peer-to-peer supports may struggle to find a resource that allows them to receive targeted and individualized support. Because many young people are starting to navigate through the process of figuring out their sexuality during formative years while they attend school, educational leaders and those that are managing school-community partnerships are strongly encouraged to learn more about options that are available to such youth, including formal mentoring

Second, educational leadership is about creating opportunities for youth from different backgrounds to have access to a safe space to learn; one pathway to do this is through awareness. By increasing awareness among educational leaders about the struggles and challenges that gay youth experience as they brush up against homophobia and heterosexism, new solutions can be created. This study provides an important starting point to build that awareness. Further, findings from this study can be used to generate new types of services that school leaders can use to make sure that more youth have access to safe learning environments.

\section{Personal Reflection}

The final section of my dissertation describes my personal reflections on the experience as well as ways in which I see my role as an educational leader transformed by this inquiry.

In 1994, I finally said the words out loud that I had struggled for years to understand about myself. After years of being bullied, feeling different, and experiencing the "otherness" that came with my sexuality, I finally found the strength to share my truth with someone else. I was 22 and on a road trip with my best friend. I remember waiting 
until the lights were turned off in our hotel room, finally saying the words "I am gay" while holding back tears and an intense fear that I would be alone and rejected. She held me while I wept, wiped the tears off my cheeks, and told me that she loved me and was there for me no matter what. This would be the first of many times I would say those words and share this part of myself - luckily, I was given a solid foundation of support from this friendship over the years.

As Daniel, Tony, and I walked around the gay neighborhood, I realized that each of us represented a different snapshot in time of what this coming-out moment looks like. My experience in the 1990s was filled with anguish, sadness, confusion, and pain. Daniel struggled to find support in college in the 2000s, finally finding a counselor who shared with him advice and tools for how to rationally understand his experience of developing an identity as a gay man. Lastly, Tony represents young people coming out in the 2010s - a group of individuals who are still brushing up against tension but also filled with such hope, possibility, and resilience. Even though we three generations had such different opportunities for support, each of us had to find his own way into the gay community. This was a powerful image for me to hold while thinking about the implications of this study for me, as a person and as a researcher. It showed that the very nature of what it means to be gay and to come out is changing.

As I reflect upon my experience conducting this study and its significance for me as an educational leader, I am reminded as to why I wanted to complete a doctoral program: to gain and use tools to translate research into practice so that I could address inequality, especially among marginalized groups of individuals. My study into mentoring and its unique opportunities to support gay youth has helped to channel this 
goal into a reality. It has given me a concrete pathway to contribute to the field through inquiry while also finding ways to speak directly to mentoring program practitioners serving this population. As an educational leader, I seek to build on the findings, assertions, and recommendations from this study by developing additional research, creating training and program tools, and helping to guide policy to give opportunities to the next generation of youth who must also find their way into the gay community. 


\section{REFERENCES}

Ahmed, S. (2007). Queer phenomenology: Orientations, objects, others. Durham, NC: Duke University Press.

American Psychiatric Association. (n.d). Therapies focused on attempts to change sexual orientation. Retrieved September 12, 2009, from http://www.psych.org/ Departments/ EDU/Library/APAOfficialDocumentsandRelated/ PositionStatements/200001a.aspx

American Psychological Association. (2008). Answers to your questions: For a better understanding of sexual orientation and homosexuality. Washington, DC: Author. Retrieved from http://www.apa.org/helpcenter/sexual-orientation.aspx

Appleby, G. A., \& Anastas, J. W. (1998). Not just a passing phrase: Social work with gay, lesbian, and bisexual people. New York, NY: Columbia University Press.

Baker, D. B., \& Maguire, C. P. (2005). Mentoring in historical perspective. In D. L. DuBois \& M. Karcher (Eds.), Handbook of youth mentoring (pp. 14-29). Thousand Oaks, CA: Sage.

Bandura, A. (1977). Social learning theory. Englewood Cliffs, NJ: Prentice Hall.

Bandura, A. (1986). Social foundations of thought and action: A social cognitive theory. Englewood Cliffs, NJ: Prentice Hall.

Barajas, J. (2004). Mentoring gay, lesbian, bisexual, and transgender youth. Folsom, CA: Center for Applied Research Solutions.

Barrera, M., \& Bonds, D. D. (2005). Mentoring relationships and social support. In D. L. DuBois \& M. Karcher (Eds.), Handbook of youth mentoring (pp. 133-142). Thousand Oaks, CA: Sage.

Bem, D. J. (2001). Exotic becomes erotic: Integrating biological and experiential antecedents of sexual orientation. In D. R. D'Augelli \& C. Patterson (Eds.), Lesbian, gay, and bisexual identities and youth: psychological perspectives (pp. 52-68). New York, NY: Oxford.

Bernal, A. T., \& Coolhart, D. (2005). Learning from sexual minorities. Guidance and Counseling, 20, 128-138.

Big Brothers Big Sisters of America. (2012). Strategic update brochure. Philadelphia, PA: Author. 
Bilchek, S. (2007). Mentoring: A promising intervention for children of prisoners. Alexandria, VA: MENTOR.

Blechman, E., \& Bopp, J. M. (2005). Juvenile offenders. In D. L. DuBois \& M. Karcher (Eds.), Handbook of youth mentoring (pp. 454-481). Thousand Oaks, CA: Sage.

Blinn-Pike, L. (2005). Pregnant and parenting adolescents. In D. L. DuBois \& M. Karcher (Eds.), Handbook of youth mentoring (pp. 467-481). Thousand Oaks, CA: Sage.

Bogden, R. C., \& Bilken, S. K. (2003). Qualitative research for education: An introduction to theory and methods. Boston, MA: Pearson Education Group.

Bogot, G. A., \& Liang, B. (2005). Gender in mentoring relationships. In D. L. DuBois \& M. Karcher (Eds.), Handbook of youth mentoring (pp. 205-217). Thousand Oaks, CA: Sage.

Bowlby, J. (1982). Attachment and loss: Retrospect and prospect. American Journal of Orthopsychiatry, 52, 709-716.

Bowlby, J. (1988). A secure base: Parent-child attachment and healthy human development. New York, NY: Basic Books.

Britney, P. A. (2005). Abused and neglected youth. In D. L. DuBois \& M. Karcher (Eds.), Handbook of youth mentoring (pp. 482-292). Thousand Oaks, CA: Sage.

Bronfenbrenner, U. (1979). The ecology of human development. Boston, MA: Harvard Press.

Brooke, J. (1998, November 21). Witnesses trace brutal killing of gay student. Retrieved from http:/www.nytimes.com/1998/11/21/us/witnesses-trace-brutal-killing-ofgay-student.html?pagewanted=all

Brown, M., \& Colbourne, M. (2005). Bent but not broken: Exploring queer youth resilience. In M. Unger (Ed.), The handbook of working with children and youth: Pathways to resilience across cultures and contexts (pp. 263-278). Thousand Oaks, CA: Sage.

Buerger, M. (2012, June 6). LGBT youths in Washington to get their first mentoring program. The Washington Post. Retrieved from http://www.washingtonpost.com

Byrne, D. (1971). The attraction paradigm. New York, NY: Academic Press. 
Callahan, C. M., \& Kyburg, R. M. (2005). Talented and gifted youth. In D. L. Dubois \& M. Karcher (Eds.), Handbook of youth mentoring (pp. 424- 439). Thousand Oaks, CA: Sage.

Cass, V. C. (1979). Homosexual identity formation: A theoretical model. Journal of Homosexuality, 4, 219-235.

Cass, V. C. (1984). Homosexual identity formation: Testing a theoretical model. Journal of Sex Research, 20, 219-235.

Cooley, C. H. (1920). Human nature and the social order. New York, NY: Scribner.

Creswell, J. W. (1998). Qualitative inquiry and research design: Choosing among five traditions. Thousand Oaks, CA: Sage.

Darling, N. (2005). Mentoring adolescents. In D. L. DuBois \& M. Karcher (Eds.), Handbook of youth mentoring (pp. 177-190). Thousand Oaks, CA: Sage.

D’Augelli, A. R. (2002). Mental health problems among lesbian, gay, and bisexual youth ages 14 to 21. Clinical Child Psychology and Psychiatry, 7, 433-456.

D’Augelli, A. R. (2006). Developmental and contextual factors and mental health among lesbian, gay, and bisexual youths. In A. M. Omoto \& H. S. Kurtzman (Eds.), Sexual orientation and mental health: Examining identity and development in lesbian, gay, and bisexual people (pp. 37-53). Washington, DC: American Psychological Association.

D’Augelli, A. R., \& Patterson, C. J. (2001). Lesbian, gay, and bisexual identities and youth: Psychological perspectives. New York, NY: Oxford.

Denzin, N. K., \& Lincoln, Y. S. (1994). The SAGE handbook of qualitative research. Thousand Oaks, CA: Sage.

Dewey, J. (1912). Interest and effort in education. Boston, MA: Haughton Mifflin.

Diamond, L. (2006). What we got wrong about sexual identity development: Unexpected findings from a longitudinal study of young women. In A. Omoto \& H. S. Kurtzman (Eds.), Sexual orientation and mental health: Examining identity and development in lesbian, gay, and bisexual people (pp. 73-94). Washington, DC: American Psychological Association.

DuBois, D. L., Holloway, B. E., Valentine, J. C., \& Cooper, H. (2002). Effectiveness of youth mentoring programs for youth: A meta-analytical review. American Journal of Community Psychology, 30(2), 157-197. 
DuBois, D. L., \& Karcher, M. J. (Eds.). (2005). Handbook of youth mentoring. Thousand Oaks, CA: Sage.

DuBois, D. L., \& Karcher, M. J. (Eds.). (2013). Handbook of youth mentoring ( $2^{\text {nd }}$ ed.). Thousand Oaks, CA: Sage.

DuBois, D. L., Neville, H. A. (1997). Youth mentoring: Investigation of relationship characteristics and perceived benefits. Journal of Community Psychology, 25, 227-234.

DuBois, D. L., Neville, H. A., Parra, G. A., \& Pugh-Lilly, A. O. (2002). Testing a new model of youth mentoring. In G. G. Noam (Ed. in chief) \& J. E. Rhodes (Ed.), $A$ critical view of youth mentoring (New Directions for Youth Development: Theory, Research, and Practice, No. 93; pp. 21-57). San Francisco, CA: JosseyBass.

DuBois, D. L., Portillo, N., Rhodes, J. E., Silverthorn, N., \& Valentine, J. C. (2011). How effective are mentoring programs for youth: A systematic assessment of the evidence. Psychological Science in the Public Interests, 12, 57-91.

Eccles, J., \& Gootman, J. A. (2002). Community programs to promote youth development. Washington, DC: National Academy Press.

Erikson, E. (1963). Childhood and society. New York, NY: Norton.

Faulkner, A. H., \& Cranston, K. (1998). Correlates of same-sex behavior in a random sample of Massachusetts high school students. American Journal of Public Health, 88, 262-266.

Fassinger, R. E., \& Miller, B.A. (1996). Validation of an inclusive model of sexual minority identity development on a sample of gay men. Journal of Homosexuality, 32, 53-78.

Fergus, S., \& Zimmerman, M. A. (2005). Adolescent resilience: A framework for understanding healthy development in the face of risk. Annual Review of Public Health, 26, 399-419.

Finnegan, D. G., McNally, E. B., Anderson, E. B., \& Shelton, C. S. (2001). Counselor competence in treating LGBT clients: A provider's introduction to substance abuse treatment for lesbian, gay, bisexual, and transgender individuals. Rockville, MD: U.S. Department of Health and Human Services.

Freedman, M. (1991). The kindness of strangers: Reflections on the mentoring movement. Philadelphia, PA: Public/Private Ventures. 
Garofolo, R., Wolf, R. C., Kessel, S., Palfrey, J., \& DuRant, R. H. (1998). The association between health risk behaviors and sexual orientation among a schoolbased sample of adolescents. Pediatrics, 101, 895-902.

Gay, Lesbian and Straight Education Network. (2008). The 2007 national school climate survey: The experiences of lesbian, gay, bisexual and transgender youth in our nation's schools. Retrieved May 25, 2013, from http://www.glsen.org/binarydata/ GLSEN_ATTACHMENTS/file/00/002/2105-1.pdf

Gay, Lesbian and Straight Education Network. (2012). The 2011 national school climate survey: Key findings on the experiences of lesbian, gay, bisexual, and transgender youth in our nation's schools. Retrieved May 15, 2013, from www.glsen.org

Gibson, P. (1989). Gay male and lesbian youth suicide: Report of the Secretary's Task Force on Youth Suicide. Washington, DC: U.S. Health and Human Services.

Glassman, M. (2001). Dewey and Vygotsky: Society, experience, and inquiry in educational practice. Educational Researcher, 30, 3-14.

Governor's Commission on Gay and Lesbian Youth. (1993). Making schools safe for gay and lesbian youth: Breaking the silence in schools and in families. Boston, MA: Author.

Graber, J. A., \& Archibald, A. B. (2001). Psychosocial change at puberty and beyond: Understanding adolescent sexuality and sexual orientation. In A. R. D'Augelli \& C. J. Patterson (Eds.), Lesbian, gay, and bisexual identities and youth: Psychological perspectives (pp. 3-26). New York, NY: Oxford University Press.

Grossman, J. B., \& Rhodes, J. E. (2002). The test of time: Predictors and effects of duration in youth mentoring programs. American Journal of Community Psychology, 30, 199- 219.

Guba, E. G., \& Lincoln, Y. S. (1994). Competing paradigms in qualitative research. In N. K. Denzin \& Y. S. Lincoln (Eds.), The SAGE handbook of qualitative research (pp. 105-117). San Francisco, CA: Sage.

Hamilton, M. A., \& Hamilton, S. F . (2005). Work and service learning. In D. L. Dubois \& M. Karcher (Eds.), Handbook of youth mentoring (pp. 348-363). Thousand Oaks, CA: Sage.

Hamilton, M. A., \& Hamilton, S. F. (2013). Work and service learning. In D. L. Dubois $\&$ M. J. Karcher (Eds.), Handbook of youth mentoring ( $2^{\text {nd }}$ ed., pp. 291-300). Thousand Oaks, CA: Sage. 
Hamilton, S. F., \& Darling, N. (1996). Mentors in adolescents' lives. In K. Hurrelmann \& S. F. Hamilton (Eds.), Social problems and social contexts in adolescence: Perspectives across boundaries (pp. 199-215). New York, NY: Pergamon.

Herek, G. (1984). Beyond "homophobia": A social psychological perspective on attitudes toward lesbians and gay men. Journal of Gay and Lesbian Social Services, 10, $1-21$.

Herrera, C., Grossman, J. B., Kuah, T., Feldman, A., Mcmaken, J., \& Jucovy, L. (2007). Making a difference in schools: The big brothers big sisters school-based mentoring impact study. Philadelphia, PA: Public/Private Ventures.

Herrera, C., \& Karcher, M. J. (2013) School-based mentoring. In D. L. Dubois \& M. J. Karcher (Eds.), Handbook of youth mentoring ( $2^{\text {nd }}$ ed., pp. 203-220). Thousand Oaks, CA: Sage.

Herrera, C., Sipe, C. L., \& McClanahan, W. S. (2000). Mentoring school-age children: Relationship development in community-based and school-based programs. Philadelphia, PA: Public/Private Ventures.

Hershberger, S. L., \& D’Augelli, A. R. (1995). The impact of victimization on the mental healthand suicidality of lesbian, gay, and bisexual youths. Developmental Psychology, 31, 65-74.

Hirsch, B. J, \& Wong, V. (2005). After-school programs. In D. L. Dubois \& M. Karcher (Eds.), Handbook of youth mentoring (pp. 364-375). Thousand Oaks, CA: Sage.

Imel, S., Kirka, S., \& Wonacott, M. E. (2002). Qualitative research in adult, career, and career-technical education. Washington, DC: Office of Educational Improvement.

Jekielek, S, Moore, K. A., \& Hair, E. C. (2002). Mentoring programs and youth development: A synthesis. Washington, DC: Child Trends.

Jucovy, L. (2000). Technical assistance packet \#1: Mentoring sexual minority youth. Portland, OR: Northwest Regional Educational Laboratory.

Just the Facts Coalition. (2008). Just the facts about sexual orientation and youth: A primer for principals, educators, and school personnel. Washington, DC: American Psychological Association. Retrieved from www.apa.org/pi/lbgc/publications/justthefacts.html

Karcher, M., Kuperminc, G. P., Portwood, S., Sipe, C. L., \& Taylor, A. S. (2006). Mentoring programs: A framework to inform program development, research, and evaluation. Journal of Community Psychology, 34, 709-724. 
Keller, T. E. (2005). The stages and development of mentoring relationships. In D. L. Dubois \& M. Karcher (Eds.), Handbook of youth mentoring (pp. 82-99). Thousand Oaks, CA: Sage.

Keller, T. E. (2006). A systematic model of the youth mentoring intervention. The Journal of Primary Intervention, 26, 169-188.

Kincheloe, J. L., \& McClaren, P. L. (1994). Rethinking critical theory and qualitative research. In N. Denzin \& Y. S. Lincoln (Eds.), The SAGE handbook of qualitative research (pp. 138-157). Thousand Oaks, CA: Sage.

King, J. R. (1999). Am not! Are too! Using queer standpoint in postmodern critical ethnography. International Journal of Qualitative Studies in Education, 12, 473490.

Larkin, M., Watts, S., \& Clifton, E. (2006). Giving voice and making sense in Interpretative Phenomenological Analysis. Qualitative Research in Psychology, 3, 102-120.

Lee, C. (2002). The impact of belonging to a high school gay/straight alliance. The High School Journal, 2, 8-25.

Lemoire, S. J., \& Chen, C. P. (2005). Applying person-centered counseling to sexual minority adolescents. Journal of Counseling and Development, 83, 146-154.

Lerner, R. M. (2007). Mentoring: A key resource for promoting positive youth development. Alexandria, VA: MENTOR/National Mentoring partnership.

Lerner, R. M., Napolitano, C. M., Boyd, M. J., Mueller, M. K., \& Callina, K. S. (2013). Mentoring and positive youth development. In D. L. Dubois \& M. J. Karcher (Eds.), Handbook of youth mentoring ( $2^{\text {nd }}$ ed., pp. 17-28). Thousand Oaks, CA: Sage.

Matan, K. I., St. Domingo, M. R., \& King, J. (2005). Faith-based organizations. In D. L. Dubois \& M. Karcher (Eds.), Handbook of youth mentoring (pp. 376-391). Thousand Oaks, CA: Sage.

McCarn, S. R., \& Fassinger, R. E. (1996). Re-visioning sexual minority identity formation: A new model of lesbian identity and its implications for counseling and research. The Counseling Psychologist, 24(3), 508-534.

McCorkal, J. A., \& Myers, K. (2003). What difference does difference make? Position and privilege in the field. Qualitative Sociology, 26, 199-231. 
Mekinda, M. A., \& Hirsch, B. J. (2013). After-school programs. In D. L. DuBois \& M. Karcher (Eds.), Handbook of youth mentoring (pp. 221-232). Thousand Oaks, CA: Sage.

MENTOR. (2003). Elements of effective practice (2nd ed.).Alexandria, VA: Author.

MENTOR. (2005). National poll on mentoring. Alexandria, VA: Author.

MENTOR. (2007). National mentoring database. Alexandria, VA: Author.

MENTOR. (2009). Elements of effective practice ( $3^{\text {rd }}$ ed.). Alexandria, WA: Author.

MENTOR. (2012). National mentoring database. Alexandria, VA: Author.

Merriam, S. (2002). Qualitative research in practice. San Francisco, CA: Jossey Bass.

Miller, H., \& Griffiths, M. (2005). E-mentoring. In D. L. Dubois \& M. Karcher (Eds.), Handbook of youth mentoring (pp. 300-313). Thousand Oaks, CA: Sage.

Moran, D. (2000). Introduction to phenomenology. London, England: Routledge.

Morris, M. (1998). Understanding the curriculum: Queer projects, queer imaginings. In W. F. Pinar (Ed.), Queer theory in education (pp. 227-237). Mahwah, NJ: Erlbaum.

Morris, M. (2005). Queer life and the school culture. Multicultural Education, 12, 8-13.

Morrow, K. V., \& Styles, M. B. (1995). Building relationships with youth in program settings: A study of big brothers/big sisters. Philadelphia. PA: Public/Private Ventures.

Moustakas, C. (1994). Phenomenological research methods. London, England: Sage.

National Center for HIV, STD, and TB Prevention, Centers for Disease Control and Prevention. (2000). Young people at risk: HIV/AIDS among America's youth. Atlanta, GA: Author.

National Gay and Lesbian Task Force. (2007). Lesbian, gay, bisexual, and transgender youth: An epidemic of homelessness. Washington, DC: Author.

Ogbu, J. U. (1990). Mentoring minority youth: A framework. New York, NY: Columbia University, Teachers College, Institute for Urban and Minority Education. 
Oregon Ballot Measure 9 (1992).

Oregon Blue Book. (n.d.). Initiative, referendum and recall: 1988-1995. Retrieved January 1, 2008, from http://bluebook.state.or.us/state/elections/elections21.htm

Pharr, S. (1988). Homophobia: A weapon of sexism. Inverness, CA: Chardon Press.

Phillips D. C., \& Soltis, J. F. (1998). Perspectives on learning. New York, NY: Teachers College Press.

Piaget, J. (1936). Origins of intelligence in the child. London, England: Routledge \& Kegan Paul.

Pinar, W. F. (1998). Queer theory in education. Mahwah, NJ: Erlbaum.

Plummer, K. (2005). Critical humanism and queer theory: Living with tensions. In N. K. Denzin \& Y. S. Lincoln (Eds.), The SAGE handbook of qualitative research (pp. 195-207). Thousand Oaks, CA: Sage.

Ramafedi, G. (1987). Male homosexuality: The adolescent's perspective. Pediatrics, 79, 326-330.

Ramafedi, G., French, S., Story, M., Resnick, M. D., \& Blum, R. (1998). The relationship between suicide risk and sexual orientation: Results of a population based study. American Journal of Public Health, 88, 57-60.

Raskin, N. J., \& Rogers, C. R. (2000). Person-centered therapy. In R. J. Corsini \& D. Wedding (Eds.), Current psychotherapies (6th ed.; pp. 133-167). Itasca, IL: P. E. Peacock Publishers.

Rhodes, J. E. (2002). Stand by me: The risks and rewards of mentoring today's youth. Cambridge, MA: Harvard University Press.

Rhodes, J. E. (2005). A model of youth mentoring. In D. L. Dubois \& M. Karcher (Eds.), Handbook of youth mentoring (pp. 30-43). Thousand Oaks, CA: Sage.

Rhodes, J. E. (2007). Fostering close and effective mentoring relationships. Alexandria, VA: Mentor.

Rhodes, J. E., \& DuBois, D. L. (2006). Understanding and facilitating the youth mentoring movement. Social Policy Report: Society for Research in Child Development, 20(3), 3, 19. 
Rhodes, J. E., \& Grossman, J. B. (2002). The test of time: Predictors and effects of duration in youth mentoring programs. American Journal of Community Psychology, 30, 199-206.

Rhodes, J. E., Spencer, R., Keller, T. E., Liang, B., \& Noam, G. (2006). A model for the influence of mentoring relationships on youth development. Journal of Community Psychology, 34, 691-707.

Rogers, C. R. (1980). A way of being. Boston, MA: Houghton Mifflin.

Rosario, M., Schrimshaw, E. W., Hunter, J., \& Braun, L. (2006). Sexual identity development among lesbian, gay, and bisexual youths: Consistency and change over time. The Journal of Sex Research, 43, 46-58.

Ross, F. (2005). Achieving cultural competence: The role of mentoring in sexual minority identity development (Unpublished doctoral dissertation). Indiana University, Bloomington, Indiana.

Rotheram-Borus, M. J., \& Langabeer, K. (2001). Developmental trajectories of gay, lesbian, and bisexual youth. In A. R. Augelli \& S. Patterson (Eds.), Lesbian, gay, and bisexual identities and youth: Psychological perspectives (pp. 97-126). New York, NY: Oxford.

Safren, S., \& Pantalone, D. (2006). Social anxiety and barriers to resilience among lesbian, gay, and bisexual adolescents. In A. M. Omoto \& H. S. Kurtzman (Eds.), Sexual orientation and mental health: Examining identity and development in lesbian, gay, and bisexual people (pp. 55-72). Washington, DC: American Psychological Association.

Sanchez, B., \& Colon, Y. (2005). Race, ethnicity, and culture in mentoring relationships. In D. L. Dubois \& M. Karcher (Eds.), Handbook of youth mentoring (pp. 191204). Thousand Oaks, CA: Sage.

Savin-Williams, R. C. (1990). Gay and lesbian youth: expressions of identity. New York, NY: Cornell.

Savin-Williams, R. C. (1994). Verbal and physical abuse as stressors in the lives of lesbian, gay male, and bisexual youth: Associations with school problems, running away, substance abuse, and suicide. Journal of Counseling and Clinical Psychology, 62, 261-269.

Savin-Williams, R. C. (2005). The new gay teenager. Cambridge, MA: Harvard University Press. 
Shlasko, G. D. (2005). Queer (v.) pedagogy. Equity and Excellence in Education, 38, 123-134.

Sipe, C. L., \& Roder, A. E. (1999). Mentoring school-age children: A classification of programs. Philadelphia, PA: Public/Private Ventures.

Smith, J. A., Flowers, P., \& Larkin, M. (2009). Interpretative phenomenological analysis: Theory, methods, and research. Los Angeles, CA: Sage.

Smith, J. A., \& Osborn, M. (2008). Interpretative phenomenological analysis. In J. A. Smith (Ed.), Qualitative psychology: A practical guide to research methods (pp. 53-80). London, England: Sage.

Spencer, R. (2004). Studying relationships in psychotherapy: An untapped resource for youth mentoring. New Directions for Youth Development, 103, 31-43.

Spencer, R. (2006). Understanding the mentoring process between adolescents and adults. Youth Society, 37, 287-315.

Spencer, R. (2007a). "I just feel safe with him": Emotional closeness in male youth mentoring relationships, Psychology of Men and Masculinity, 8, 185-198.

Spencer, R. (2007b). “It's not what I expected": A qualitative study of youth mentoring relationship failures. Journal of Adolescent Research, 22, 331-354.

Sullivan, N. (2003). A critical introduction to queer theory. Edinburgh, Scotland: Edinburgh University Press.

Szalacha, L. (2003). Safer sexual diversity climates: Lessons learned from an evaluation of Massachusetts safe schools program for gay and lesbian students. American Journal of Education, 110, 58-86.

Tierney, J. P., Grossman, J. B., \& Resch, N. (1995). Making a difference: An impact study of Big Brothers/Big Sisters. Philadelphia, PA: Public/Private Ventures.

Tierney, W. (1999). Praxis at the millennium: Epistemological authority, voice, and qualitative research. Qualitative Studies in Education, 12, 451-456.

United States Centers for Disease Control and Prevention. (2008). HIV/AIDS among youth: CDC HIV/AIDS fact sheet. Atlanta, GA: Author.

United States Centers for Disease Control and Prevention. (2012). HIV among youth in the US: Protecting a generation. CDC Vital Signs fact sheet. Atlanta, GA: Author. 
United States Holocaust Memorial. (n.d.) Homosexuals: Victims of Nazi violence.

Retrieved January 1, 2008, from http://www.ushmm.org/wlc/article.php?lang= en\&ModuleId $=10005218$

Vygotsky, L. (1978). Mind in society. Cambridge, MA: Harvard University Press.

Walker, G. (2005). Youth mentoring and public policy. In D. L. Dubois \& M. Karcher (Eds.), Handbook of youth mentoring (pp. 525-545). London, England: Sage.

Weinberger, S. G. (2005). Developing a mentoring program. In D. L. Dubois \& M. Karcher (Eds.), Handbook of youth mentoring (pp. 220-233). Thousand Oaks, CA: Sage.

Zimmerman, M. A., Bingenheimer, J. B., \& Behrendt, D. E. (2005). Natural mentoring relationships. In D. L. Dubois \& M. Karcher (Eds.), Handbook of youth mentoring (pp. 82-99). Thousand Oaks, CA: Sage. 
APPENDIX A

PATHWAYS TO MENTORING INFLUENCE MODEL 
Pathways to Mentoring Influence Model (Rhodes, 2002, 2005)

\section{Mediators}

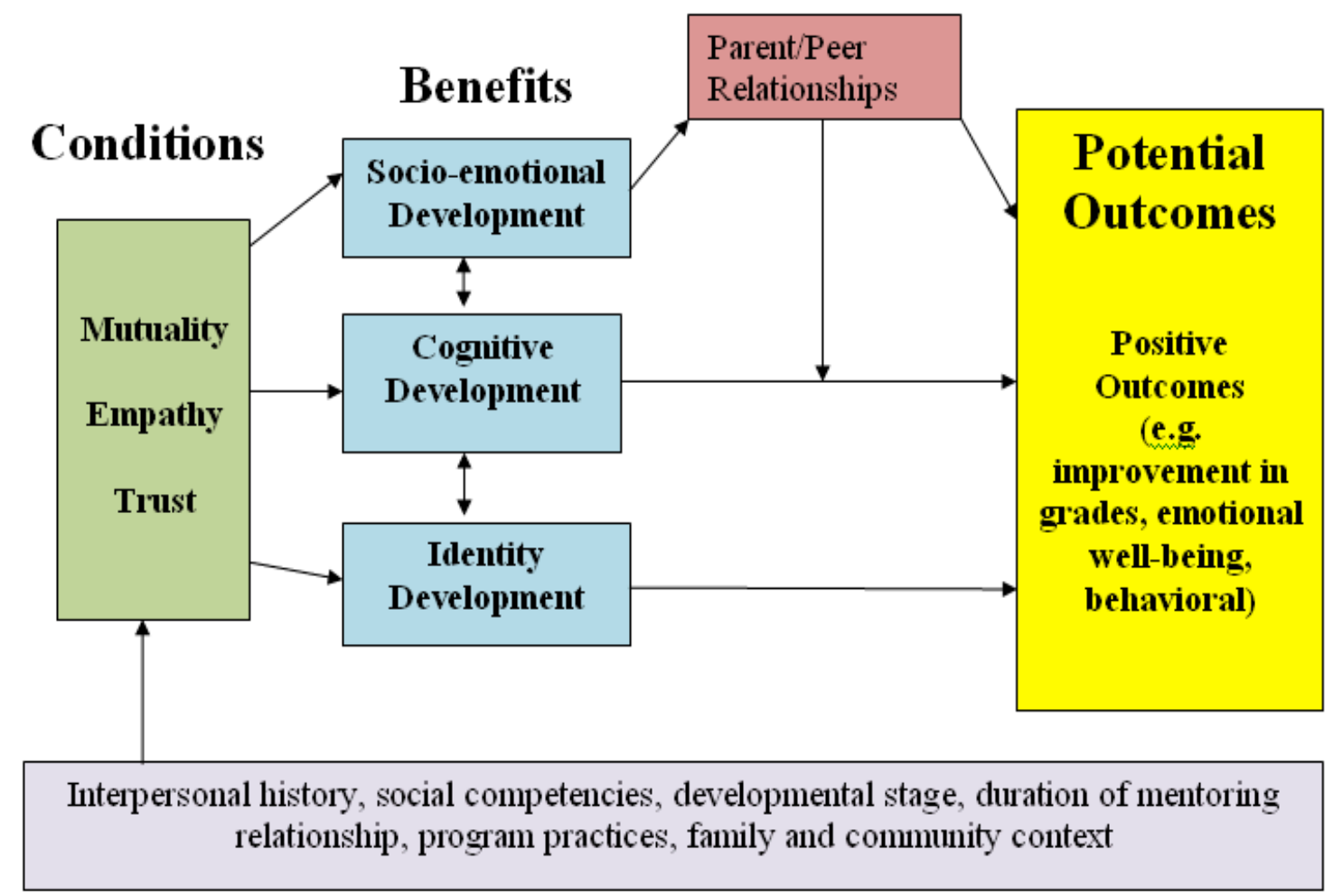

Moderators 
APPENDIX B

CULTURAL EXPLORATION MODEL 
Cultural Exploration Model (Ross, 2005)

Sexual minority cultural exploration is a process including:

$\begin{array}{ccc} & \text { Are facilitated } & \text { And } \\ \text { about } & \text { by } & \text { lead to: }\end{array}$

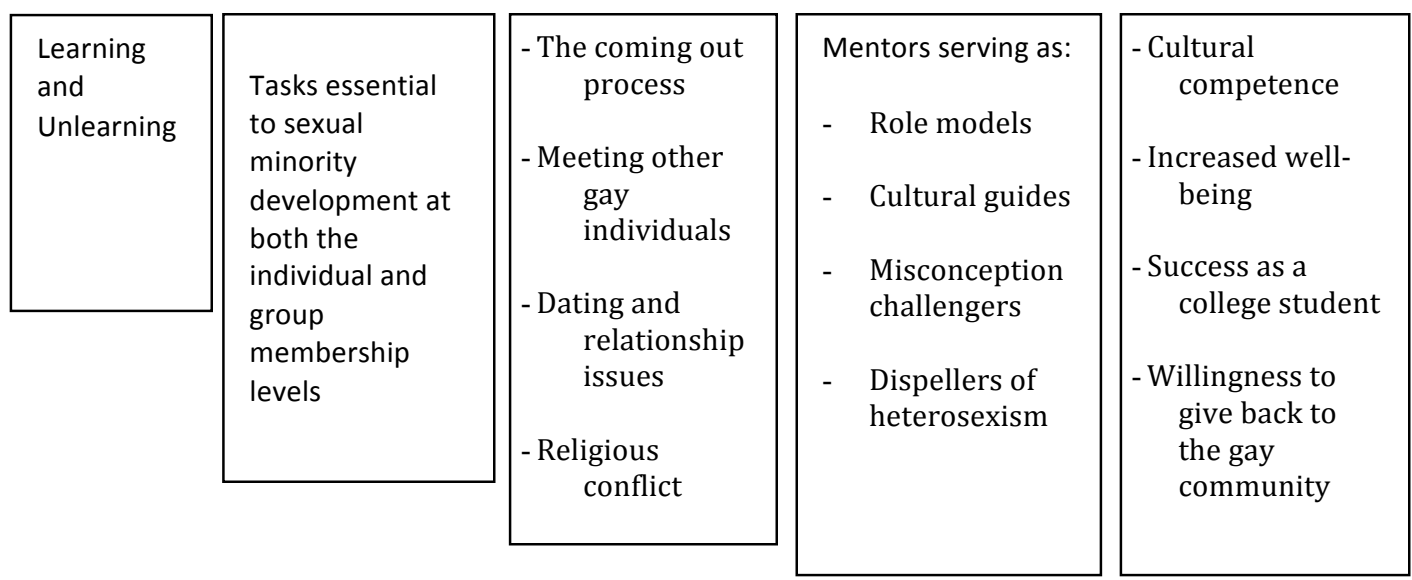


APPENDIX C

OUTREACH FLYER TO MENTORS 
Christian Rummell, a doctoral student at Portland State University, is conducting a research study that examines the experience of mentoring relationships for gay youth.

\section{What will I have to do:}

If you decide to take part in this study, you will be asked to participate in an interview that will last approximately 90 minutes. You may be asked follow up questions. Some of the topics that will be covered in this interview:

- Your relationship with your mentee

- Your perceptions of your mentee's growth over time

- How you see your relationship helping your mentee overcome any struggles related to being gay

\section{Are there any risks?}

Your relationship with your mentee may be very personal. Also, issues regarding sexual orientation may feel uncomfortable and embarrassing. If you agree to take part, you may experience a range of risks, including discomfort, anger, sadness, guilt, or embarrassment because of some of the questions that are asked. You don't have to answer any questions you do not want to. And, if you don't want to continue your participation, you can stop at any time. If you are upset after the interview(s), you can contact Christian Rummell, the researcher for this project. You may also contact the Human Subjects Review Committee at Portland State University at 503-725-4288.

\section{What will I get in return?}

You will get a chance to reflect on the growth that you and your mentee have experienced over time. Your participation in this study will help to give other mentoring programs and relationships the chance to benefit from your experiences.

\section{What are you doing to protect me and my mentee?}

Your privacy is important. Therefore, you will be protected in the following ways:

- Your name will not be disclosed at anytime during this study.

- Your name and identifiable information will be kept in a locked file cabinet and no one other than the researcher and his advisor will be able to see it.

\section{Any questions?}

If you have any questions about this study, this form, or the interviews/field observations, you can talk to your interviewer, Christian Rummell, 415-689-0993. Or, you can also contact the chair of the Human Subjects Committee of Portland State University about your rights as a research participant. Hours are 9:00am to 5:00pm. The office address is: Research and Strategic Partnerships, Market Center Building, $6^{\text {th }}$ Floor, 1600 SW $4^{\text {th }}$ Ave. Portland, Oregon 97201. The telephone number is 503-725-4288. 
APPENDIX D

OUTREACH FLYER FOR MENTEES 


\section{BE PART OF AN IMPORTANT PROJECT Mentoring for Gay Youth Study}

Christian Rummell, a doctoral student at Portland State University isr doing a research project on mentoring relationships for gay youth.

\section{What Will I Have to Do?}

If you want to take part in this project, I will ask you and your mentor to talk with me a couple of times over the next three to five months - one session will include you and your mentor and me and the second session will include only you and me. The conversational interview will be on these topics:

- Your relationship with your mentor

- Your experience as a gay youth

\section{Are There Any Risks?}

Talking about issues like your mentoring relationship and being gay can be very personal. You do not have to take part in this study. If you agree to take part, you may feel uncomfortable, angry, sad, guilty, frustrated, or embarrassed because of some of the questions I ask. You don't have to answer any questions you don't want to. And if you don't want to go on, you can stop at any time. You should also know that I am a mandatory reporter and must share with the authorities any information you disclose about harming yourself or others. I also must report any suspected abuse or neglect of children.

This study is not sponsored by your mentoring program and your decision to participate or not to participate will not change your relationship with your mentor or your continued participation in the program. This project is optional.

\section{What Will I Get in Return?}

1. An opportunity to think about your relationship with your mentor.

By responding to questions about your relationship, you can think about the ways you have changed and grown since your relationship started.

2. Knowing that you are helping others.

Many people feel good about helping others. I can learn so much from you and teach others how to benefit from relationships like yours.

\section{What should I do if I want to participate?}

1. Read over the attached letter that describes your informed consent and sign.

2. Send back the signed letter and the letter signed by your parents if you are under 18) in the attached self-addressed envelope. (You can also give this to the staff member from your mentoring program)

3. I'll give you and your mentor a call to set up a time to meet in person at your program's office.

4. Make sure you choose a pseudonym or "fake" name that you want to use when we meet up for our first interview. 
APPENDIX E

MENTOR INFORMED CONSENT LETTER 
Dear

My name is Christian Rummell and I am a doctoral student at Portland State University in Portland, Oregon. I am doing a study on mentoring relationships for gay youth. I'd like to invite you to participate in my study because you have volunteered as a mentor to a gay youth.

As part of the study, I will ask you and your mentee to meet with me for approximately 90 minutes to talk about your relationship. This in-person meeting will include an art activity and a follow-up conversation that asks you to think about what your relationship "looks like." I will also ask to gain permission to access your program records, including such documents as your match meeting records, intake forms, surveys, and match coordinator notes.

This study may have several benefits to you, including giving you and your mentee the chance to reflect on the growth that you have experienced since you started your relationship. Findings from the study may also give other mentoring programs insight into how to better serve gay youth.

The study may also give you some level of discomfort. You may be asked to answer questions that are embarrassing and/or create anxiety. However, if at any time you wish to discontinue your participation for any reason whatsoever, you are free to withdraw from this study. You may also choose to not answer any question for whatever reason. You should also know that I am a mandatory reporter and must share with the authorities any information you disclose about harming yourself or others. I also must report any suspected abuse or neglect that you and/or your mentee share.

Any information that is obtained in connection with this study and that can be linked to you or identify you will be kept confidential. Mentor identities will be kept confidential by assigning pseudonyms. All digital recordings, transcriptions, and final reporting will not include your name. All records will be kept in a locked file cabinet and also on a password protected computer.

Participation in this study is entirely voluntary. Your decision to participate or not will not affect your relationship with the researcher or with Portland State University nor your continued relationship with the mentoring program. If you decide to take part in the study, you may choose to withdraw at any time without penalty. Please keep a copy of this letter for your records.

If you have concerns or problems about your participation in this study or your rights as a research subject, please contact the Human Subjects Research Review Committee, Office of Research and Strategic Partnerships, Market Center Building, $6^{\text {th }}$ Floor, 1600 SW $4^{\text {th }}$ Avenue, Portland, Oregon 97201. The telephone number is (503) 725-4288. If you have questions about the study itself, contact Christian Rummell at 2065 Oak Street \#301, San Francisco California, 94117. The telephone number is (415) 689-0993.

Sincerely,

Christian Rummell

Portland State University 
If I sign, what does it mean?

This is a consent form. Your signature below means that:

- You have read and understand what this form says.

- You are willing to take part in the study by talking with the researcher in a 90-minute interview and follow up questions.

- You give permission for the researcher to access your mentoring program records, intake forms, and documents related to your relationship with your mentee.

- You know that you do not have to take part in this study. And even if you agree, you can change your mind and stop at any time. You may also decide not to answer a particular question, but to continue to participate in the study.

- You will get a copy of this form to keep for yourself.

Participant Signature

$\overline{\text { Date } \quad \text { Participant Name, Printed }}$

Interviewer Signature

Date Interviewer Name, Printed

\section{Additional Resources}

If the interview brings up any difficult feelings or issues in your mentee and he wants to speak with someone, he can talk to a staff member from your mentoring program or access the following help/talk lines for additional support:

- National Help Center - Peer counseling Phone: (888) 843-4564 Website: www.glbtnationalhelpcenter.org Availability: M-F evenings; Saturday afternoon

- Youth Talk Line Phone: (800) 246-7743 Availability: Mon-Sat 9:30 pm to midnight (Eastern Time) 
APPENDIX F

INFORMED CONSENT FOR ADULT MENTEE (18 AND OLDER) 
Dear

My name is Christian Rummell and I am a doctoral student at Portland State University. I am doing a study on mentoring relationships for gay youth. I'd like to invite you to participate in my study because you have been matched as a mentee with a gay mentor for over a year.

As part of the study, I will ask you and your mentor to meet with me for approximately 90 minutes to talk about your relationship. This in-person meeting will include an art activity and a follow-up conversation that asks you to think about what your relationship "looks like."

You will also be asked to have a second interview with me in approximately 3-5 months to follow up on things you shared during the first session. The second session will also include questions about your experiences as a gay youth and how your mentor has offered you support.

Lastly, you will be asked to allow me to have access to your program records, including your intake, surveys, and case management notes.

This study may have several benefits to you, including giving you and your mentor the chance to reflect on the growth that you have experienced since you started your relationship. Findings from the study may also give other mentoring programs insight into how to better serve gay youth.

The study may also give you some level of discomfort. You may be asked to answer questions that are embarrassing and/or create anxiety. However, if at any time you wish to discontinue your participation for any reason whatsoever, you are free to withdraw from this study. You may also choose to not answer any question for whatever reason.

Any information that is obtained in connection with this study and that can be linked to you or identify you will be kept confidential. Mentee identities will be kept confidential by assigning pseudonyms. All digital recordings, transcriptions, and final reporting will not include your name. All records will be kept in a locked file cabinet and also on a password protected computer. However, because I am a mandatory reporter, I need to let you know that if you share with me that you intend to harm yourself or others I am required to report this to the authorities for your protection.

Participation in this study is entirely voluntary. Your decision to participate or not will not affect your relationship with the researcher, the mentoring program, your mentor, or with Portland State University. If you decide to take part in the study, you may choose to withdraw at any time without penalty. Please keep a copy of this letter for your records.

If you have concerns or problems about your participation in this study or your rights as a research subject, please contact the Human Subjects Research Review Committee, Office of Research and Strategic Partnerships, Market Center Building, $6^{\text {th }}$ floor, $1600 \mathrm{SW} 4^{\text {th }}$ Avenue, Portland, Oregon 97201. The telephone number is (503) 725-4288. If you have questions about the study itself, contact Christian Rummell at 2065 Oak Street \#301, San Francisco California, 94117, (415) 689-0993.

Sincerely,

Christian Rummell

Portland State University 
If I sign, what does it mean?

This is a consent form. Your signature below means that:

- You have read and understand what this form says

- You are willing to take part in the study by talking with the researcher in two interviews.

- You are willing to give the researcher access to your mentoring program records, including intake form, survey materials, and case management notes.

- You know that you do not have to take part in this study. And even if you agree, you can change your mind and stop at any time. You may also decide not to answer a particular question, but to continue to participate in the study.

- You understand that the researcher is required to report certain things to the authorities, including if you

- You will get a copy of this form to keep for yourself.

Participant Signature

Interviewer Signature

\author{
$\overline{\text { Date } \quad \text { Participant Name, Printed }}$
}

$\overline{\text { Date } \quad \text { Interviewer Name, Printed }}$

Additional Resources:

If the interview brings up issues you want to talk to someone about, you can speak with a staff member from your mentoring program or access the following:

- National Help Center - Peer counseling Phone: (888) 843-4564 Website: www.glbtnationalhelpcenter.org Availability: M-F evenings; Saturday afternoon

- Youth Talk Line Phone: (800) 246-7743 Availability: Mon-Sat 9:30 pm to midnight (Eastern Time) 
APPENDIX G

OUTREACH SCRIPT FOR PROGRAM 
$<$ This will be the script I use to give staff from Mentoring Program information and guidance on participant outreach for my study.>

Thank you for agreeing to assist me with this study.

I really appreciate your help identifying and recruiting mentoring matches to be participants for my study. I also want to thank you in advance for following these important and detailed directions for doing outreach with all of the potential participants (and those that will give legal approval), including mentees, mentors, and parents/guardians. These steps and the directions that I am giving you have been preapproved by Portland State University and have been established to make sure that the young people and volunteers in your program are participating in a study that follows ethical standards dealing with human subjects.

1. In the next couple of days you will receive a packet from me that includes materials that will be used to recruit participants for this study. This packet consists of the following forms:

a. Outreach Flyers for Mentees and Parents

b. Informed Consent Form for Parent

c. Informed Consent Form for Adolescent Mentee (currently under 18 years of age)

d. Informed Consent Form for Adult Mentee (currently over 18 years of age but was under 18 when the mentoring match began)

e. Informed Consent Forms for Adult Mentor

f. Outreach Flyers for Adult Mentors

2. At this point, you should have identified potential matches that meet stated criteria for this study (a reminder: the matches should've been matched for one year or longer, consist of a match between gay adult males and gay male youth, have established a close bond, and have completed all program intake and case management requirements for the duration of their match).

3. Next, you will begin to start asking potential matches that meet these criteria if they are interested in participating in this study. In order to make sure that the youth in your program don't feel pressured to participate by their mentors, begin doing outreach for this study by first asking the mentees and their parent/guardian if they want to participate. Please note: If you have more than five matches that meet the criteria, I recommend starting with the matches that you feel have established the closest bonds and also those matches that have offered the greatest amount of support to the mentee around issues that he has faced related to his sexual identity and orientation. 
These are the specific steps you will take to do the outreach:

a. First, conduct outreach to mentees and their parents. Provide the packet of materials that include the outreach flyer and informed consent to each mentee/parent/guardian in the matches you identified that meet the criteria for this study. You can give these to the mentee and his parent/guardian in-person or via mail. If the mentee is now 18 years of age (but started his match when he was under 18), be sure to use the Informed Consent form for Adult Mentee (you will not need his parent/guardian approval).

b. Once you have mailed the packet or delivered the outreach flyer and letters of consent in-person, follow up with the mentee to see if he had a chance to look over the materials and to see if he and his parent/guardian are interested in participating (for mentees under age 18). If they are interested in participating, have them fill out the Adolescent Mentee Informed Consent Form and the Parent/Guardian Informed Consent Form and mail to me using the provided envelope. The mentee/parent/guardian can also return them to you and you can mail to me using the provided envelope. Remind them that their decision to participate or not will not influence their continued relationship with you and the mentoring program. If they are not interested, thank them for looking over the materials and let them know that this decision will not influence their continued relationship with you and your mentoring program.

c. Once you have received a signed copy of the materials from the mentee (either by having them submit to you or by hearing from me when I have received the mailed copies), you should then ask the mentee's mentor if he is also interested in participating in the study. Please give him a copy of the mentor outreach flyer and the Adult Mentor Letter of consent. Let him know that his decision to participate or not is separate from his relationship with your program and will not be held against or for him in any way. If the mentor is interested in participating, ask him to sign the consent and to mail directly to the researcher or return the form to you (to mail to the researcher).

4. Once I have received the signed materials from each participant (either from you or directly from them), I will follow up via phone to further explain the study and to schedule time with the matches to conduct my in-person interviews. 
APPENDIX H

INTERVIEW PROTOCOL (17 MONTHS) 
Interview Protocol (17 months)

1. Tell me about your mentoring relationship "map." Could you share more about each of the things that you included on the "map"?

2. In what ways has your mentoring relationship changed over time?

3. Tell me a story about how you both worked together to overcome a challenge.

4. How would your life be different if you didn't have this mentoring relationship?

5. Why did you want to participate in a mentoring relationship specifically for gay youth? 
APPENDIX I

INTERVIEW PROTOCOL (22 MONTHS) 
Interview Protocol (22 months)

1. What significant events have happened in your lives since we last met up 5 months ago?

2. Please review the timeline of your relationship. What other details can you provide about each of these milestones and what they meant to your relationship?

3. Tell me about more how you have changed since you were matched, specifically related to how you see yourself as a member of the gay community.

4. How is your mentoring relationship different from other types of support you have received? Why? 